\title{
Root Cause of Degradation in the Creep Strength of Martensitic Steel
}

\author{
Manabu TAMURA ${ }^{1}$ \\ ${ }^{1}$ Free Scientist, Yokohama, Japan \\ Correspondence: Manabu Tamura, 6-45-2 Hinominami Konann-ku, Yokohama, 234-0055, Japan. Tel: \\ 81-45-891-1039. E-mail: mtamura.1943@pep.ne.jp
}

Received: August 15, 2021

Accepted: November 13, $2021 \quad$ Online Published: November 23, 2021

doi:10.5539/jmsr.v11n1p1

URL: https://doi.org/10.5539/jmsr.v11n1p1

\begin{abstract}
Creep curves of Grade 91 and 92 steels were analyzed by applying an exponential law to the temperature, stress, and time parameters to investigate the formation process of the Z-phase, which lowers the long-term rupture strength of high-Cr martensitic steel. The activation energy $(Q)$, activation volume $(V)$, and Larson-Miller constant $(C)$ were obtained as functions of creep strain. At the beginning of creep, sub-grain boundary strengthening occurs because of dislocations that are swept out of the sub-grains, and this is followed by strengthening owing to the rearrangement of $\mathrm{M}_{23} \mathrm{C}_{6}$ and the precipitation of the Laves phase. Heterogeneous recovery and subsequent heterogeneous deformation start at an early stage of transient creep near several of the weakest boundaries because of the coarsening of the precipitates; this results in the simultaneous decreases in $Q$, $V$, and $C$ even in transient creep. Further, this activity triggers an unexpected degradation in strength because of the accelerated formation of the Z-phase even in transient creep. The stabilization of $\mathrm{M}_{23} \mathrm{C}_{6}$ and the Laves phase is important to mitigate the degradation of the long-term rupture strength of high-strength martensitic steel. The stabilization of the Laves phase is especially important for $\mathrm{Cr}$-Mo systems because $\mathrm{Fe}_{2} \mathrm{Mo}$ is easily coarsened at approximately $600{ }^{\circ} \mathrm{C}$ compared to $\mathrm{Fe}_{2} \mathrm{~W}$ in Grade 92 steel.
\end{abstract}

Keywords: creep, Grade 91, Grade 92, MX, $\mathrm{M}_{23} \mathrm{C}_{6}$, Laves phase, Z-phase, degradation mechanism, activation energy

\section{Introduction}

Grade 91 and 92 steels, which were originally developed by Oak Ridge National Laboratory and Combustion Engineering Corporation (Sikka, Cowgill, \& Roberts, 1983) and Nippon Steel Corporation (Hasegawa, 2014), respectively, exhibit improved efficiencies of power generation, which reduces their negative effect on global warming (Masuyama, 2001; Kimura, Sato, Bergins, Imano, \& Saito, 2011; Muroki, 2017). Since the development of these steels, several critical issues have surfaced over the years. The most significant issues related to these steels include the low rupture strength of the welded joints (Abson \& Rothwell, 2013) and the unexpected degradation of the base metal in long-term rupture strength observed after conducting creep tests longer than several tens of thousands of hours (Kushima, Kimura, \& Abe, 1999; Sawada, Kushima, Kimura, \& Tabuchi, 2007). For solving this unexpected reduction in strength of base metal, a considerable number of studies have focused on developing new alloys (Abe, 2006a; 2008; 2011; Hashizume et al., 2009; Dudova, Plotnikova, Molodov, Belyyakov, \& Kaibyshev, 2012), estimating methods for long-term rupture strength (Tamura, 2015a; Maruyama, 2019), and investigating the unexpected decline in strength metallurgically (Abe, 2006b). The formation of coarse Z-phase particles at the expense of finely dispersed MX particles and recovery zones near the primary austenite grain boundaries (PAGBs) are considered dominant sources of the unexpected decline in strength (Kushima et al., 1999; Suzuki, Kumai, Kushima, Kimura, \& Abe, 2003; Sawada, Kushima, \& Kimura, 2006; Danielsen, 2007; Hald, 2008; Kimura, Sawada, Kushima, \& Toda, 2013). MX represents the carbonitride with cubic structure, where $\mathrm{M}$ indicates metallic elements such as $\mathrm{Nb}, \mathrm{V}$, and $\mathrm{Cr}$ and $\mathrm{X}$ indicates $\mathrm{C}$ or $\mathrm{N}$, or both. Kimura et al. (2013) and Sawada, Kushima, Hara, Tabuchi, and Kimura (2014a) reported the negative effect of Ni contained in the specification range of Grade $91(\mathrm{Ni} \leq 0.40$ mass $\%$, hereinafter \%) on the long-term rupture strength during the formation of Z-phase particles. Sawada et al. (2019a) recently reported the harmful effect of the presence of micro-segregation before creep tests on the long-term rupture strength of ASME Grade T91. However, the following three issues have not been properly elucidated: i) the number densities of Z-phase particles in the ruptured specimens of Grade 91 steel tested at $600^{\circ} \mathrm{C}$ are larger than those of Grade 92 steel (Sawada et al., 2006), ii) the start time of the Z-phase formation reported by Sawada et al. (2007) does not coincide with the inflection 
point on the stress-rupture curves in high-strength martensitic steels such as Grade 91 steel (Kushima et al., 1999), which was highlighted by Yan, Wang, Shan, and Yang (2013), and iii) Hu et al. (2009) and Di-Gianfrancesco, Vipraio, and Venditti (2013) suggest that the direct cause of the unexpected decline in rupture strength may be dependent on the stability of the Laves phase, however this proposal is not generally supported.

For these abovementioned issues, Tamura and Abe (2021a) analyzed creep curves of laboratory-prepared steel of 9Cr-1W and 9Cr-4W steel by applying an exponential law (Tamura, Esaka, \& Shinozuka, 1999, 2000, 2003; Kabadwal, Tamura, Shinozuka, \& Esaka, 2010; Tamura, Abe, Shiba, Sakasegawa, \& Tanigawa, 2013; Tamura \& Abe, 2015b; Tamura, 2017) to time to rupture $t_{r}$ or time to a specific strain $t_{\varepsilon}$ as a function of the test temperature $T$ and stress $\sigma$. That is, the observed creep variables of $T, \sigma$, and $t_{r}$ or $t_{\varepsilon}$ are converted to activation energy $Q$, activation volume $V$, and Larson-Miller constant $C$ (Larson \& Miller, 1952) without using any adjustable parameters. The variations of $Q, V$, and $C$ (hereinafter, $Q V C$ for all parameters) as functions of creep strain are discussed metallurgically; the following conclusions are obtained: i) Sub-grain boundary strengthening by swept-out dislocations (SBSD) is an essential process at an initial stage of creep of martensitic steel. ii) Hardening by the dissolution and fine re-precipitation (DFRP) of $\mathrm{M}_{23} \mathrm{C}_{6}$ and the precipitation of Laves phase are added to SBSD for high $\mathrm{Cr}$ martensitic steel; this increases $Q$. iii) After the peaks of $Q V C$, heterogeneous recovery and simultaneously occurring heterogeneous deformation (HRHD) start at a later stage of transient creep near some of the weakest boundaries because of the coarsening of the precipitates, and this triggers the unexpected degradation in rupture strength caused by the coarsening of the Laves phase. Tamura and Abe (2021a) highlighted that the occurrence of HRHD at a later stage of transient creep is the root cause for the degradation in the creep strength of martensitic steel. Therefore, Tamura and Abe (2021b) applied this idea of HRHD for the unexpected degradation in the long-term creep strength of Grade 91 and 92 steels and concluded the following: i) SBSD is an essential process at the initial stage of the creep of martensitic steel with high strength. ii) Hardening by the DFRP of fine $\mathrm{M}_{23} \mathrm{C}_{6}$ particles and the precipitation of the Laves phase are added to the SBSD for high-Cr martensitic steel with high strength, which increases $Q$ with increasing strain. iii) After the peaks of $Q V C$, HRHD starts at an early stage of the transient creep near several of the weakest boundaries in Grade 91 and 92 steels because of the coarsening of the precipitates, and this triggers an unexpected degradation in long-term rupture strength because of the accelerated formation of the Z-phase that consumes the fine MX particles inside or near the HRHD zone. iv) The stabilization of $\mathrm{M}_{23} \mathrm{C}_{6}$ and the Laves phase is important for mitigating the degradation in the long-term rupture strength of high-strength martensitic steels. v) The online monitoring of creep curves and $Q V C$ analysis make it possible to detect signs for long-term unexpected degradation around targeted conditions within a relatively short time.

However, there are no detailed discussions regarding why the degree of degradation in the strength of Grade 92 steel is less severe than that in the strength of Grade 91 or why the rupture strength of Grade 92 steel is stronger than that of Grade 91. Therefore, this study aims to identify the origin of the differences between the long-term rupture strengths of Grade 91 and 92 steels; the differences in the precipitation behavior during creep between Grade 91 and 92 steels are discussed in detail based on the results of the $Q V C$ analysis.

\section{Analysis Method and Meanings of Parameters $Q, V$, and $C$}

\subsection{Calculation of $Q, V$, and $C$}

The calculation method was provided in detail in a previous work (Tamura \& Abe, 2021a); here, we explain the method in brief. The $t_{r}$ or $t_{\varepsilon}$ can be expressed as

$$
t_{r} \text { or } t_{\varepsilon}=t_{0} \exp \{(Q-\sigma V) / R T\}
$$

where, $R, T$, and $\sigma$ are the gas constant, absolute temperature $(\mathrm{K})$, and applied normal tensile stress, respectively (Tamura et al., 1999). When the pre-exponential factor $\left(t_{0}\right)$ of Equation 1 is related to the well-known Larson-Miller constant $(C)$, the equation is given by

$$
t_{0}=10^{-C} \text {. }
$$

From Equations 1 and 2, we obtain

$$
\log \left(t_{r} \text { or } t_{\varepsilon}\right)=Q / 2.3 R T-V / 2.3 R \cdot \sigma / T-C=[Q]-[V]-C .
$$

The regression analysis of $\log \left(t_{r}\right.$ or $\left.t_{\varepsilon}\right)$ as a function of $1 / T$ and $\sigma / T$ based on Equation 3 yields three parameters $Q, V$, and $C$. In Equation 3, $[Q]=Q / 2.3 R T$ and $[V]=\sigma V / 2.3 R T$ are absolute numbers, and they are used in the subsequent sections. The $Q$ and $V$ in Equation 1 represent the apparent activation energy and apparent activation volume for rupture or specific strain, respectively. For simplicity, we refer to them as activation energy and activation volume, respectively. Usually, the stress vs. $t_{r}$ data are plotted in a double log figure based on the Norton law (Norton, 1929). However, we assume Equation 3, and therefore, a linear 
relationship for the $\sigma-t_{r}$ is obtained in a semi-logarithmic diagram (x-axis indicates the logarithm of $t_{r}$ or $t_{\varepsilon}$ and the $y$-axis, linear stress). Tamura et al. (1999) confirmed that when rupture data for several heat-resistant steels are classified into two or three groups based on test conditions, the rupture data for each group satisfy Equation 1. A technical merit of applying an exponential law to rupture data is that it is easy to estimate long-term rupture strength by extrapolating the linear relationship obtained from a specific data group using Equation 1 in a semi-logarithmic diagram to a given test condition beyond the test conditions of the data group. Alternatively, the estimation can be performed graphically because the regression lines at different temperatures obtained using Equation 3 are approximately parallel with each other.

Equation 1 is introduced by considering an activation process for dislocation motion (Schoeck, 1980), Orowan equation (Orowan, 1940), and Monkman-Grant relationship (Monkman \& Grant, 1956). Therefore, when Equation 1 is applied to $t_{\varepsilon}$, the linear relationship between $\sigma$ and the logarithm of $t_{\varepsilon}$ for a given data group should be confirmed for a wide range of test conditions. Further, the linear relationship between the minimum creep rate $(M C R)$ and $t_{\varepsilon}$ in a double logarithmic diagram should be confirmed based on the Monkman-Grant relationship. All data studied were checked, and the typical examples were shown in previous work (Tamura \& Abe, 2021a; 2021b). The validity of applying Equation 1 to the creep data of martensitic steel with high strength was already confirmed although the scattering for times to low strains are rather large.

In the Data Sheet of Grade 92 steel, No. 48B (National Institute for Materials Science: NIMS, 2018), an instantaneous strain $\varepsilon_{0}$, time to $0.5,1,2,5 \%$ strain, and $t_{r}$ together with $M C R$ are listed; therefore, the strain rate $\dot{\varepsilon}\left(\varepsilon_{i}\right)$ at a strain of $\varepsilon_{i}$, where $i$ denotes the order number from the minimum strain reported, is calculated as

$$
\dot{\varepsilon}\left(\varepsilon_{i}\right)=\left(\varepsilon_{i}-\varepsilon_{i-1}\right) /\left(t_{i}-t_{i-1}\right),
$$

where $t_{i}$ is the time to the $i^{\text {th }}$ strain. The accuracy of the strain rate calculated using Equation 4 is not very high because strain intervals are rather large. Therefore, creep rates near the $M C R$ should be focused on because the strain rate near $M C R$ is rather small and the sign of an increase rate of strain rate changes from negative to positive with increasing creep time. Further, creep rates just before rupture are calculated to utilize the data of $t_{r}$ and rupture elongation $(E L)$; however, the strain rates are largely affected by necking for $t_{\varepsilon} / t_{r}>0.9$ (Lim et al., 2011).

\subsection{Metallurgical Meanings of $Q, V$, and $C$}

\subsubsection{Activation energy}

For a model based on crystallography, $Q$ is defined as the magnitude of the energy barrier that must be overcome for a dislocation in an activation process. Conversely, $Q$ calculated from Equation 3 is the apparent activation energy calculated from the measurable and macroscopic variables $T, \sigma$, and $t_{r}$ or $t_{\varepsilon}$, and therefore, the value of $Q$ is obtained assuming that $C$ does not depend on $T$. Thus, $Q$ contains not only the magnitude of the average creep resistance to mobile dislocations but also the effect of the temperature dependence of $C$ (Schoeck, 1980; Tamura et al., 2000). In addition, $Q$ contains the effect of the back stress against a moving dislocation caused by the grain boundaries, sub-boundaries, and stress field arising from other dislocations and precipitates (Tamura et al., 2000). Therefore, the $Q$ decreases because of the reduction of the back stress, when the sub-grains grow, the dislocation density decreases, and the precipitates are coarsened during long-term creep at high temperatures. We frequently use the term sub-grain, which indicates the minimum region in which an identical slip system is operating. Thus, sub-grains denote the lath martensite, block, packet, and sub-grain itself. However, the value of $Q$ does not decrease without limits. It is established that the value of $Q$ in the high-temperature creep of materials is almost equivalent to the activation energies for self-diffusion (Sherby et al., 1953; Tamura, 2017); therefore, the lower limit of $Q$ approximately approaches that for the self-diffusion of the alpha-iron, i.e., $267 \mathrm{kJmol}^{-1}$ (Oikawa, 1982). The magnitude of the back stress can be also roughly estimated using an exponential law; the details are discussed in a previous paper (Tamura \& Abe, 2021b).

\subsubsection{Larson-Miller Constant}

The Larson-Miller constant $C$ can be calculated as the third term in Equation 3, and it is well-known that the value of $C$ is $\sim 20$ for many heat-resistant steels when the units for the test temperature and $t_{r}$ are Kelvin and hours, respectively (Tamura et al. 2013). The Larson-Miller constant is formulated as

$$
C=\log \left(\rho \lambda v_{e f f} b / 2 C_{M G}\right)+\Delta S / 2.3 R
$$

where $\rho, b, C_{M G}, \lambda, v_{e f f}$, and $\Delta S$ denote the dislocation density that contributes creep strain, length of Burgers vector, Monkman-Grant constant, maximum distance that a dislocation can move from a starting point to the next stable position through the activation process, effective attempt frequency per unit time to overcome 
the obstacles, and entropy change involved in the activation process, respectively (Tamura et al., 2013). Though the $1^{\text {st }}$ term of Equation 5 depends on $\rho$, the value of the $1^{\text {st }}$ term of Equation 5 is approximately 13 for typical heat-resistant steels (Tamura \& Abe, 2021a; 2021b). Therefore, the $2^{\text {nd }}$ term of the entropy term is roughly 7 for $C \cong 20$, which corresponds to the entropy change related to the formation and migration of vacancies during creep controlled by self-diffusion. High values of $C>30$ are reported for many martensitic steels with high strength. The increase in $C$ is caused by an increase in the entropy term of Equation 5 because the increase in the $1^{\text {st }}$ term caused by the high dislocation density of martensitic steel with high strength is not so large (Tamura \& Abe, 2021a).

Moving dislocations receive not only the applied stress but also the back stress arising from the surroundings. Simultaneously, the surroundings receive the effect of the stress and strain fields of the moving dislocations. However, these influences and the kinetic energy of the moving dislocations are irrelevant to the observed creep strain. Therefore, these energies are treated as heat loss in the system at a constant temperature when we analyze creep rate and $t_{r}$ assuming a thermally activated process. The heat loss is accounted for in the formulation of the Gibbs free energy as entropy change, i.e., as a part of $C$. Further, the influence of the back stress is accounted for in $Q$ as the barrier to be overcome. Therefore, both $Q$ and $C$ increase with increases in dislocation density and the formation of finer sub-structures. Consequently, the values of $Q$ and $C$ for martensitic steels are large, typically $Q=800 \mathrm{kJmol}^{-1}$ and $C=35$. Similarly, both $Q$ and $C$ are small when the dislocation density is low and the sub-grain size increases after long-term creep. In extreme cases, the values of $Q$ and $C$ for the creep of a single crystal of pure iron are calculated as $294.0 \mathrm{kJmol}^{-1}$ and 12.06 , respectively, from the analysis of creep data reported by Karashima, Iikubo, Watanabe, and Oikawa, (1971). The values of $Q$ and $C$ for the creep of the polycrystals of pure iron are calculated as $259.2 \mathrm{kJmol}^{-1}$ and 10.94 , respectively from the creep data reported by Karashima, Iikubo, and Oikawa, (1972). Moreover, the values of $Q=259.2 \mathrm{kJmol}^{-1}$ and $C=18.56$ for $0.2 \%$ carbon steel (Tamura et al., 2013) and $Q=418 \mathrm{kJmol}^{-1}$ and $C=20.99$ as the average for 3 heats of $0.5 \mathrm{Cr}-0.5 \mathrm{Mo}$ steel (Tamura et al., 1999) are obtained. For many heat-resistant steels, $C \sim 20$ is confirmed. The value of $C$ for the creep of the studied martensitic heat-resistant steels is considerably larger, i.e., $C>30$. This is because martensitic steels contain many dislocations and possess very fine sub-structures. Therefore, energy loss, i.e., an increase in entropy, becomes very large for the movement of dislocations. The changes in $C$ can largely be regarded as changes in the entropy term of $\Delta S / 2.3 R$ in Equation 5 when martensitic sub-structures are maintained even after the long-term creep of high $\mathrm{Cr}$ martensitic steel with high strength.

\subsubsection{Activation Volume}

From Equation 3, $V$ is formulated as

$$
V=-2.3 R T\left(\partial \log t_{r} / \partial \sigma\right)_{T} .
$$

Thus, the magnitude of $V$ is visually understood in a semi-logarithmic diagram of the $\sigma-\log t_{r}$ relationship because $V$ is inversely proportional to the magnitude of the slope of the $\sigma-\log t_{r}$ relationship at constant temperature. The term, $\sigma V$ in Equation 1 is equal to the work performed by a specimen on a loading system in an activated state or the potential drop of the loading system (Esherby, 1956; Mura \& Mori, 1976). In addition, the potential drop is equal to the force on a dislocation $\tau b$ times the area swept out of the dislocation in an activated state, where $\tau$ denotes a shear stress on a slip plane and is proportional to $\sigma$. The $V$ generally increases after long-term creep because the swept-out area by dislocation motion increases in the sub-grain when the size of the sub-grain increases or the densities of obstacles for a dislocation decrease due to recovery (Tamura et al., 2000).

\subsubsection{Inter-Relationships among $Q, V$, and $C$}

Although $Q$ is an important parameter for creep strength, creep strength is not always high when $Q$ is large. This is because Equations 1 and 2 indicate that $t_{r}$ is the product of a very large value, i.e., $\exp \{(Q-\sigma V) / R T\}$ and a very small value of $10^{-C}$. Since $Q$ is large compared to $\sigma V, Q$ and $C$ should have a strong positive correlation (Tamura \& Abe, 2021a; 2021b). However, note that $Q$ and $C$ have different meanings.

On the one hand, $Q$ denotes the magnitude of the barrier that must be overcome for a moving dislocation caused by nearby precipitates, dislocations, boundaries, and the entire specimen. On the other hand, $V$ is an important parameter in creep, but $V$ is a factor reflecting the movable area for a dislocation. That is, $V$ is a parameter that only relates to the microstructures inside sub-grains, which is essentially different from $Q$.

\section{Heterogeneous Deformation}

We assumed uniform deformation in the previous sections. However, Kushima et al. (1999) reported that the 
extremely recovered zone in the vicinity of PAGBs with a width of approximately $1 \mu \mathrm{m}$ was formed in a ruptured specimen of Grade T91 steel tested at $600^{\circ} \mathrm{C}$ under $100 \mathrm{MPa}\left(t_{r}=34141 \mathrm{~h}\right)$, where the unexpected drop in rupture strength was clearly confirmed. Such heterogeneously recovered zones (HRZs) are observed in the ruptured specimens of not only Grade 91 steel, but also Grade 92 steel (Sawada \& Kimura, 2019b). Further, the HRZ is already formed at an early stage of accelerating creep, near the MCR point of Grade 91 steel (Kimura, Suzuki, Toda, Kushima, \& Abe, 2002).

Strain concentration should occur in these HRZs or the HRZ will deform locally. The strain rate in the HRZ is expected to be higher than the observed creep rate. Consequently, the stress and strain concentrations should occur around or inside the HRZ. This phenomenon is referred to as HRHD (heterogeneous recovery and heterogeneous deformation). $t_{r}$ corresponding to the higher strain rate in the HRZ decreases based on the Monkman-Grant relationship (Monkman \& Grant, 1956). Sawada et al. (2006) and Sawada, Kushima, Tabuchi, and Kimura (2011) reported that strain promotes the formation of the Z-phase that consumes finely dispersed MX with cubic structure. Therefore, when the HRHD occurs, the formation of the Z-phase is accelerated compared to that during homogeneous deformation. Once the HRHDs occur, the rupture strength of martensitic steel with high strength is lowered unexpectedly.

The changes in $Q V C$ for the cases of the occurrence of stress and strain concentrations in an HRHD zone can be simulated using Equation 1. The results showed that $Q V C$ decrease simultaneously with an increase in strain (Tamura \& Abe, 2021b). The simultaneous decreases in $Q V C$ are observed from the later stage of transient creep of $9 \mathrm{Cr}-4 \mathrm{~W}$ steel and from the early stage of transient creep of Grade 91 and 92 steels at approximately $600{ }^{\circ} \mathrm{C}$ under low stresses; for these cases, HRHD should start to occur although a microstructural investigation is not yet performed (Tamura \& Abe, 2021a; 2021b).

A similar phenomenon is confirmed in the creep behavior of the welded joints of martensitic steel; in this case, QVC decrease simultaneously as compared with those of the base metal (Tamura \& Abe, 2021a).

\section{Materials}

In the previous work (Tamura \& Abe, 2021b), creep curves of all types of $9 \mathrm{Cr}$ martensitic steel with high strength were not analyzed because of the limitations of capacity for each manuscript $(<8 \mathrm{MB})$. In this study, the creep curves of the plate material, ASME Grade 91, is analyzed and the root cause of the degradation of the 9Cr martensitic steel with high strength is studied by combining the results of ASME Grades P92, T92, and T91 shown in the previous work. Table 1 summarizes the form of the product, heat treatment conditions, chemical composition, prior austenitic grain size number, and hardness of the materials tested (Rockwell hardness number: HRC); the precipitates before and during the creep tests are also listed (NIMS, 2007; 2014; 2018). In Table 1, MJP, MJT, MGC, and MgC represent the reference code numbers for single heat used in NIMS. Further, P92/MJP, T92/MJT, T91/MGC, and pl-91/MgC indicate the steels in this study, and the abbreviated names MJP, MHT, MGC, and MgC are also used for some cases. When we refer to previous work or generally describe scientific facts, we use Grade P92 or T92 and Grade T91 or 91 according to the ASME standard. Further, we use Grade 91 steel and Grade 92 steel to provide the general descriptions for $9 \mathrm{Cr}-1 \mathrm{MoVNb}$ and 9Cr-1.8W-0.5MoVNbB steels, respectively. The major differences between T91/MGC and pl-91/MgC are the Ni content and stress-relief annealing. The major differences between P92/MJP and T92/MJT are the hardness and Si content; MJP is rather soft compared to MJT, and the Laves phase is considered less formed in the MJP because its Si content is smaller than that of MJT (Hosoi, Wade, Kunimitsu, \& Urita, 1986).

Microstructural changes in high-Cr martensitic steels during creep are summarized in detail in the previous paper (Tamura \& Abe, 2021b) and individual research works are referred to in the later sections as necessary. 
Table 1. Materials analyzed and their characteristics. The chemical composition is presented in mass \%. The steel plate of pl-91/MgC was stress-relief-annealed at $730^{\circ} \mathrm{C}$ for $8.4 \mathrm{~h}$ after tempering.

\begin{tabular}{ccccc}
\hline Steel & P92/MJP & T92/MJT & T91/MGC & pl-91/MgC \\
\hline Product form & Pipe & Tube & Tube & Plate \\
Austenitizing $/{ }^{\circ} \mathrm{C}$ & 1070 & 1100 & 1050 & 1060 \\
Tempering $/{ }^{\circ} \mathrm{C}$ & 780 & 780 & 765 & 760 \\
PAGS number & 7.3 & 7.8 & 9.2 & 8.7 \\
$\mathrm{HRC}$ & 14 & 16 & 18 & 17 \\
$\mathrm{C}$ & 0.11 & 0.098 & 0.09 & 0.10 \\
$\mathrm{Si}$ & 0.10 & 0.29 & 0.29 & 0.24 \\
$\mathrm{Ni}$ & 0.17 & 0.13 & 0.28 & 0.04 \\
$\mathrm{Cr}$ & 9.26 & 9.50 & 8.70 & 8.74 \\
$\mathrm{Mo}$ & 0.42 & 0.36 & 0.90 & 0.94 \\
$\mathrm{~W}$ & 1.67 & 1.74 & 0.22 & - \\
$\mathrm{V}$ & 0.16 & 0.19 & 0.072 & 0.21 \\
$\mathrm{Nb}$ & 0.057 & 0.062 & 0.044 & 0.0582 \\
$\mathrm{~N}$ & 0.0462 & 0.0462 & & - \\
$\mathrm{B}$ & 0.002 & 0.002 & $\mathrm{M}_{23} \mathrm{C}_{6}, \mathrm{MX}_{23} \mathrm{C}_{6}, \mathrm{MX}$, Laves phase, Z-phase \\
Before test & \multicolumn{2}{c}{$\mathrm{M}_{23} \mathrm{C}_{6}, \mathrm{MX}, \mathrm{BN}$} &
\end{tabular}

PAGS: Prior austenite grain size.

\section{Results}

\subsection{Time to Rupture and Analysis of Creep Curves for pl-91/MgC Steel}

The results of the analysis for P92/MJP, T92/MJT, and T91/MGC have already been reported in a previous work (Tamura \& Abe, 2021b). Therefore, only the results for $\mathrm{pl}-91 / \mathrm{MgC}$ are explained below. Figure 1 shows the $\sigma-t_{r}$ relationship for pl-91/MgC (NIMS, 2014). The data were classified into 6 groups, Grs.I-IIIb. In the classification, the $\sigma-t_{r}$ relationship of of T91/MGC, a steel similar to pl-91/MgC (Tamura \& Abe, 2021b) was referred. However, a data point at $700{ }^{\circ} \mathrm{C}$ and $40 \mathrm{MPa}$ could not be classified into any group. The stress vs. $t_{\varepsilon}$ diagrams were obtained using the digital data of $\mathrm{pl}-91 / \mathrm{MgC}$ (NIMS, 2014) and were also referred, where $\varepsilon=0.2-5 \%$. Here, the creep data at $5 \%$ strain is converted from the $t-\dot{\varepsilon}$ diagrams and the $t-\varepsilon$ diagrams in the data sheet (NIMS, 2007). The typical diagrams for $\varepsilon=0.2$ and $0.5 \%$ are shown in Appendix, Figures A1 and A2. The regression analyses for each data group were conducted using Equation 3 and the regression lines are shown in Figures 1, A1, and A2 for each temperature in each group using the $Q V C$ s obtained. 


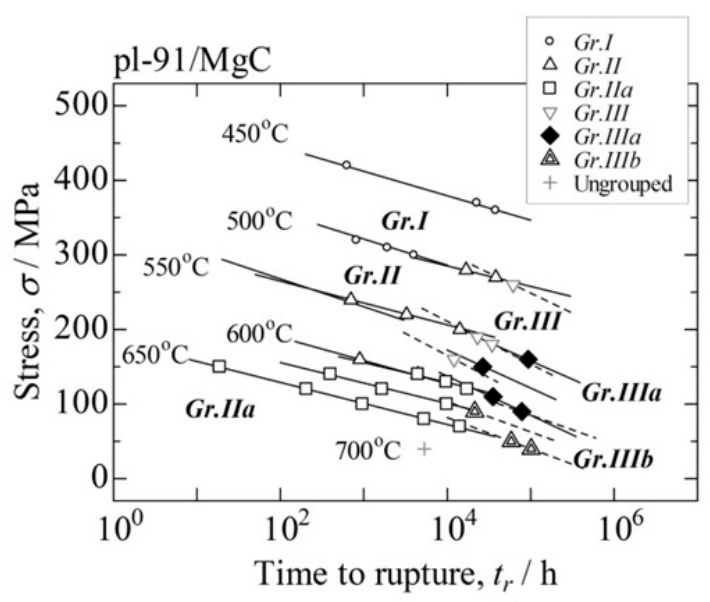

Figure 1. Stress vs. time to rupture relationship for pl-91/MgC. Definitions of Gr.I etc., are explained in the text. Creep tests were conducted at $25^{\circ} \mathrm{C}$ intervals; however, the test temperatures are only shown in every $50{ }^{\circ} \mathrm{C}$

Figure 1 indicates that, at $550{ }^{\circ} \mathrm{C}$, the $t_{r} \mathrm{~s}$ of $\mathrm{Gr} . I I$ are longer than the extrapolated $t_{r} \mathrm{~s}$ of Gr.I for the stresses in Gr.II; however, the rupture data of Gr.I is lacking, i.e., $t_{I I}>t_{I}$, but $t_{I I I}$ or $t_{I I I a}<t_{I I}$ at lower stresses, where $t_{X}$ denotes the creep time for Gr.X at a specific condition. The $\sigma-t_{r}$ relationship at $550{ }^{\circ} \mathrm{C}$ in Figure 1 shows that the change to an S-shape or the hardening in the rupture strength occurs after approximately $200 \mathrm{~h}$, which corresponds to Gr.II or a degradation in rupture strength occurs after approximately $20000 \mathrm{~h}$, which corresponds to Gr.III or Gr.IIIa. This trend is also confirmed at $600{ }^{\circ} \mathrm{C}$ and the degradation in rupture strength is observed more clearly in Gr.IIIa. The degradation behaviors at $550{ }^{\circ} \mathrm{C}$ along the S-shape were confirmed in the $\sigma-t_{0.5}, t_{1}, t_{2}$, and $t_{5}$ diagrams and the $\sigma-t_{0.5}$ relationship is shown in Figure A2 as an example although the data are lacking for Gr.IIIa. However, the $\sigma-t_{0.2}$ diagram changes to an inverse J-shape as shown in Figure A1, or the degradation in strength is not confirmed at $0.2 \%$ strain in Gr.III. This indicates that the degradation in strength is initiated in the strain range of $0.2-0.5 \%$ at $550{ }^{\circ} \mathrm{C}$ in Gr.III. Further, the inverse $\mathrm{J}$-shape relationship is observed at $600{ }^{\circ} \mathrm{C}$ in plain $9 \mathrm{Cr}-1 \mathrm{~W}$ steel and at $550{ }^{\circ} \mathrm{C}$ and $\varepsilon=0.2 \%$ in MGC. The $\mathrm{S}$-shape relationship in $\sigma-t_{r}, t_{\varepsilon}$ diagrams at a constant temperature is frequently observed at $600-650{ }^{\circ} \mathrm{C}$ in MJP, MJT, MGC, and $9 \mathrm{Cr}-4 \mathrm{~W}$ steel accompanying degradation in the long-term creep strength (Tamura $\&$ Abe, 2021b).

We find another data group, Gr.IIIb, instead of Gr.IIIa in a higher temperature and lower stress range. Both Grs.IIIa and IIIb are also found in the $\sigma-t_{r}$ relationship of T91/MGC (Tamura \& Abe, 2021b). The slope of an extrapolated regression line to $600{ }^{\circ} \mathrm{C}$ of Gr.IIIb is clearly slower than that for Gr.IIIa as seen in Figure 1. The test conditions where the breakdown in strength is a critical issue in Grade 91 and 92 steels correspond to Grs.IIIa and IIIb (Kushima et al., 1999; Sawada et al., 2011).

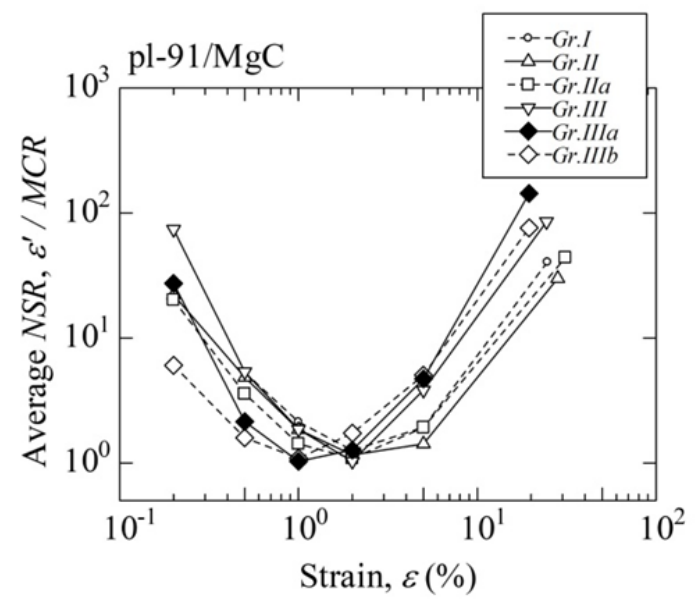

Figure 2. Average $N S R$ vs. strain relationship for pl-91/MgC 
Figure 2 shows the relationship between the strain and the average normalized strain rate (NSR) plotted in a double logarithmic diagram, where the strain rate at a specific strain is divided by each MCR and then the NSRs are averaged for each group. In Figure 2, the number of data for both Grs.IIIa and IIIb are only one and the strain in the far right for each group is the average of the EL. Further, the changes in the average $N S R$ for $\mathrm{MgC}$ shown in Figure 2 are qualitatively similar to those of P92/MJP, T92/MJT, and T91/MGC shown in the previous work (Tamura \& Abe, 2021b). In Figure 2, the characteristics of each group are clearly shown: the average NSRs for Grs.III and IIIa at an early stage of transient creep are rather high compared to those of Grs.I and II followed by rapid hardening (the slope, $\Delta \log ($ average $N S R) / \Delta \log \varepsilon$, is steep). Strains for the $M C R$ s for each group in Figure 2 range between $1-2 \%$. Under accelerating creep, the average NSRs for Grs.III, IIIa, and IIIb become large. The rapid strain hardening in transient creep for Grs.III and IIIa seems to trigger the subsequent increase in the creep rate during accelerating creep, which leads to the breakdown in rupture strength as indicated in Figure 1.
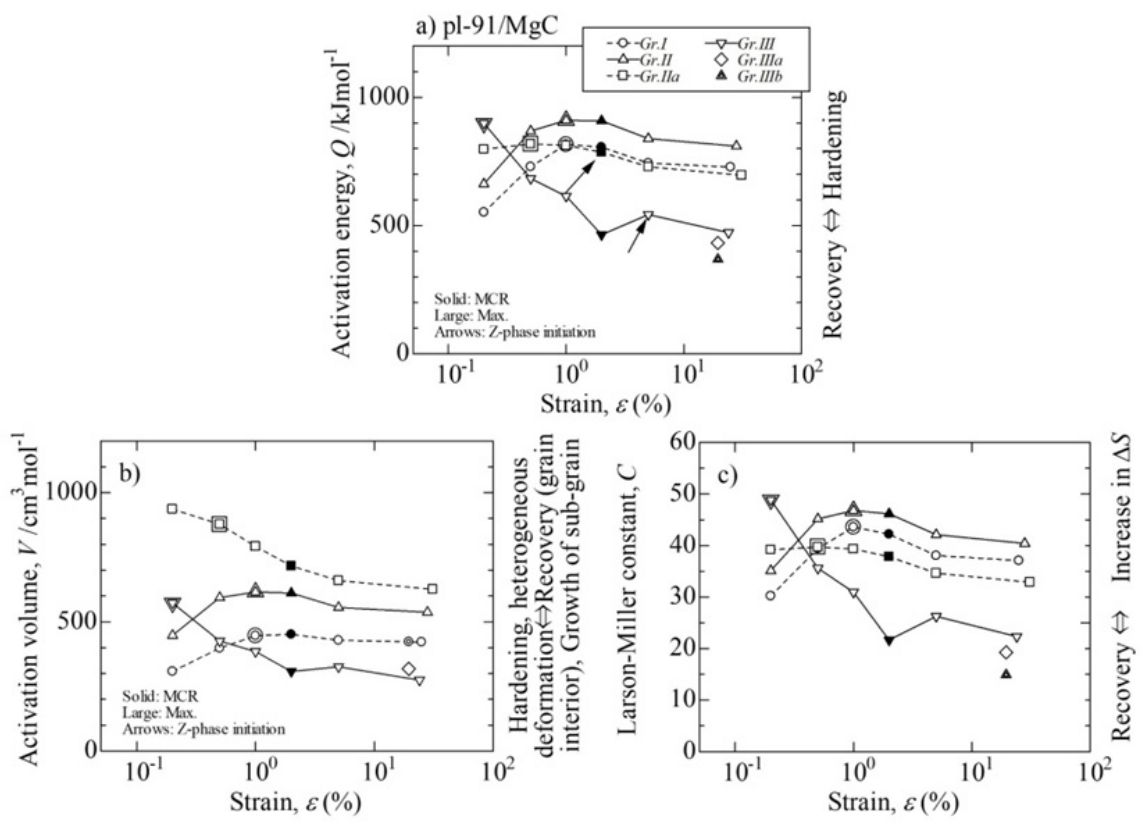

Figure 3. Results of $Q V C$ analysis as functions of creep strain for each group of pl-91/MgC steel; a) activation energy, b) activation volume, and c) Larson-Miller constant. Arrows indicate strains corresponding to the start time of the formation of the Z-phase (Gr.IIa and Gr.III)

Figure 3 shows the variations of $Q V C$ as functions of strain for each group, but the $Q V C$ s during creep for Grs.IIIa and IIIb were not obtained because of an insufficient number of data. The Z-phase is formed during the creep of Grs.IIa, III, IIIa, and IIIb (Strains for the initiation of the Z-phase formation are indicated by arrows for Grs.IIa and III in the figure). The values of $Q$ at ruptures for Grs.III, IIIa, and IIIb where the breakdown in rupture strength is observed (Figure 1) are lower than $500 \mathrm{kJmol}^{-1}$ and larger than the $Q$ for the self-diffusion of alpha-iron (Oikawa, 1982); however, the values of $C$ are approximately 20, which means that the microstructure is considerably recovered. On the other hand, $Q>700 \mathrm{kJmol}^{-1}$ and $C>30$ are obtained for Grs. I, II, and IIa at rupture, which implies the hard microstructure is maintained until rupture.

\subsection{Characteristic Features of Each Data Group}

\subsubsection{Gr.I}

The average test conditions for Gr.I of pl-91/MgC are $486{ }^{\circ} \mathrm{C}, 331 \mathrm{MPa}, t_{0.2}=15 \mathrm{~h}, t_{0.5}=279 \mathrm{~h}, t_{1}=$ $1883 \mathrm{~h}, t_{2}=5554 \mathrm{~h} t_{5}=8989 \mathrm{~h}$, and $t_{r}=9808 \mathrm{~h}$. The $Q V C$ shown in Figure 3 increase up to $\varepsilon=1 \%$, and then decrease. This behavior is the same as those of P92/MJP, T92/MJT, T91/MGC expect that the peak strains are $2 \%$ or larger. The Z-phase is not formed for Gr.I, which is the same as that for these steels. The average test temperature for $\mathrm{pl}-91 / \mathrm{MgC}$ is low compared to the other steels listed in Table 1 because the creep data tested at $450{ }^{\circ} \mathrm{C}$ are included. The initial increase in $Q V C$ is caused by SBSD and grain boundary strengthening resulting from $\mathrm{M}_{23} \mathrm{C}_{6}$ being similar to those of each Gr.I of P92/MJP, T92/MJT, and T91/MGC 
(Tamura \& Abe, 2021b). Although the peak value of $Q=816.6 \mathrm{kJmol}^{-1}$ of $\mathrm{MgC}$ is lower than $Q=854.7$ and $917.7 \mathrm{kJmol}^{-1}$ for Grs.I of MJT and MGC (both are tubular products), respectively, the value of $Q$ is comparable to $806.1 \mathrm{~kJ} / \mathrm{mol}^{-1}$ for MJP; this is attributed to the differences in the initial hardness for each (see Table 1). However, it cannot be denied that the precipitation of the Laves phase assists grain boundary strengthening in the transient creep of MGC and $\mathrm{MgC}$ (both are Grade 91 steel) because the Laves phase possibly precipitates for $G r . I$ of the similar steel of T91/MGC to pl-91/MgC (Tamura \& Abe, 2021b). After $\varepsilon>1 \%$, the $Q V C$ gradually decrease. However, $M C R$ occurs at $\varepsilon=2 \%$, and therefore, the recovery inside sub-grains and the coarsening of precipitates occurs heterogeneously between the $1-2 \%$ strain. Thus, HRHD is already initiated from the later stage of the transient creep. The occurrence of HRHD in the transient creep is confirmed in MGC, but is not observed in Gr.I for both MJP and MJT (Tamura \& Abe, 2021b). After the MCR point though the $Q V C$ gradually decrease up to rupture because of recovery, the $Q V C$ values at the rupture are rather high. Therefore, the hard microstructure of martensitic steel still holds at rupture.

\subsubsection{Gr.II}

The average test conditions for pl-91MgC are $550{ }^{\circ} \mathrm{C}, 216 \mathrm{MPa}, t_{0.2}=12 \mathrm{~h}, t_{0.5}=202 \mathrm{~h}, t_{1}=1190 \mathrm{~h}$, $t_{2}=4150 \mathrm{~h} t_{5}=9820 \mathrm{~h}$, and $t_{r}=11208 \mathrm{~h}$. The $Q V C$ increase up to $\varepsilon=1 \%$, and then decrease. This behavior is similar to those for P92/MJP, T92/MJT, and T91/MGC except that the peak strains for MJP are 2\%. The initial increase in $Q$ and $V$ is caused by SBSD and the grain boundary strengthening is caused by $\mathrm{M}_{23} \mathrm{C}_{6}$ and Laves phase similar to the cases for Gr.II of MJP, MJT, and MGC because the Laves phase is considered to form from approximately $2000 \mathrm{~h}$ ( $1.1 \%$ strain) under the average condition for Gr.II of pl-91/MgC based on the TTP diagram for the Laves phase using a $9 \mathrm{Cr}-1 \mathrm{MoVNb}$ steel plate (Tamura, Hayakawa, Yoshitake, Hishinuma, \& Kondo, 1988). The QVC behavior along the strain axis of Gr.II is similar to the behavior for Gr.I, but each value is larger than each of Gr.I through the entire duration of creep, and therefore, it is reasonable to consider that a similar creep phenomenon to Gr.I occurs more remarkably in Gr.II by increasing the temperature and that HRHD doubtlessly occurs between $1-2 \%$ strain. In the accelerating creep, precipitation hardening by the Laves phase is superior to the recovery of the martensite structure and coarsening of $\mathrm{M}_{23} \mathrm{C}_{6}$ and the Laves phase. Moreover, the Z-phase does not form at the average temperature of $550{ }^{\circ} \mathrm{C}$ (Sawada et al., 2007), and therefore, the Z-phase is considered to not be found through the entire duration until rupture and the strengthening particles of XM are not consumed. The average temperature for Gr.II of $\mathrm{MgC}$ is lower than those for each Gr.II of MJT and MJP. This is because the nose temperature of the TTP curve of $\mathrm{Fe}_{2} \mathrm{Mo}$ is lower than that of $\mathrm{Fe}_{2} \mathrm{~W}$ (Tamura et al., 1988). The maximum value of $Q=910.5 \mathrm{kJmol}^{-1}$ for $G r . I I$ of $\mathrm{MgC}$ is higher than that for Gr.I. This value is comparable to that of MGC and is smaller than those for MJP and MJT, $Q \sim 1000 \mathrm{kJmol}^{-1}$ (Tamura \& Abe, 2021b). This can be attributed to the lower amount of Laves phase precipitated for MgC and MGC compared to those for MJP and MJT, which is inferred from the total amount of Mo and W for each steel (based on atomic fraction). Therefore, the strengthening effect in $\mathrm{T} 91 / \mathrm{MGC}$ and $\mathrm{pl}-91 / \mathrm{MgC}$ is not as great as those for Gr.II of Grade 92/MJP and MJT. Further, the characteristic feature of Gr.II in the martensitic steel listed in Table 1 is similar to hardening caused by the precipitation of the Laves phase, which is promoted as compared to the case of Gr.I. This hardening initiates from the early stage of creep $\left(t_{0.5}=202 \mathrm{~h}\right)$, and this trend is similar to the other three steels $\left(t_{1}=139 \mathrm{~h}, t_{0.5}=19 \mathrm{~h}\right.$, and $t_{0.2}=7.8 \mathrm{~h}$ for P92/MJP, T92/MJT, and T91/MGC, respectively) as reported in the previous work (Tamura \& Abe, 2021b).

\subsubsection{Gr.IIa}

Average test conditions for pl-91/MgC are $630{ }^{\circ} \mathrm{C}, 115 \mathrm{MPa}, t_{0.2}=53 \mathrm{~h}, t_{0.5}=457 \mathrm{~h}, t_{1}=1747 \mathrm{~h}$, $t_{2}=4336 \mathrm{~h} t_{5}=6939 \mathrm{~h}$, and $t_{r}=5834 \mathrm{~h}$. The reason for $t_{r}<t_{5}$ is that the short-term rupture data are included at $625{ }^{\circ} \mathrm{C}$ although the $t_{\varepsilon} \mathrm{s}$ are not indicated. The $M C R$ occurs at approximately $2 \%$ strain on average. The Z-phase forms in an accelerating creep according to the TTP diagram for Grade T91 (Sawada et al., 2007) obtained using ruptured specimens of T91, while neglecting the effect caused by the difference between T91 and pl-91/MgC. According to the TTP diagram of Laves phase using the aged specimens of a $9 \mathrm{Cr}-1 \mathrm{MoVNb}$ steel plate (Tamura et al., 1988), the Laves phase starts to form near the MCR point. Therefore, the formation of the $Z$-phase and the coarsening of the Laves phase may induce negative effects on the accelerating creep. Neither the Laves phase nor the Z-phase forms in each Gr.IIa of the other three steels listed in Table 1; however, the Z-phase forms in a later stage of the accelerating creep of T91/MGC and the Laves phase forms in the later stage of the accelerating creep of P92/MJP based on each TTP diagram (Sawada et al., 2007; Tamura et al., 1988). These microstructural changes differ from pl-91/MgC; however, the $Q V C$ behavior with the creep strain of the four types of steel listed in Table 1 are roughly the same as each other even though their test conditions and QVC values are different. The values of the $Q V C$ s are rather large and decrease gradually throughout the entire duration of creep except for each initial stage of transient creep, or the $Q V C$ of all steels listed in Table 1 
decrease simultaneously even in transient creep. In the case of pl-91/MgC, $Q$ and $C$ increase slightly up to $\varepsilon=0.5 \%$ and decrease. $V \sim 1000 \mathrm{~cm}^{3} \mathrm{~mol}^{-1}$ is already attained at $\varepsilon=0.2 \%$, and then, it decreases. The high value of $V$ indicates that a highly recovered state with the growth of sub-grains continues through the entire duration of creep. However, up to $0.5 \%$ strain of transient creep, $Q$ and $C$ increase and $V$ decreases; this strain range corresponds to transient creep, which shows that HRHD with the DFRP mechanism for $\mathrm{M}_{23} \mathrm{C}_{6}$ occurs. After $\varepsilon>0.5 \%$ and up to the $M C R$ point, the $Q V C$ decrease simultaneously. These facts indicate that HRHD occurs in addition to the recovery in the transient creep, and the occurrence of the HRHD is necessary to maintain transient creep. Further, similar phenomena are found in Gr.IIa of P92/MJP, T92/MJT, and T91/MGC (Tamura \& Abe, 2021b)

\subsubsection{Gr.III}

The average test conditions for pl-91/MgC are $544{ }^{\circ} \mathrm{C}, 198 \mathrm{MPa}, t_{0.2}=48 \mathrm{~h}, t_{0.5}=975 \mathrm{~h}, t_{1}=5217 \mathrm{~h}$, $t_{2}=18942 \mathrm{~h} t_{5}=35412 \mathrm{~h}$, and $t_{r}=32830 \mathrm{~h}$. The reason for $t_{r}<t_{5}$ is the same as that for Gr.IIa. MCR occurs at $\varepsilon \sim 2 \%$, and the Z-phase does not form during the entire duration of creep at an average temperature of $544{ }^{\circ} \mathrm{C}$ according to the TTP diagram for T91/MGC (Sawada et al., 2007). However, it is considered that the Laves phase is formed after approximately $2200 \mathrm{~h}$ according to the TTP diagram of the Laves phase using the aged specimens of a $9 \mathrm{Cr}-1 \mathrm{MoVNb}$ steel plate (Tamura et al., 1988) while neglecting the minor difference between the two alloy systems. Here, $2200 \mathrm{~h}$ corresponds to $\varepsilon \sim 1.2 \%$ and it is in transient creep. The QVC values decrease from an initial stage at $\varepsilon=0.2 \%$ largely up to the $M C R$ point and then decrease moderately or are flat up to rupture for each. Although the initial hardening behavior is not observed for Gr.III in Figure 3 as confirmed for those of Grs.II and IIa, the initial value of $Q$ for Gr.III is sufficiently high and comparable to those for the peak value of $Q$ for Gr.II. Therefore, SBSD with the DFRP of $\mathrm{M}_{23} \mathrm{C}_{6}$ is already completed up to $\varepsilon=0.2 \%$ or the grain boundary strengthening by Laves phase may already operate under a creep circumstance up to $\varepsilon=0.2 \%$, though the later consideration is opposite to the estimation from the TTP diagram of Laves phase (Tamura et al., 1988) as mentioned above. Figure 3b) clearly shows that $V$ decreases from the initial stage of the creep up to the $M C R$ point of $\varepsilon=0.5 \%$. Even if the laves phase forms at an early stage of creep, the newly formed Laves phase particles precipitate only on the boundaries and not inside sub-grains under the creep conditions for Gr.III (Sawada et al.,1999; Panait, Bendick, Fuchsmann, Gourgues-Lorezon, \& Besson, 2010a; Yan et al., 2013). Alternatively, the precipitation of the Laves phase on the boundaries does not decrease the moving area of dislocations, and therefore, the decrease in $V$ should not be affected by the hardening caused by the Laves phase. Therefore, HRHD (Tamura \& Abe, 2021b) occurs from $\varepsilon=0.5 \%$ through transient creep accompanying the DFRP mechanism for $\mathrm{M}_{23} \mathrm{C}_{6}$ and the grain boundary strengthening by the Laves phase. Indeed, the degradation in strength for Gr.III is confirmed from $t_{0.5}=975 \mathrm{~h}<t_{M C R}$, as shown in Figure A2, where $t_{M C R}$ indicates the time to reach an $M C R$ point and $t_{M C R} \sim t_{2}=18942 \mathrm{~h}$. In addition, for the other steels P92/MJP, T91/MJT, and T91/MGC, the degradation in strength for each Gr.III is confirmed in a strain range of $0.5-1 \%$ in the transient creep (Tamura \& Abe, 2021b) although the test conditions for the three steels listed in Table 1 are not the same. However, the Z-phase is considered to form at $\varepsilon=1.5 \%$ for each steel according to the TTP diagram (Sawada et al., 2007). The abovementioned facts may indicate that the formation of the Z-phase is not always necessary; however, the formation and subsequently occurring coarsening of the Laves phase is necessary for the degradation in strength. Indeed, the degradation in strength is confirmed in $9 \mathrm{Cr}-4 \mathrm{~W}$ steel without the Z-phase wherein only the $\mathrm{M}_{23} \mathrm{C}_{6}$ and Laves phase form during creep (Tamura \& Abe, 2021a). The possible occurrence of HRHD and the degradation in the strength during transient creep are similar issues to understand the creep of martensitic steel especially in transient creep.

\subsubsection{Gr.IIIa}

The average test conditions for $\mathrm{pl}-91 / \mathrm{MgC}$ are $581^{\circ} \mathrm{C}, 128 \mathrm{MPa}$, and $t_{r}=33762 \mathrm{~h}$. The $Q V C$ values at the rupture are $432.4 \mathrm{kJmol}^{-1}, 318.2 \mathrm{~cm}^{3} \mathrm{~mol}^{-1}$, and 19.28 , respectively. The average times to a specific strain are not obtained for Gr.IIIa because creep data are reported only under the conditions of $600{ }^{\circ} \mathrm{C}, 110 \mathrm{MPa}$, and $t_{r}=35420 \mathrm{~h}$. Therefore, the $Q V C$ values are not displayed as functions of creep strain, as shown in Figure 3. Creep rates at $600{ }^{\circ} \mathrm{C}$ and $110 \mathrm{MPa}$ are calculated using Equation 4 and the results are shown in Figure 2. According to this curve, the $M C R$ occurs at $\varepsilon=1 \%(10400 \mathrm{~h})$. The Laves phase starts to form at a very early stage of transient creep $(\varepsilon=0.3 \%$ and approximately for $2000 \mathrm{~h})$ according to the TTP diagram of Laves phase using the aged specimens of a $9 \mathrm{Cr}-1 \mathrm{MoVNb}$ steel plate (Tamura et al., 1988), which neglects the minor difference between the two alloy systems. The Z-phase starts to form near the $M C R$ point $(\varepsilon=1.2 \%$ and approximately for $12500 \mathrm{~h}$ ) according to the TTP diagram for Z-phase using the ruptured specimens of Grade T91/MGC (Sawada et al., 2007) neglecting the minor differences between MGC and MgC. The QVC values at rupture are $432.4 \mathrm{kJmol}^{-1}, 318.2 \mathrm{~cm}^{3} \mathrm{~mol}^{-1}$, and 19.28 , respectively. These values are comparable to those of 
Gr.III for each and comparable to those of the lowest values among the QVC values for all data groups including the QVCS for all specific strains shown in Figure 3. Indeed, the degradation in long-term rupture strength is a critical issue for Gr.IIIa of not only high $\mathrm{Cr}$ martensitic steel reported in the previous work (Tamura $\&$ Abe, 2021b) but also pl-91/MgC, although the test conditions for each Gr.IIIa are not completely the same. The QVC values for Gr.IIIa at an initial stage of the creep of the other three steels than $\mathrm{MgC}$ listed in Table 1 are rather high, and they decrease largely with an increasing creep strain up to approximately each $M C R$ point and then they are roughly flat. The Laves phase is inferred to form at a very early stage of creep and the Z-phase is considered to start to form near the MCR point for P92/MJP, T92/MJT, and T91/MGC (Tamura \& Abe, 2021b) according to the TTP diagrams of the Z-phase shown in the previous work (Tamura et al., 1988; Sawada et al., 2007). If pl-91/MgC in a Gr.IIIa-condition is assumed to show similar precipitation behavior to that for MJP, MJT, and MGC, the initial $Q V C$ values of $\mathrm{MgC}$ are considered rather high and decrease largely up to the $M C R$ point; therefore, HRHD occurs at the initial stage of the transient creep, although the calculated data are absent.

\subsubsection{Gr.IIIb}

In Figure 1, Gr.IIIb is clearly different from Gr.IIIa; however, the $t_{\varepsilon}$ data are not reported. The average test conditions are $642{ }^{\circ} \mathrm{C}$ and $60 \mathrm{MPa}$ (average $t_{r}=60435 \mathrm{~h}$ ) and Gr.IIIb is positioned at a higher temperature and lower stress site than those for Gr.IIIa. The $N C R$ s for pl-91/MgC are calculated using a single creep curve tested at $650{ }^{\circ} \mathrm{C}, 50 \mathrm{MPa}$, and $t_{r}=58451 \mathrm{~h}$, and the results are shown in Figure 2 . The $M C R$ point is at $\varepsilon=1 \%$. The $Q V C$ values at the rupture are $368.6 \mathrm{kJmol}^{-1}, 422.9 \mathrm{~cm}^{3} \mathrm{~mol}^{-1}$, and 14.92 , respectively. The value of $Q$ is slightly larger than that for the self-diffusion of $\alpha$-Fe and the value of $V$ is larger than that for Gr.IIIa. In addition, the value of $C$ is lower than that of Gr.IIIa. The start time of the Laves phase and Z-phase formation is approximately $4000 \mathrm{~h}$ at the average temperature, and therefore, the $t_{r} \mathrm{~s}$ in Gr.IIIb are affected by the formation of the Laves phase and the Z-phase. Therefore, referring to the low values of $Q$ and $C$, the microstructure in a gauge portion at rupture must be recovered considerably. The value of $V$ is larger than that of Gr.IIIa; further, the degree of HRHD is not as remarkable as that compared of Gr.IIIa, and thus, the breakdown in strength tends to be moderated. According to the regression line at $600^{\circ} \mathrm{C}$ for Gr.IIIb given in Figure 1 indicated using a broken line, the abrupt breakdown in the strength experienced in Gr.IIIa can be mitigated if the creep test is performed at $600{ }^{\circ} \mathrm{C}$ under a lower stress compared to that performed for Gr.IIIa.

\subsection{Factorial Analysis}

Figure 1 shows that $t_{r}$ in Gr.II are longer than those estimated from Gr.I and that in Gr.III are shorter than those estimated from Gr.II. Thus, it is necessary to investigate the relationship between these facts and metallurgical reactions. The $t_{\varepsilon} \mathrm{s}$ and $t_{r} \mathrm{~s}$ for both Grs.I and II under the conditions of the average temperature and stress of Gr.II were calculated (these variables are symbolized as $t_{I}$ and $t_{I I}$, respectively); $[Q],[V]$, and $C$ were calculated according to Equation 3 for each case; and the differences between the obtained values of $[Q],[V]$, and $C(\Delta[Q], \Delta[V], \Delta C$ hereinafter) were also calculated. Results for each strain are summarized in Table 2 . In the table, the differences between logarithmic $t_{I}$ and $t_{I I}$, i.e., $\log \left(t_{I I} / t_{I}\right)$ are also shown. The detrimental factors for $\log \left(t_{I I} / t_{I}\right)$ are shown in bold italics. Here, the negative values for $[V]$ and $C$ are listed to set the summation of the above three in each column equal to $\log \left(t_{I I} / t_{I}\right)$. Further, Table 2 indicates that, in all examined strain ranges, an increase in $Q$, i.e., $\Delta[Q]$, is the detrimental term for the hardening in $G r . I I$ and caused by the precipitation of the Laves phase and DFRP of $\mathrm{M}_{23} \mathrm{C}_{6}$. This is reasonable when referring to the previous work (Tamura \& Abe, 2021b).

Similar calculations were performed for Grs.II and III; the results are summarized in Table 3. Further, Table 3 indicates that in all strain ranges examined excepting for $\varepsilon=0.2 \%$, a decrease in $\Delta[Q]$ is the detrimental term for the degradation in the strength for Gr.III, which is caused by the HRHD accompanying the coarsening of the Laves phase. The Z-phase does not form until $\varepsilon=5 \%$ in Gr.III of pl-91/MgC, which refers to the TTP diagram of the Z-phase using ruptured specimens of T91/MGC (Sawada et al., 2007). Therefore, the Z-phase is not considered to largely affect the degradation of the Gr.III of pl-91/MgC. 
Table 2. Factorial analysis for $t_{r}$ and $t_{\varepsilon}$ of Grs.I and $I I$ under the average test conditions for Gr.II of pl-91/MgC steel $\left(550^{\circ} \mathrm{C}, 216 \mathrm{MPa}\right)$ and the detrimental terms for $\log \left(t_{I I} / t_{I}\right)$ are shown in bold-italics.

\begin{tabular}{ccccccc}
\hline Strain (\%) & 0.2 & 0.5 & 1 & 2 & 5 & 27 \\
\hline$\Delta[Q]$ & $\mathbf{7 . 0 2}$ & $\mathbf{8 . 8 5}$ & $\mathbf{5 . 7 9}$ & $\mathbf{6 . 5 3}$ & $\mathbf{6 . 0 8}$ & $\mathbf{5 . 1 9}$ \\
$-\Delta[V]$ & -1.91 & -2.69 & -2.32 & -2.19 & -1.74 & -1.58 \\
$-\Delta C$ & -4.94 & -5.74 & -3.19 & -3.98 & -4.05 & -3.32 \\
$\log \left(t_{I I} / t_{I}\right)$ & 0.16 & 0.42 & 0.45 & 0.35 & 0.29 & 0.28 \\
\hline
\end{tabular}

However, it is not denied that the Z-phase forms at an early stage of transient creep because of the occurrence of HRHD. These considerations are feasible referring to the previous work on P92/MJP, T92/MJT, and T91/MGC (Tamura \& Abe, 2021b). Table 3 also shows that $t_{I I I}<t_{I I}$ for $\varepsilon=0.2 \%$ and the determinant term(s) are $\Delta[V]$ and $\Delta C$, or $\Delta[V]+\Delta C>0$ and is not $\Delta[Q]$. Figure A1 shows that, at $\varepsilon=0.2 \%$, the $t_{I I I} \mathrm{~s}$ are longer than the estimated $t_{I I}$ s. This is because the reliability of the $Q V C$ values at $\varepsilon=0.2 \%$ is rather as low as $t_{r}$ at $500{ }^{\circ} \mathrm{C}$ and $300 \mathrm{MPa}$ is short as compared with the other data in Gr.I.

Table 3. Factorial analysis for $t_{r}$ and $t_{\varepsilon}$ of Grs.II and III under the average test conditions for Gr.III of pl-91/MgC steel $\left(544^{\circ} \mathrm{C}, 198 \mathrm{MPa}\right)$ and the detrimental terms for $\log \left(t_{I I I} / t_{I I}\right)$ are shown in bold-italics.

\begin{tabular}{cllllll}
\hline Strain (\%) & 0.2 & 0.5 & 1 & 2 & 5 & 26 \\
\hline$\Delta[Q]$ & 15.16 & $\mathbf{- 1 1 . 8 5}$ & $\mathbf{- 1 8 . 9 0}$ & $\mathbf{- 2 8 . 4 4}$ & $\mathbf{- 1 8 . 9 6}$ & $\mathbf{- 2 1 . 5 8}$ \\
$-\Delta[V]$ & $\mathbf{- 1 . 5 7}$ & 2.14 & 2.93 & 3.86 & 2.92 & 3.34 \\
$-\Delta C$ & $\mathbf{- 1 3 . 7 2}$ & 9.57 & 15.82 & 24.51 & 15.85 & 18.06 \\
$\log \left(t_{I I I} / t_{I I}\right)$ & -0.13 & -0.13 & -0.15 & -0.08 & -0.20 & -0.18 \\
\hline
\end{tabular}

\section{$5.4\left[Q_{s}\right],\left[V_{s}\right]$, and $C_{s}$ Analysis}

The strain rate is an important parameter reflecting the state of microstructure at a given strain; however, in the above analyses, $Q V C$ are obtained using $t_{r}$ and $t_{\varepsilon}$ and not the strain rates at a specific strain. This is because the rupture data are most popular, the number of $t_{r}$ accumulated is very large, and the creep rates near rupture calculated using Equation 4 are remarkably affected by the necking of a specimen. However, for analyzing the creep behavior of transient creep and key factors that promote the accelerating creep in detail, $Q_{s}, V_{s}$, and $C_{s}$ should be evaluated again using the strain rates at a specific strain calculated using Equation 4, instead of using $t_{r}$ and $t_{\varepsilon}$. An equation similar to Equation 3 is obtained by referring to Equations 1 and 2, and the regression analyses were made.

$$
\log \dot{\varepsilon}=-\left[Q_{s}\right]+\left[V_{s}\right]+C_{s},
$$

where the square brackets denote the same meanings as in Equation 3. The results of $Q_{s}, V_{s}$, and $C_{s}$ for $G r . I I$ of $\mathrm{pl}-91 / \mathrm{MgC}$ steel were drawn as the functions of strain, and it was found that the variations in $Q_{s}, V_{s}$, and $C_{s}$ were very similar to those shown in Figure 3 although the figures are omitted for simplicity. Instead, the relationship between the changes in $Q_{s}, V_{s}$, and $C_{s}$ with increasing strain and changes in the corresponding strain rate were analyzed. Table 4 shows differences in the $\left[Q_{s}\right],\left[V_{s}\right], C_{s}$, and $\log \dot{\varepsilon}$ in Equation 7 between two adjacent strains, $\Delta\left[Q_{s}\right], \Delta\left[V_{s}\right], \Delta C_{s}$, and $\Delta \log \dot{\varepsilon}$ at an average temperature and under an average stress for $G r . I I$ of $\mathrm{MgC}$. Note that the negative values for $\Delta\left[Q_{s}\right]$ are listed in Table 4 to set the summation of the above three in each column equal to $\Delta \log \dot{\varepsilon}$ and the determinant terms for the strain rate are indicated in bold italics. We think that changes in $\Delta \log \dot{\varepsilon}$ can be explained by the changes in $\Delta\left[Q_{S}\right]$ when we look only at the changes in $Q_{S}$, i.e., the magnitude of resistance to the mobile dislocations. However, this is not the case. Table 4 indicates that an $M C R$ point is near $\varepsilon=2 \%$, which coincides with Figure 2. The determinant term for $\dot{\varepsilon}$ up to $\varepsilon=1 \%$ increases in $\left[Q_{s}\right]$, and it is caused by the grain boundary strengthening because of the dislocations that are swept out, $\mathrm{M}_{23} \mathrm{C}_{6}$, and the Laves phase. Further, between $\varepsilon=1 \%$ and the $M C R$ point, $\varepsilon=1-2 \%$ decreases in $\left[V_{s}\right]+C_{s}$ are the determinant terms while $\left[Q_{s}\right]$ surely decreases in this strain range. In an accelerating creep, a decrease in $\left[Q_{s}\right]$ is the unique determinant term, which is caused by the progress of recovery and coarsening of microstructure. Table 5 lists similar results for Gr.III. An MCR point is near $\varepsilon=2 \%$. Table 5 indicates that although at an early stage of transient creep, $\varepsilon=0.2-0.5 \%$, an increase in $\left[Q_{s}\right]$ is certainly the determinant 
term in a strain range of $0.5-2 \%$; up to an $M C R$ point, $-\Delta\left[Q_{s}\right]+\Delta\left[V_{S}\right]$ or $\Delta\left[V_{s}\right]+\Delta C_{s}$ are the determinant terms. In accelerating creep, a decrease in $\Delta\left[Q_{s}\right]$ or $-\Delta\left[Q_{s}\right]+\Delta\left[V_{S}\right]$ is the determinant term; however, the effect of necking may be considered in a strain range of $\varepsilon>5 \%$.

Table 4. Changes in $Q_{s}, V_{s}, C_{s}$, and $\log (\dot{\varepsilon})$ between two adjacent strains for Gr.II of pl-91/MgC steel

\begin{tabular}{clllll}
\hline Strain range & {$[0.2-0.5 \%]$} & {$[0.5-1 \%]$} & {$[1-2 \%]$} & {$[2-5 \%]$} & {$\left[5 \%-t_{r}\right]$} \\
\hline$-\Delta\left[Q_{s}\right]$ & -4.47 & $-\mathbf{1 . 9 6}$ & 0.75 & 7.30 & $\mathbf{6 . 4 7}$ \\
$\Delta\left[V_{S}\right]$ & 0.48 & 0.16 & $-\mathbf{0 . 1 5}$ & -1.25 & -0.67 \\
$\Delta C_{s}$ & 3.04 & 1.33 & $-\mathbf{0 . 8 1}$ & -5.90 & -4.35 \\
$\log (\dot{\varepsilon}, \% / \mathrm{h})$ & -0.95 & -0.46 & -0.21 & 0.15 & 1.44 \\
\hline
\end{tabular}

Tables 4 and 5 indicate that $\Delta V_{s}<0$ with increasing strain is essentially necessary to hold transient creep, even though $\left[Q_{s}\right]$ starts to decrease with an increase in strain or recovery becomes remarkable in the later stage of transient creep. Thus, HRHD occurs in this strain range. Similar phenomena are confirmed in P92/MJP, T92 MJT, and T91/MGC (Tamura \& Abe, 2021b). For these steels, the Z-phase certainly form within time to reach each $M C R$ point, and therefore, an HRHD zone is easily formed as discussed in the previous work (Tamura \& Abe, 2021b). In the case of pl-91/MgC, there is insufficient time to form the Z-phase in transient creep thermally. However, not only the coarsening of the Laves phase but also the possible formation of Z-phase need to occur in an HRHD zone for Gr.III of pl-91/MgC because the metallurgical reactions are easily accelerated with an assist of straining.

Table 5. Changes in $Q_{s}, V_{s}, C_{s}$, and $\log (\dot{\varepsilon})$ between two adjacent strains for $G r . I I I$ of pl-91/MgC steel

\begin{tabular}{clllll}
\hline Strain range & {$[0.2-0.5 \%]$} & {$[0.5-1 \%]$} & {$[1-2 \%]$} & {$[2-5 \%]$} & {$\left[5 \%-t_{r}\right]$} \\
\hline$-\Delta\left[Q_{s}\right]$ & $-\mathbf{5 . 1 9}$ & $\mathbf{- 0 . 8 3}$ & 14.55 & $\mathbf{2 3 . 9 6}$ & $\mathbf{1 . 8 6}$ \\
$\Delta\left[V_{s}\right]$ & 1.74 & $\mathbf{- 0 . 7 0}$ & $\mathbf{- 2 . 9 8}$ & -3.53 & $\mathbf{0 . 3 0}$ \\
$\Delta C_{s}$ & 3.04 & 0.81 & $\mathbf{- 1 1 . 8 9}$ & -19.83 & -0.56 \\
$\log (\dot{\varepsilon}, \% / \mathrm{h})$ & -0.41 & -0.72 & -0.33 & 0.60 & 1.60 \\
\hline
\end{tabular}

\section{Discussion}

\subsection{Degradation in 100000 h Rupture Strength of 9Cr Martensitic Steel with High Strength}

The rupture strengths of Grade 91 and 92 steels decrease unexpectedly after tens of thousands of hours at a specific temperature between $600-650{ }^{\circ} \mathrm{C}$ (Kushima et al., 1999; Sawada et al., 2007; Tamura \& Abe, 2021b). Figure 4 shows a comparison between the rupture strengths of P92/MJP, T92/MJT, T91/MGC, and pl-91/MgC at $600{ }^{\circ} \mathrm{C}$ (Figure 1 and Tamura \& Abe, 2021b). The rupture strength at $600{ }^{\circ} \mathrm{C}$ decreases along Gr.I $\rightarrow$ Gr.II $\rightarrow$ Gr.III $\rightarrow$ Gr.IIIa (Gr.IIIb) in the S-shape for all steels. In Gr.II, the steels are strengthened by the Laves phase. In the Gr.IIIa region of Figure 4, the strengthening effect of MX is partially diminished by the formation of the Z-phase, and as a result, the degradation in strength occurs for these steels. The rupture data of $t_{r}>100000 \mathrm{~h}$ for Grade P91 (Panait et al., 2010b) is plotted in Figure 4 (symbolized as P91/Panait). The rupture data of P91/Panait lies on a regression line for Gr.IIIa of pl-91/MgC, and therefore, the rupture data of P91/Panait is considered to belong to Gr.IIIa although the data for shorter time are absent. The behavior of Gr.III lies between that of Grs.II and IIIa for all steels. The $100000 \mathrm{~h}$ rupture strength at $\sim 600{ }^{\circ} \mathrm{C}$ can be estimated from rupture data in Gr.IIIa regions and the maximum allowable tensile strength is determined with reference to the $100000 \mathrm{~h}$ rupture strength at a specific temperature. Although the test conditions for Gr.IIIa are not defined strictly, Gr.IIIa for many high $\mathrm{Cr}$ martensitic steel with high strength are observed in a similar temperature and stress range. Rupture strengths for $100000 \mathrm{~h}$ of these steels are estimated from Equation 1 while substituting QVC values obtained for each steel and a specific temperature; the results are summarized in Table 6 . The rupture strength of pl-91/MgC at $625^{\circ} \mathrm{C}$ is not obtained because of the lack of long-term data shown in Figure 1. In the calculation, the regression line for the appropriate data group when the regression lines around $100000 \mathrm{~h}$ become complicated is selected by considering the following scenarios: (i) the rupture strength decreases in the S-shape 
for all steels investigated and (ii) there is a tendency for the slope of the $\sigma-\log t_{r}$ relationship to become gentler beyond $100000 \mathrm{~h}$ compared to that of Gr.IIIa.

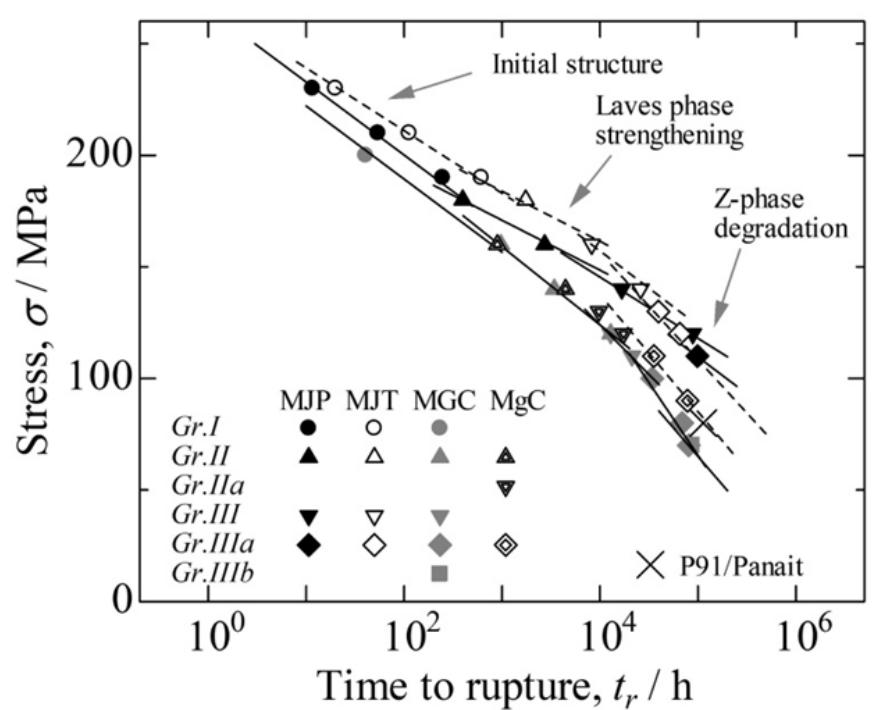

Figure 4. Comparison between the $\sigma-t_{r}$ relationships at $600{ }^{\circ} \mathrm{C}$ of P92/MJP, T92/MJT, T91/MGC, and $\mathrm{pl}-91 / \mathrm{MgC}$. Rupture data for P91/Panait is presented by Panait et al. (2010b)

The rupture strengths for steels at $600{ }^{\circ} \mathrm{C}$ follow the order MJP $>$ MJT $\gg \mathrm{MgC}>\mathrm{MGC}$; those for Grade 92 steel are naturally higher than those for Grade 91 steel. In most cases shown in Table 6, the $100000 \mathrm{~h}$ strengths are calculated using the data in Gr.IIIa, where the degradation in rupture strength is a critical issue. Tamura (2015a) showed that the estimation method based on an exponential law introduced here is appropriate compared to methods based on the power law (Kimura, 2009) that is generally employed by analyzing long-term rupture data of Grade 122 (NIMS, 2013). Further, Tamura (2015a) also indicated that long-term rupture data are necessary to ensure the high accuracy of the estimation for the $100000 \mathrm{~h}$ rupture strength. If the longest rupture data of high strength steel is limited to within $10000 \mathrm{~h}$, the effect of the Laves phase strongly reflects the estimated $100000 \mathrm{~h}$ rupture strength, which results in over estimation. For estimating the $100000 \mathrm{~h}$ rupture strength of high-strength martensitic steel with high accuracy, rupture data longer than approximately $70000 \mathrm{~h}$ are required because microstructures change unexpectedly around the Gr.IIIa region. Further, the applied load in actual functional power plants is far lower than the $100000 \mathrm{~h}$ rupture strength, and therefore, it is difficult to estimate either the microstructure or the related mechanical behavior or both, although changes in the microstructure are considered moderated compared to those of Gr.IIIa. Table 6 and Figure 4 indicate that there are certain levels of differences not only between Grade 91 and Grade 92 steels, but also among heats belonging to the same steel grade. Such differences are confirmed in the other heats of Grade 91 and 92 steels than those summarized in Table 6 (NIMS, 2007; 2013; 1014; 2018). The reasons for these differences have been studied (Kimura et al., 2013; Sawada, Kushima, Tabuchi, \& Kimura, 2014b; Sawada et al., 2014a; 2019a); however, they have not been sufficiently clarified. Thus, although the creep strength of Grade 92 steel is considered to sufficiently credible, there is room for further improvement.

Table 6. Estimated rupture strength for $100000 \mathrm{~h}$ at temperatures indicated for P92/MJP, T92/MJT, T91/MGC, and $\mathrm{pl}-91 / \mathrm{MgC}$. Symbols in parentheses denote each corresponding data group used for the estimation

\begin{tabular}{ccccc}
\hline $\mathrm{MPa}$ & MJP & MJT & MGC & MgC \\
\hline $600^{\circ} \mathrm{C}$ & $109.4($ IIIa $)$ & $108.5($ IIIa $)$ & $65.9($ IIIa $)$ & 85.1 (IIIa) \\
$625^{\circ} \mathrm{C}$ & $84.4($ IIIa $)$ & $78.9($ IIIa $)$ & $46.3($ IIIb) & - \\
$650^{\circ} \mathrm{C}$ & $59.5($ IIIa $)$ & $52.6(I V)$ & $43.9($ IV $)$ & $40.3($ IIIb) \\
\hline
\end{tabular}




\subsection{Causes of Degradation}

\subsubsection{A Question}

Sawada et al. (2006) indicated that the number density of the Z-phase $\left(\rho_{Z}\right)$ in a gauge portion is higher than that of a grip portion of a ruptured specimen, and therefore, the larger $E L$ of T91/MGC causes a higher $\rho_{Z}$, which leads to severe degradation in T91/MGC compared to that of T92/MJT, as shown in Figure 4.

The degradation in creep strength for Gr.IIIa is similar to the degradation in rupture strength as shown in Figure 4 is already confirmed at a smaller strain $(0.5 \%)$, as indicated in Figure A2 for $\mathrm{MgC}$ and the corresponding figures for MJP, MJT, and MGC in the previous work (Tamura \& Abe, 2021b). Further, Sawada et al. (2011) reported that the number density of MX decreases with increasing creep strain in response to the increase in the $\rho_{Z}$ using creep-interrupted specimens of T91/MGC tested at $600{ }^{\circ} \mathrm{C}$ under $70 \mathrm{MPa}$ (Gr.IIIa conditions). Therefore, it is interesting to compare the relationships between the $\sigma-t_{1}$ relationships at $600{ }^{\circ} \mathrm{C}$ for MJP, MJT, MGC, and MgC; the results are shown in Figure 5. $t_{1}$ for P91/Panait is read from creep curves obtained at $600{ }^{\circ} \mathrm{C}$ under $80 \mathrm{MPa}$ (Panait et al., 2010b), and it is indicated by a cross mark in Figure 5. Only a single regression line is drawn for $\mathrm{Gr} . I I$ of $\mathrm{MgC}$ in Figure 5 because of the insufficient number of data at $600{ }^{\circ} \mathrm{C}$. Clear differences in creep strength in Grs.III and IIIa for the same $t_{1}$, or the same nominal strain of $1 \%$, between Grades 91 (MGC) and 92 (MJP and MJT) can be clearly observed in Figure 5 regardless of the differences in rupture elongation between Grades 91 (MGC) and 92 (MJP and MJT). This trend that the creep strengths in Grs.III and IIIa for $t_{1}$ under the same nominal strain of Grade 92 steel are higher than those for Grade 91 steel is confirmed in pl-91/MgC and P91/Panait; however, the number of data points for $\mathrm{MgC}$ and P91/Panait are limited.

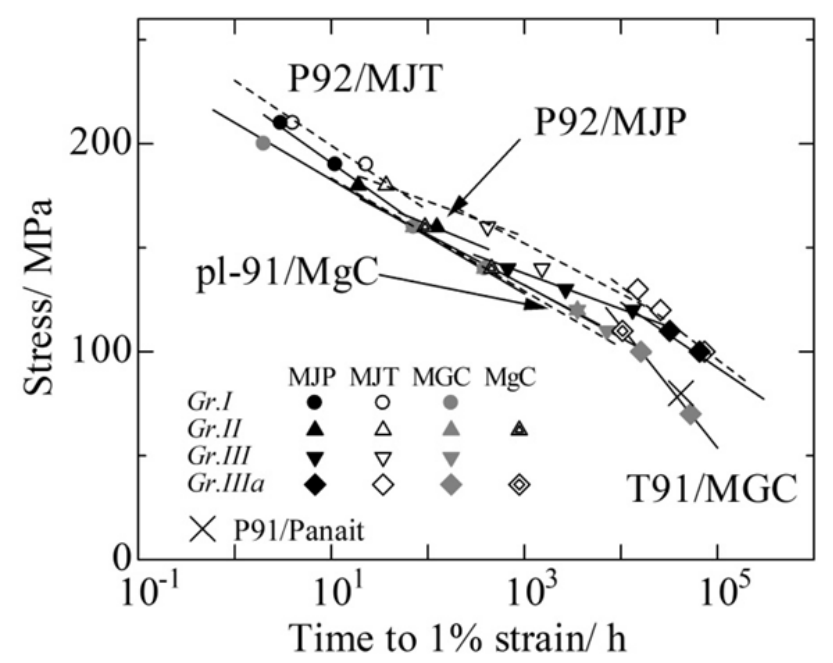

Figure 5. Comparison between the $\sigma-t_{1}$ relationships at $600{ }^{\circ} \mathrm{C}$ of P92/MJP, T92/MJT, T91/MGC, and $\mathrm{pl}-91 / \mathrm{MgC}$

The values of the start time of the Z-phase formation at $600{ }^{\circ} \mathrm{C}$ for T92/MJT and T91/MGC are approximately 8000 and $10000 \mathrm{~h}$, respectively (Sawada et al., 2007), and each time is near the border line of each Gr.IIIa region in Figure 5. The $t_{1} \mathrm{~s}$ for Gr.IIIa of MJT and MGC are 27220 and $29527 \mathrm{~h}$, respectively (Tamura \& Abe, 2021b). Therefore, the Z-phase is considered to have already been formed within the time duration of $1 \%$ strain in the Gr.IIIa of both steels. The $\rho_{Z}$ s for the $t_{1} \mathrm{~s}$ of MJT and MGC can be estimated as follows: The $\rho_{Z}$ of MGC in a specimen crept to a $1 \%$ strain at $600{ }^{\circ} \mathrm{C}$ and $70 \mathrm{MPa}\left(t_{1}=52581 \mathrm{~h}, t_{r}=80737 \mathrm{~h}\right)$, a member of Gr.IIIa, and it can be read as $2 \mathrm{E} 11 \mathrm{~m}^{-2}$ from the figure shown in the previous work (Sawada et al., 2011). Although the $\rho_{Z}$ of creep-interrupted specimens of MJT is not yet investigated, the $\rho_{Z}$ of a ruptured specimen tested at $600{ }^{\circ} \mathrm{C}$ and $130 \mathrm{MPa}\left(t_{1}=14900 \mathrm{~h}, t_{r}=39540 \mathrm{~h}\right.$; NIMS, 2018) can be read as $1.4 \mathrm{E} 11 \mathrm{~m}^{-2}$ (Sawada et al., 2006). These data are a member of Gr.IIIa in this study and $t_{r}$ is the longest among the specimens with the observed $\rho_{Z}$. We can infer that the $\rho_{Z}$ value of MJT crept to $1 \%$ strain at $600{ }^{\circ} \mathrm{C}$ for the similar duration as that for MGC is estimated not to exceed this value $\left(1.4 \mathrm{E} 11 \mathrm{~m}^{-2}\right)$ assuming that $t_{r}=39540 \mathrm{~h}$ for MJT is almost the same temporal time as $t_{1}=52581 \mathrm{~h}$ and considering that creep strain promotes the precipitation of 
the Z-phase (Sawada et al., 2006). Under the same specific strain condition of $1 \%$, the $\rho_{Z}$ of T91/MGC is higher than that of T92/MJT, which should be correlated to the degradation in creep strength shown in Figure 5. Therefore, if the reasons for the degradation in strength for $t_{r}$ and $t_{1}$ in each Gr.IIIa shown in Figures 4 and 5 are similar, it is insufficient to consider that the larger $E L$ is responsible for the formation of a larger amount of the Z-phase, which leads to lower rupture strength of Grade 91 steel than Grade 92 steel, while considering the variations of $\rho_{Z}$ mentioned above. Instead, it is natural that the Z-phase forms easily during creep in Grade 91 steel compared to Grade 92 steel, which leads to degradation in the long-term creep strength shown in Figures 4 and 5. Thus, a new model is required to explain the degradation in the long-term rupture strength of martensitic steel.

\subsubsection{Modeling of Microstructural Variations during the Creep of Gr.IIIa}

Many researchers (Kushima et al., 1999; Suzuki et al., 2003; Sawada et al., 2006; Danielsen, 2007; Hald, 2008; Kimura et al., 2013) agree that the main cause of unexpected degradation in the long-term rupture strength is the partial disappearance of strengthening factors of MX caused by the formation of the Z-phase. Sawada et al. (2007) indicated that the TTP curves of the Z-phases for Grade 91 and 92 steels are very similar. Further, Kocer, Abe, and Soon (2009) reported that the Cr content is the main driving force for the formation of the Z-phase that is secondarily impacted by the $\mathrm{Nb}, \mathrm{V}$, and $\mathrm{N}$ of the alloy system. Therefore, considerations based on the thermodynamic stability and TTP diagram for the Z-phase in martensitic steel indicate few differences in the degree of degradation in the rupture strength of Grade 91 and 92 steels caused by the amount of the Z-phase formed. The differences in the degree of degradation in the strength for each Gr.IIIa shown in Figure 4 need to be explained by considering the formability of the Z-phase, and not by the thermal stability of the Z-phase.

Table 7. Comparison of the time to rupture at $600{ }^{\circ} \mathrm{C}$ under the stress indicated, the number density of Z-phase in a ruptured specimen $\left(\rho_{Z}\right)$, rupture elongation $(E L)$, and activation volume for Gr.IIIa among the steels indicated. Creep data of P91/Panait is presented by Panait et al. (2010b)

\begin{tabular}{cccccc}
\hline Steel & Stress / MPa & $t_{r} / \mathrm{h}$ & $\rho_{z} / 1 \mathrm{E} 11 / \mathrm{m}^{-2}$ & $E L(\%)$ & $V / \mathrm{cm}^{3} \mathrm{~mol}^{-1}$ \\
\hline P92/MJP & 130 & 38067 & $(1.3)$ & 20 & 505.1 \\
T92/MJT & 130 & 39539 & 1.4 & 11 & 348.5 \\
& 100 & 34141 & 3.3 & 22 & 256.4 \\
T91/MGC & 70 & 80737 & 7.6 & 33 & 318.2 \\
pl-91/MgC & 90 & 78237 & 1.9 & 28 & \\
P91/Panait & 80 & 113431 & (a few) & 7.3 & \\
\hline
\end{tabular}

Equation 6 shows that $V$ is inversely proportional to the slope of the $\sigma-\log t_{r}$ relationship, and therefore, the slope denotes that the rate of degradation in strength $\Delta \sigma / \Delta \log t_{r}$ in the Gr.IIIa region is inversely proportional to $V$ (Tamura \& Abe, 2021a; 2021b). Though $t_{r}$ in the Gr.IIIa region is affected not only by the slope of the $\sigma-\log t_{r}$ relationship but also by the hardening process in the Gr.II region as shown in Figure 4, the $t_{r}$ in the Gr.IIIa region should be correlated with the value of $V$ in the Gr.IIIa region itself. The lower $V$ may evoke a higher $\rho_{Z}$ in the Gr.IIIa region of the high Cr martensitic steel containing MX. Therefore, the $t_{r}$ at $600{ }^{\circ} \mathrm{C}$ under a stress indicated in the Gr.III $a$ region, $\rho_{Z}, V$, and $E L$ for each steel are listed anew in Table 7; the creep related data are shown in the literature (NIMS, 2014; 2018). The $V$ s for MJP, MJT, and MGC are reported in the previous paper (Tamura \& Abe, 2021b) and the $V$ for $\mathrm{MgC}$ are shown in Figure 3. The $\rho_{Z} \mathrm{~s}$ for T92/MJT and T91/MGC (100 MPa) are reported by Sawada et al. (2006). The $\rho_{Z}$ s for MGC (70 MPa) and MgC are read from a graph reported by Sawada et al. (2014a). The $\rho_{Z}$ for MJP is not reported yet; however, it can be inferred to be $1.3 \mathrm{E} 11 \mathrm{~m}^{-2}$ from a graph reported by Sawada et al. (2006) that ignores differences between MJT and MJP. For the data of P91/Panait (Panait et al., 2010b), $\rho_{Z}$ is not yet investigated; however, $\rho_{Z}$ is reported to be lower than that of MX, and the $E L$ is estimated from the creep curves shown in their paper. Table 7 indicates a tendency that $\rho_{Z}$ is higher, and thus, $t_{r}$ is shorter for steels with higher $E L$ values. However, when we compare the upper three data in Table 7 with $t_{r}=30000-40000 \mathrm{~h}$ among MJP, MJT, and MGC, this tendency observed between $\rho_{Z}$ and $E L$ does not always hold true. The ELs for MJP and MGC (100 MPa) are larger than that for MJT, but the $t_{r} \mathrm{~s}$ for these three steels are comparable. Instead, the corresponding values of $V$ for Gr.IIIa listed in Table 7 seem to depict a better correlation among $V, \rho_{Z}$, and $t_{r}$. Indeed, the tendency of correlation between $V$ and $t_{r}$ may be true under lower stresses although the correlation between $V$ and $t_{r}$ 
under $130 \mathrm{MPa}$ is not so good for MJP and MJT. $t_{r} \approx 45486 \mathrm{~h}$ can be estimated for T91/MGC at $600{ }^{\circ} \mathrm{C}$ under $90 \mathrm{MPa}$ using the data under 70 and $100 \mathrm{MPa}$ shown in Table 7. This value is obviously shorter than the observed value, $t_{r}=78237 \mathrm{~h}$ for $\mathrm{pl}-91 / \mathrm{MgC}$ tested at the same conditions; $V$ for MGC is smaller than that for $\mathrm{MgC}$. Further, $t_{r}$ is short when the $V$ is small (Table 7), which suggests that the HRHD is expected to occur in the Gr.IIIa region when referring to the document in Section 3; in addition, HRHD easily occurs in Grade 91 steel compared to that in Grade 92 steel.

Table 8. Average temperature, time to rupture, $Q V C_{\max }$, and $M C R$ for each data group of P92/MJP, T92/MJT, and T91/MGC. The minimum creep time for detectable degradation as compared with an adjacent shorter time data group $(M T D)$ and start time for the Z-phase formation $(T Z F)$. Strains corresponding to each time are shown in $\%$ in each parenthesis

\begin{tabular}{|c|c|c|c|c|}
\hline \multirow{2}{*}{ Steel } & \multirow{2}{*}{ Items } & \multicolumn{3}{|c|}{ Time /h (strain, \%) } \\
\hline & & Gr.II & Gr.III & Gr.IIIa \\
\hline \multirow{6}{*}{ P92/MJP } & Av. Temp. $/{ }^{\circ} \mathrm{C}$ & 640 & 634 & 634 \\
\hline & Av. $t_{r} / \mathrm{h}$ & 2974 & 18618 & 62811 \\
\hline & $Q V C_{\max }$ & $1015(2)$ & $1857(1)$ & $4968\left(0.5^{* *}\right)$ \\
\hline & $M T D$ & - & $9453(2)$ & $27074(1)$ \\
\hline & $M C R$ & $2658(5)$ & $9453(2)$ & $27074(1)$ \\
\hline & $T Z F$ & 3500 & 3700 & 3700 \\
\hline \multirow{6}{*}{ T92/MJT } & Av. Temp. $/{ }^{\circ} \mathrm{C}$ & 637 & 613 & 622 \\
\hline & Av. $t_{r} / \mathrm{h}$ & 5136 & 25317 & 49878 \\
\hline & $Q V C_{\max }$ & $174(1)$ & $220\left(0.5^{* *}\right)$ & $4815\left(0.5^{* *}\right)$ \\
\hline & $M T D$ & - & $1990(1)$ & $27220(1)$ \\
\hline & $M C R$ & $4608(5)$ & $14733(2)$ & $27220(1)$ \\
\hline & $T Z F$ & 3600 & 4700 & 4300 \\
\hline \multirow{6}{*}{ T91/MGC } & Av. Temp. $/{ }^{\circ} \mathrm{C}$ & 610 & 580 & 583 \\
\hline & Av. $t_{r} / \mathrm{h}$ & 3709 & 24613 & 58699 \\
\hline & $Q V C_{\max }$ & $830(1)$ & $7288\left(1^{*}\right)$ & $1260\left(0.2^{* *}\right)$ \\
\hline & $M T D$ & - & $17420(2)$ & $12377\left(0.5^{* *}\right)$ \\
\hline & $M C R$ & $2197(2)$ & $17420(2)$ & $29527(1)$ \\
\hline & $T Z F$ & 6200 & 13500 & 13500 \\
\hline \multirow{6}{*}{$\mathrm{Pl}-91 / \mathrm{MgC}$} & Av. Temp. $/{ }^{\circ} \mathrm{C}$ & 550 & 544 & 581 \\
\hline & Av. $t_{r} / \mathrm{h}$ & 11208 & 32830 & 58415 \\
\hline & $Q V C_{\max }$ & $911(1)$ & $473\left(0.2^{* *}\right)$ & - \\
\hline & $M T D$ & - & $975(0.5)$ & - \\
\hline & $M C R$ & $4150(2)$ & $18942(2)$ & $10400\left(1^{* * *}\right)$ \\
\hline & $T Z F$ & 28000 & 37000 & 12433 \\
\hline
\end{tabular}

Bold-italics: shorter time than $T Z F$

* Strain for $V_{\max }$ is $0.5 \%$ and time to $0.5 \%$ strain is $1614 \mathrm{~h}$.

** No available data below the indicated strain.

*** Based on a single creep curve tested at $600{ }^{\circ} \mathrm{C}$ and $110 \mathrm{MPa}$

The variations in $Q V C$ during creep of P92/MJP, T92/MJT, T91/MGC, and pl-91/MgC were explained previously for each data group based on metallurgical observations. The degradation in strength for Grs.IIIa of 
P92/MJP and T91/MJT and Grs.IIIa and IIIb of each T91/MGC and pl-91/MgC is a critical issue. In these data groups, the formation of the Z-phase is common at $600{ }^{\circ} \mathrm{C}$, and therefore, we need to be able to construct a metallurgical model of microstructural variations for the degradation in strength through the creep behavior of these four steels. In addition, the formation of the Z-phase is confirmed for $G r s . I I$ and $I I I$ at $600{ }^{\circ} \mathrm{C}$. Therefore, the average temperature, average $t_{r}$, time to the $Q V C_{\max }, M T D, M C R$, and TZF for Grs.II, III, and IIIa of MJP, MJT, MGC, and MgC, respectively, are surveyed, and the results are listed in Table 8, where MTD denotes the minimum creep time for the detectable degradation at $600{ }^{\circ} \mathrm{C}$ when compared to an adjacent shorter time data group that was determined using both the average $t_{\varepsilon, r}-\sigma$ and $t-\varepsilon$ diagrams for each data group; further, $T Z F$ represents the start time for the Z-phase formation estimated from Sawada's work (Sawada et al., 2007). In Table 8, the corresponding creep strains to each time are listed in parentheses.

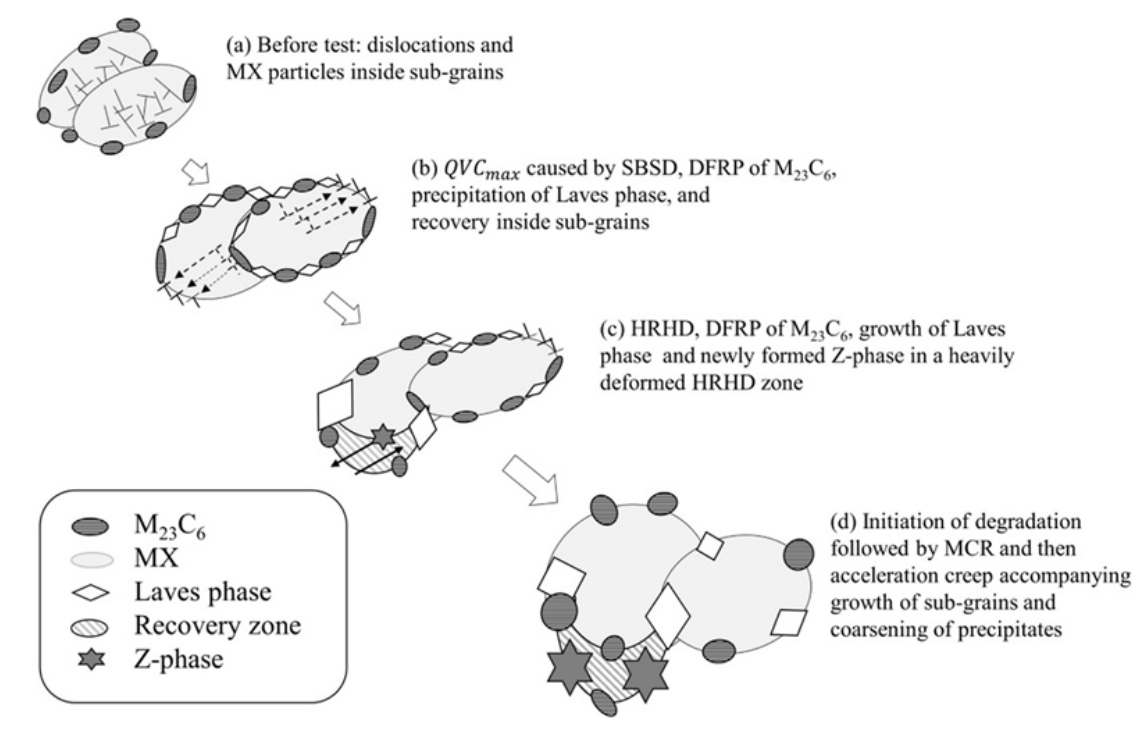

Figure 6. Schematic for microstructural degradation during creep for Gr.IIIa of high Cr martensitic steel with high strength

Based on the information obtained in Section 5.2 and Table 8 and the possible occurrence of HRHD deduced from Table 7, the microstructural degradation processes during creep in Gr.IIIa of high Cr martensitic steel with high strength is explained as follows: From the beginning of transient creep, SBSD and grain boundary strengthening by $\mathrm{M}_{23} \mathrm{C}_{6}$ and the Laves phase occur and the $Q V C$ reach the maximum value for each. When HRHD occasionally occurs near the weakest boundaries, the $Q V C$ subsequently start to decrease simultaneously. At that time, the $\mathrm{M}_{23} \mathrm{C}_{6}$ and Laves phase on or near boundaries are quickly coarsened; therefore, $Q$ decreases because the diffusion of atoms becomes active based on an increase in creep strain in an HRHD zone.

In addition, in a heavily deformed HRHD zone, some strengthening particles of MX need to be temporally dissolved into the matrix and transported towards the nearby boundaries by gliding dislocations. When the dislocations reach near the boundaries, more stable compounds of the Z-phase with tetragonal structure instead of MX with cubic structure are newly formed from the super-saturated matrix with the constituent elements of MX (i.e., $\mathrm{N}, \mathrm{Nb}$, and $\mathrm{V}$ ) along with an abundant supply of $\mathrm{Cr}$ from near the boundaries; alternatively, the excess $\mathrm{N}, \mathrm{Nb}$, and $\mathrm{V}$ atoms are used to coarsen the pre-existing Z-phase, and the $Q$ decreases further because of the recovery and coarsening of precipitates in the HRHD zones. As a result of these sequential reactions, the creep strength at a strain in transient creep of Gr.IIIa becomes lower compared to that of Gr.III. Even when $Q$ continues to decrease in this manner with increasing nominal strain, the transient creep holds if $\Delta\left[V_{s}\right]+\Delta C_{s}<$ $\Delta\left[Q_{S}\right](<0)$ is satisfied, as indicated in Tables 4 and 5. When $Q$ decreases further because of the increase in the formation of the Z-phase accompanying the consumption of some MX particles, and the decrease in $\left[Q_{s}\right]$ is equal to the decrease in $\left[V_{s}\right]+C_{s}$, and the creep rate reaches an $M C R$ point and then the accelerating creep starts. In accelerating creep, an increase in the sub-grain size, the coarsening of the Z-phase consuming some MX particles, and the coarsening of both the Laves phase and $\mathrm{M}_{23} \mathrm{C}_{6}$ are progressing, and eventually, $t_{r}$ is shortened 
in Gr.IIIa unexpectedly. These degradation processes are illustrated schematically in Figure 6. Two points are significant in the illustration: First, SBSD followed by HRHD processes indicate the essence of the transient creep of high $\mathrm{Cr}$ martensitic steel with high strength, and second, the degradation in strength starts to occur even in the transient creep region because the Z-phase starts to form dissolving some MX particles with the aid of straining within a heavily deformed HRHD zone. This model denotes that a chronological sequence for the events in Gr.IIIa is roughly expressed as

$$
\text { SBSD, DFRP of } \mathrm{M}_{23} \mathrm{C}_{6} \text {, Laves phase } \leq Q V C_{\text {max }} \leq \mathrm{HRHD} \leq T Z F \leq M T D \leq M C R<t_{r} .
$$

This model can clearly explain the mechanism for the degradation in strength. The value of time indicated in Table 8 for Gr.IIIa roughly satisfied Equation 8. However, there are still some questions about this model concerning the existence of the peaks of $Q V C$, and the formation of the Z-phase at a small nominal strain, which is not larger than an $M C R$ point as much as degrading the strength and existence of an HRHD zone.

\subsubsection{Existence of Peaks in QVC in Gr.IIIa}

The QVC do not clearly peak in Gr.IIIa for all steels investigated as shown in Table 8. This problem can be explained as follows: Figure 7 compares the relationships between $\varepsilon$ and $Q$ for Grs.III and IIIa (IIIb) of MJP, MJT, MGC, and MgC. As shown in Figure 7, the hardening process caused by SBSD, $\mathrm{M}_{23} \mathrm{C}_{6}$, and Laves phase is not confirmed for Gr.IIIa like a process (b) in Figure 6. However, we believe the existence of the hardening process at a very early stage of transient creep in Gr.IIIa. The first reason is that the value of $Q_{\max }$ for each Gr.IIIa is as large as those for not only Gr.III of all steels discussed here but also Gr.III of 9Cr-4W steel, where the hardening in transient creep is caused by dislocations, $\mathrm{M}_{23} \mathrm{C}_{6}$, and Laves phase as explained in Section 5 for $\mathrm{MgC}$ and in the previous work for the other steels (Tamura \& Abe, 2021a; 2021b). The second reason is that we can infer the existence of peaks in $Q$ for Gr.IIIa of all steels discussed by analogy: In the adjacent data group of Gr.III, we can easily believe the existence of a peak in $Q$ for MJT at a small strain below $0.5 \%$ like those for MJP and MGC because the creep behavior for all steels discussed is similar with each other as explained in Sections in 5.2. However, the peaks in QVC are lacking for MJT, and moreover, the degradation behavior during creep for Gr.IIIa of all steels discussed are similar to the behavior of Gr.III to some extent although the SBSD is weak in Gr.IIIa because of a higher recovery rate under low stresses. Further, other evidences for the real existence of the boundary hardening process in an early stage of transient creep for Gr.IIIa are presented below.

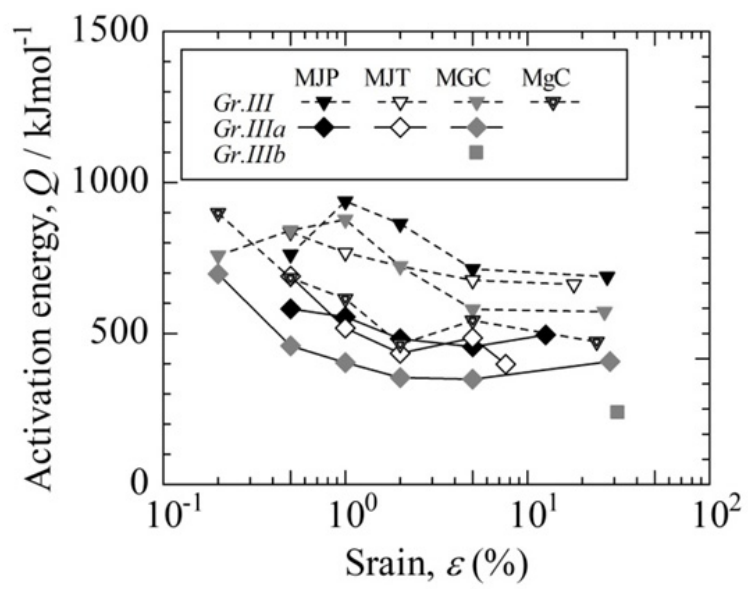

Figure 7. Comparison among the activation energy during creep for Grs.III, IIIa, and IIIb of MJP, MJT, MGC, and $\mathrm{MgC}$

As listed in Table 8, the $Q_{\max }$ for Gr.IIIa of MGC occurs at $\varepsilon=0.2 \%$ for $1260 \mathrm{~h}$ on average. However, it can be evaluated by analyzing the individual creep data of T91/MGC tested at $600{ }^{\circ} \mathrm{C}$ and $70 \mathrm{MPa}$ (Sawada et al., 2011), which is a member of Gr.IIIa in this study, that a creep strain of $0.2 \%$ at $600{ }^{\circ} \mathrm{C}$ and $70 \mathrm{MPa}$ for $Q_{\max }$ corresponds to a creep time of approximately $4000 \mathrm{~h}$ (Tamura \& Abe, 2021b). At this time, the dislocation density inside the sub-grains of a crept specimen at $600{ }^{\circ} \mathrm{C}$ and $70 \mathrm{MPa}$ tends to decrease, but the hardness does not change as compared with that before the test (Sawada et al., 2011). Thus, grain boundary hardening, i.e., 
SBSD, $\mathrm{M}_{23} \mathrm{C}_{6}$, and the Laves phase should occur because the Laves phase is very fine (approximately $100 \mathrm{~nm}$ at $600{ }^{\circ} \mathrm{C}$ for $1000 \mathrm{~h}$ ) near the condition where $Q$ shows the maximum for Gr.IIIa of MGC (Suzuki, Kumai, Kushima, Kimura, \& Abe, 2000). The above-mentioned combination of $\varepsilon=0.2 \%, 600{ }^{\circ} \mathrm{C}, 70 \mathrm{MPa}$, and $4000 \mathrm{~h}$ for MGC is estimated from the published data of a $t-\dot{\varepsilon}$ diagram. When we estimate the corresponding time using a $t-\varepsilon$ diagram, approximately $1000 \mathrm{~h}$ are obtained for $t_{0.2}$ instead referring to the data $t_{0.2}=261 \mathrm{~h}$ under $100 \mathrm{MPa}$ (Tamura \& Abe, 2021b). In this case, grain boundary hardening with the recovery of the inside sub-grains is inferred to be accomplished. Therefore, the estimated microstructure for the $t_{0.2}$ of a crept specimen of $\mathrm{MGC}$ at $600{ }^{\circ} \mathrm{C}$ under $70 \mathrm{MPa}$ possibly supports the existence of a peak in $Q$ at a very early stage of transient creep for Gr.IIIa of T91/MGC.

\subsubsection{Formation of HRHD zone}

A concept of HRHD was proposed by investigating the creep behavior of $9 \mathrm{Cr}-4 \mathrm{~W}$ steel in the previous work (Tamura \& Abe, 2021a), and it was evoked from the following two points of views: the three parameters of QVC decrease after $Q V C_{\max }$ simultaneously in a later section of transient creep as confirmed in Figure 3 for pl-91/MgC and in the previous work (Tamura \& Abe, 2021b), which imagines that recovery should occur within a small nominal strain range after remarkable strain hardening by SBSD, DFRP of $\mathrm{M}_{23} \mathrm{C}_{6}$, and precipitation of fine Laves phase at the beginning of creep. The second one is that the QVC for welded joints are small compared to those of the base metal, as explained in the previous work (Tamura \& Abe, 2021a). Hence, we explained the creep phenomena of the martensitic steel on the assumption that HRHD occurs by analogy when $V$ decreases. We can easily assume the strain concentration in this area if we assume the existence of a locally recovered zone; therefore, we can determine that the formation of Z-phase is promoted in an HRHD zone based on the experimental results that creep strain promotes the formation of the Z-phase (Sawada et al., 2006; 2011). Therefore, the accelerating formation of the Z-phase in an HRHD zone is believed even within a small nominal strain not larger than a strain at an MCR point. The formation of the Z-phase near an HRHD zone progresses with the dissolution or disappearance of a strengthening factor of MX, and this results in the degradation in strength for Grs.IIIa even in a small strain of 1\% as shown in Figure 5. Further, there is no contradiction in the above explanation of the creep phenomena of martensitic steel, and therefore, we believe the existence of HRHD. We confirmed that $V$ decreases for the welded joint as shown in the literature (Tamura \& Abe, 2021a), and therefore, small values of $V$ observed in the transient creep of martensitic steel evoke the occurrence of local or heterogeneous deformation like a welded joint and the decrease in rupture strength. Sawada, Bauer, Kauffmann, Mayr, and Klenk (2010) reported that the $\rho_{Z}$ 's in the HAZ of the ruptured specimens at $600{ }^{\circ} \mathrm{C}$ of the welded joints of Grade E911 are approximately one order of magnitude larger than those for the base metal, and this depends on $t_{r}$ and the location of sampling in HAZ. The $\rho_{Z}$ of base metal is approximately $1.7 \mathrm{E} 10 \mathrm{~m}^{-2}$, and it is similar to that of T92/MJT (Sawada et al., 2006). The increase in $\rho_{Z}$ for the welded joints compared with the base metal were explained because of the effects of the increased precipitation site for the Z-phase and the multiaxial stress in HAZ. They showed rupture data only at $600{ }^{\circ} \mathrm{C}$, and therefore, although the values for $Q$ and $C$ cannot be calculated, the value of $V$ calculated from their data using Equation 6 are $298 \mathrm{~cm}^{3} \mathrm{~mol}^{-1}$ for up to $10000 \mathrm{~h}$ and $73 \mathrm{~cm}^{3} \mathrm{~mol}^{-1}$ for $10000-35000 \mathrm{~h}$, respectively. These values of $V$ are extremely low compared to the $V \mathrm{~s} \sim 500-800 \mathrm{~cm}^{3} \mathrm{~mol}^{-1}$ for Grade 92 steel and the $t_{r}$ 's are considerably shorter than those for T92/MGC (Tamura \& Abe, 2021b). These data indicate that the local deformation of the welded joint causes a decrease in $V$, an increase in $\rho_{Z}$, and thus, a decrease in $t_{r}$; further, these data also satisfy a sufficient condition for the existence of HRHD during the creep of high $\mathrm{Cr}$ martensitic steel.

Via experiments, a locally recovered zone is observed in the ruptured specimens of T91/MGC (Kushima et al., 1999) and T92/MJT (Sawada \& Kimura, 2019b) tested under each condition of Gr.IIIa and in the crept specimens for an accelerating creep of MGC including a strain near an $M C R$ point tested under a condition of Gr.IIIa (Kimura et al., 2002). However, any locally recovered zone is yet to be reported in the grip portions of specimens tested under various conditions. Therefore, a locally recovered zone, i.e., an HRHD zone, is certainly formed by creep straining and not by thermal aging; however, a locally recovered area in the crept specimen to a small strain in transient creep is yet to be confirmed. As shown in Figure A2 and reported in the previous work (Tamura \& Abe, 2021a; 2021b), the degradation in strength for the conditions of Gr.IIIa is confirmed during transient creep. Therefore, an HRHD zone must be surely formed with a small strain in transient creep. However, not only the size, shape, and distribution, but also the degree of straining of a locally recovered zone, i.e., the characteristics of an HRHD zone, are yet to be investigated systematically. These factors can influence the formability of the Z-phase near HRHD zones, and therefore, the degradation in strength. When such information on an HRHD zone is clarified, variations in the degradation in strength for Gr.IIIa as shown in Figures 4 and 5 can be explained more deeply, and they should thus be controlled. Morooka, Tomoda, Adachi, Morito, and 
Kamiyama (2008) observed heterogeneous deformation inside a sub-block of a martensitic structure by employing both an electron back-scattered diffraction method and a neutron diffraction method; therefore, the characterization of an HRHD zone during creep shall be clarified more deeply in the future.

\subsubsection{Formation of Z-Phase under Low Stresses}

Danielsen (2007) and Danielson and Hald (2009) proposed a new model for the formation of Z-phase particles by $\mathrm{Cr}$ diffusion onto an MX particle from the high $\mathrm{Cr}$ martensite matrix. Cipolla et al. (2010) supported the Danielsen's model and provided experimental evidence using a model alloy of carbon-free Fe-12Cr-1.3Ni-NbVN alloy aged at $600-700{ }^{\circ} \mathrm{C}$ for a maximum of $10000 \mathrm{~h}$. However, simple calculations on T91/MGC indicate that the diffusion distance of $\mathrm{Cr}$ in alpha-iron at $600{ }^{\circ} \mathrm{C}$ is more than one order of magnitude larger as compared with the estimated inter-particle distance of MX: Sawada et al. (2011) reported that the number density of MX $\left(\rho_{M X}\right)$ of as received T91/MGC is approximately $8 \mathrm{E} 12 \mathrm{~m}^{-2}$, and therefore, the inter-particle distance of MX is estimated to be $\sqrt{1 / \rho_{M X}}=0.35 \mu \mathrm{m}$. The diffusion distance of $\mathrm{Cr}$ in the alpha-iron is $4.1 \mathrm{\mu} \mathrm{m}$ at $600{ }^{\circ} \mathrm{C}$ for $1000 \mathrm{~h}$. Here, the calculation of the diffusion distance for $\mathrm{Cr}$ atom, i.e., $2 \sqrt{D t}$, is performed assuming $D_{0}=0.00023 \mathrm{~m}^{2} \mathrm{~s}^{-1}, Q=238.8 \mathrm{kJmol}^{-1}$ (Oikawa, 1982), $t=1000 * 3600 \mathrm{~s}$, and $T=873 \mathrm{~K}$ in $D=D_{0} \exp (-Q / R T)$. Therefore, the diffusion distance of $\mathrm{Cr}$ is considerably larger than the inter-particle distance of MX during the creep of T91/MGC even for the conditions of $600{ }^{\circ} \mathrm{C}$ for $1000 \mathrm{~h}$. The inter-particle distance of MX increases by not only increasing creep time and temperature, but also the amount of Z-phase formed; however, the diffusion distance of $\mathrm{Cr}$ in alpha-iron increases with increasing time and temperature. The inter-particle distance of $\mathrm{MX}$ in a ruptured specimen of $\mathrm{T} 91 / \mathrm{MGC}$ at $600{ }^{\circ} \mathrm{C}$ and $70 \mathrm{MPa}$ $\left(t_{r}=80737 \mathrm{~h}\right)$ is estimated as $\sqrt{1 / \rho_{M X}}=1.41 \mu \mathrm{m}$ (Sawada et al., 2011), and the corresponding diffusion distance becomes $37.1 \mu \mathrm{m}$. Except below $10 \mathrm{~h}$ at $600{ }^{\circ} \mathrm{C}$, the diffusion distance of $\mathrm{Cr}$ in alpha-iron is always larger than the inter-particle distance of MX at $600{ }^{\circ} \mathrm{C}$. Therefore, according to Danielsen's model (2007), fine particles similar in composition to the Z-phase, $(\mathrm{Cr}, \mathrm{Nb}, \mathrm{V}) \mathrm{X}$, must be easily formed within a very short time duration, e.g., several tens of hours, because the Z-phase is thermodynamically more stable than MX (Kocer et al., 2009). However, such particles are not observed until at least $\sim 10000 \mathrm{~h}$ at $600{ }^{\circ} \mathrm{C}$ (Sawada et al., 2007). These facts suggest that the interfacial energy of a Z-phase particle with a tetragonal structure in the martensitic steel matrix, which is usually observed on or near the boundaries in high $\mathrm{Cr}$ martensitic steel with high strength, is considered to be substantially larger than that of the MX phase with cubic structure based on the classical nucleation and growth theory of precipitation (Turnbull \& Fisher; 1949). Therefore, numerous $\mathrm{Nb}$ and $\mathrm{V}$ atoms are expected to be transported to the large-angle boundaries with the help of moving dislocations such as PAGBs and to pre-existing Z-phases where the tetragonal structure is formed. An alternative interpretation is also possible: Even if the fine particles of $(\mathrm{Cr}, \mathrm{Nb}, \mathrm{V}) \mathrm{X}$ can be formed within a short time duration based on Danielsen's model, provided that their structure is cubic and their interfacial energy is low, these structures are unstable because of interactions with the dislocations (Tamura, Iida, Kusuyama, Shinozuka, \& Esaka, 2004). Thus, the number density of the $(\mathrm{Cr}, \mathrm{Nb}, \mathrm{V}) \mathrm{X}$ particles remains extremely low even if the $(\mathrm{Cr}, \mathrm{Nb}, \mathrm{V}) \mathrm{X}$ particles can be formed. In addition, when the size is below $20 \mathrm{~nm}$, these fine particles are not detected by the elemental mapping method as Z-phase particles, which is a method adopted by Sawada et al. (2007) to determine the TTP diagram of the Z-phase. Sawada, Kubo, and Abe (2003) demonstrated that when TEM was used, the number density of MX particles $<20 \mathrm{~nm}$ decreases to a very low level after aging for $727 \mathrm{~h}$ at $700{ }^{\circ} \mathrm{C}$ when compared with that of the as-received specimen. Therefore, even if $(\mathrm{Cr}, \mathrm{Nb}, \mathrm{V}) \mathrm{X}$ particles could be formed, the particles would grow rapidly. Although Danielsen's model is simple and straightforward, it is not easily accomplished in high-strength 9Cr martensitic steel with high strength.

Sawada et al. (2011) demonstrated that the number density of MX particles in T91/MGC decreases during creep at $600{ }^{\circ} \mathrm{C}$ and reaches $<10 \%$ of the initial value at rupture $\left(t_{r}=80737 \mathrm{~h}\right)$. Furthermore, the massive Z-phase is formed near the boundaries by consuming nearby MX particles. The $\rho_{Z}$ increases with an increase in the strain up to a comparable value to that of the MX at rupture. This is clear evidence that the formation of the Z-phase is the main reason for the degradation in the long-term creep strength. We can obtain the relationship between $\rho_{Z}$ and $\varepsilon$ by combining these data with the $\rho_{Z}$ values for the grip portions (Sawada et al., 2014b) and utilizing the relevant creep curves (Sawada et al., 2011). The results are shown in Figure 8, which indicate that $\rho_{Z}$ increases steeply with an increase in strain for $\varepsilon \leq 0.5 \%$. The $\rho_{Z}$ in the gauge portion is definitely larger than that in the grip portion, even though the differences are not so large. The $\rho_{Z}$ in a gauge portion increases gradually with an increase in the logarithm of the creep strain for $\varepsilon \geq 1 \%$, and it is approximately three times larger than that of the grip portion. In other words, the majority of the Z-phase was not formed thermally, but it formed readily with the aid of the creep strain. The observed creep range, $t \geq 10000 \mathrm{~h}$ and $\varepsilon \geq 0.26 \%$, corresponds to accelerating creep because $M C R$ is estimated to occur at $6585 \mathrm{~h}$ and $\varepsilon=0.23 \%$ from the creep curves reported in the 
literature (Sawada et al., 2011). The rate of increase in $\rho_{Z}$ decreases during accelerating creep (when $\varepsilon \geq 1 \%$ ), which may be attributed to the coarsening of the Z-phase. There are no data confirming the Z-phase formation in transient creep of MGC at $600{ }^{\circ} \mathrm{C}$ under $70 \mathrm{MPa}$. Instead, the Z-phase formation is estimated to start approximately near the $M C R$ point, i.e., $6585 \mathrm{~h}$. This estimation does not contradict the observation that the Z-phase starts to form in ruptured specimens between $t_{r}=3415(140 \mathrm{MPa})$ and $t_{r}=12859 \mathrm{~h}(120 \mathrm{MPa})$ (NIMS, 2007; Sawada et al., 2007). Therefore, Equation 8 must be interpreted as $S B S D \leq Q_{\max } \leq H R H D \leq$ $T Z F \approx M C R<t_{r}$ for MGC at $600{ }^{\circ} \mathrm{C}$ under $70 \mathrm{MPa}$, although the existence of both $Q_{\max }$ and HRHD are not yet experimentally confirmed. Under stresses considerably lower than $70 \mathrm{MPa}$ of $\mathrm{T} 91 / \mathrm{MGC}, t_{0.2}$ becomes longer than $10000 \mathrm{~h}$ (Tamura \& Abe, 2021b). Thus, the Z-phase is formed within the time $t_{0.2}$ even though we cannot confirm whether $t_{0.2}$ belongs to the transient creep. The occurrence of HRHD is expected to promote the formation of the Z-phase. However, because the sub-grains grow at the same time, the HRHD effect, i.e., the effect of strain concentration on the formability of the Z-phase, will be mitigated.

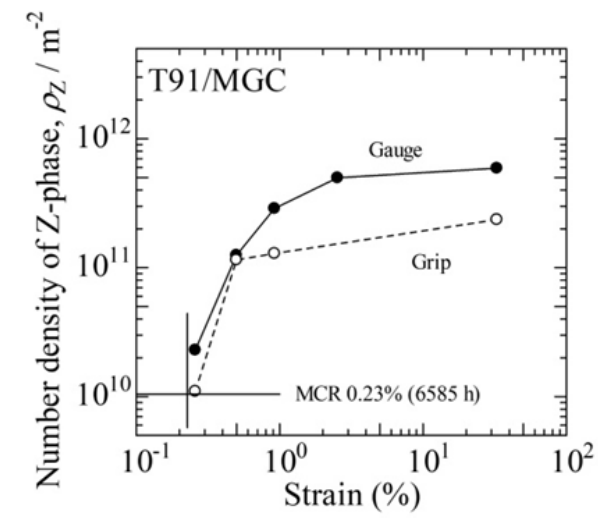

Figure 8. Number density of Z-phase as a function of creep strain for the gauge and grip portions of T91/MGC tested at $600{ }^{\circ} \mathrm{C}$ and $70 \mathrm{MPa}$

We are yet to observe any definite evidence for the formation of the Z-phase in the transient creep after the peak of QVC for Gr.IIIa of MGC along with Grs.III and IIIa of Grade 91 and 92 steels. However, if we assume the existence of an HRHD zone, it can be reasonably believed that the concentrated strain generated in an HRHD zone increases the transportation velocity and volume of solute atoms, which promotes the dissolution of MX and the local formation of the Z-phase. The average creep behaviors for Grs.III and IIIa of MJP, MJT, MGC, and $\mathrm{MgC}$ under this scenario are summarized in Table 8 .

Even though we reasonably deduce the existence of the local Z-phase formation in an HRHD zone during transient creep, the distribution of the Z-phase may not necessarily be heterogeneous. This does not imply that the observed values of the $\rho_{Z}$ shown in Figure 8 are inaccurate. Our deduction does not contradict the experimental results provided by Sawada (2007), and thus, the formation of the Z-phase in transient creep is possible. The size of an HRHD zone formed in the transient creep may be smaller than the size of the primary austenite grains from the following microstructural viewpoints: The inter particle distance of the Z-phase is estimated from Figure 8 to be $2-3 \mu \mathrm{m}(0.5-1 \%$ strain, $30000-50000 \mathrm{~h})$, which corresponds to the scenario wherein several particles $\sim 100 \mathrm{~nm}$ in diameter of the Z-phase (Suzuki et al., 2003) are on the PAGBs for each primary austenite grain $\sim 10 \mu \mathrm{m}$ in diameter (NIMS, 2014). Such scenarios are frequently confirmed in high-Cr martensitic steel (Sawada et al., 2007). Moreover, the size of an HRZ observed near PAGBs (Kushima et al., 1999; Sawada \& Kimura, 2019b; Kimura et al., 2002) is extremely small (several micrometers at most).

6.2.6 Dislocation-Assisted Acceleration of Precipitation Phenomena

Sawada et al. $(2006 ; 2014 \mathrm{~b})$ reported that the $\rho_{Z}$ in the gauge portion at the rupture of T91/MGC is larger than that in a grip. Moreover, the $\rho_{Z}$ in the gauge portion of T91/MGC is higher than that of T92/MJT with a shorter $E L$. This accelerated formation of the Z-phase in T91/MGC is attributed to a creep strain (Sawada et al., 2006; 2014b). However, Table 7 suggests that an increase in $\rho_{Z}$ in the ruptured specimen is not satisfactorily explained only by a value of $E L$. Further, the role of creep strain in the reactions involved in the formation of the Z-phase are yet to be successfully elucidated.

Z-phase particles are massive and are formed on or near boundaries in high-Cr martensitic steel with high 
strength (Suzuki et al., 2000; Kimura et al., 2002; Sawada et al., 2006; 2007; Sawada, Suzuki, Kushima, Tabuchi, \& Kimura, 2008). It is well known that boundary precipitates grow faster than those inside grains (Brailsford \& Aaron, 1969). The coarsening of Z-phase particles on the boundaries is similarly understood based on the model that boundary diffusion is faster than lattice diffusion (Shewmon, 1963). Models for the coarsening of grain boundary precipitates are constructed by combining lattice diffusion and boundary diffusion (Hori \& Saji, 1981; Hassan \& Corney, 2017). Solute atoms are transported onto boundaries by lattice diffusion, and then, they migrate to targeting precipitates by grain boundary diffusion. Numerous dislocations inside the sub-grains in martensitic steel and the consequent pipe diffusion through these dislocations (Shewmon, 1963) may assist in the transportation of solute atoms. Within a short duration, a solute-depleted zone of slower atoms or a precipitation free zone is formed near boundaries. However, this is not the case for creep.

The size of the boundary precipitates in a gauge portion becomes larger than those for a grip during long-term creep; for example, the sizes of the $\mathrm{M}_{23} \mathrm{C}_{6}$ carbides in a gauge portion in the crept specimens of Grade P92 are larger than those for a grip (Ennis, Zielinska-Lipiec, \& Czyrska-Filemonowicz, 2000; Ennis \& Czyrska-Filemonowicz, 2003). The sizes of the Laves phase in a gauge portion in ruptured specimens are larger than those for a grip in ruptured specimens of a low-carbon $9 \mathrm{Cr}-3 \mathrm{Co}-2 \mathrm{~W}-0.4 \mathrm{MoVNbMB}$ steel (Fedorova, Kipelova, Belyakov, \& Kaibyshev, 2013). In these phenomena, creep deformation changes the shape of the boundaries and consequently promotes boundary diffusion, which can cause larger precipitates on boundaries in a gauge portion. If creep strain can assist in the transportation of solute atoms in addition to lattice diffusion, the coarsening of boundary precipitates is also prompted. According to the abovementioned model, the total amount of precipitates on the boundaries should be controlled by the total amount of constituent elements transported from inside the grains because the diffusion velocity inside grains is slower than that along the boundaries at average temperatures at which creep tests are conducted. In a gauge portion, excess dislocations inside sub-grains are fewer than those in a grip because of the recovery, and therefore, the increase in the amount of mass transportation caused by pipe diffusion in a gauge portion do not exceed than those in a grip. Therefore, the total amount of precipitates in a gauge portion should not exceed that in a grip even though sizes of the precipitates are promoted because of creep deformation in a gauge portion.

Murata et al. (2009) showed that the volume fractions of $\mathrm{M}_{23} \mathrm{C}_{6}$ in a grip portion of creep ruptured specimens crept at $650{ }^{\circ} \mathrm{C}$ for $8000-40000 \mathrm{~h}$ of $9.5 \mathrm{Cr}-3.6 \mathrm{~W}-3 \mathrm{CoVNbBN}$ and $10.5 \mathrm{Cr}-3.6 \mathrm{~W}-3 \mathrm{CoVNbBN}$ steels are similar to that before test; further, these values are comparable only to the calculated values using a thermodynamic calculation software. This indicates that the total amount of $\mathrm{M}_{23} \mathrm{C}_{6}$ in a gauge portion is not promoted by creep deformation when the precipitation is completed thermodynamically before the creep test. In this case, only the redistribution or refining on the sub-boundaries, i.e., DFRP, and the coarsening on large angle boundaries occur. The precipitation of MX is approximately completed before test and the coarsening on large angle boundaries occurs. Further, the redistribution of MX inside sub-grains occurs with the aid of moving dislocations. In the case of the Laves phase, the precipitation of the Laves phase is approximately completed for up to $10000 \mathrm{~h}$ at $600{ }^{\circ} \mathrm{C}$ (Suzuki et al., 2003 for T91; Haetterstrand \& Andren, 2001 for Grade 92 steel). Therefore, for $t>10000 \mathrm{~h}$, only the coarsening on the boundaries occurs with the aid of creep deformation. However, for $t<10000 \mathrm{~h}$, not only hardening caused by the Laves phase but also the enhancement of precipitation and growth or coarsening of the Laves phase in high Cr martensitic steel are observed (Cui, Kim, Kang, \& Miyahara,2001). These authors investigated the precipitation behavior of the Laves phase in Fe-10Cr-6W-(3Co) alloys and demonstrated that the number densities of the Laves phase in the alloys with the stress of $80 \mathrm{MPa}$ at $600{ }^{\circ} \mathrm{C}$ for $200 \mathrm{~h}$ are larger than those aged under the same temperature and duration, respectively; in addition, the TEM images show that the size for the crept specimen is larger than that for the aged one. These results on the number density and TEM observation suggest us that the total amount and size of the Laves phase in the crept specimen are considered larger than those for the aged one when the precipitation is not completed yet.

For the Z-phase, Sawada et al. $(2006 ; 2014 \mathrm{~b})$ reported that $\rho_{Z} \mathrm{~s}$ in the gauge portion at the rupture of T91/MGC at $600{ }^{\circ} \mathrm{C}\left(t_{r}=34141\right.$ and $\left.80737 \mathrm{~h}\right)$ are larger than those in a grip, and $\rho_{Z}$ is correlated with the total amount of the Z-phase formed by referring to the data on $\rho_{M X}$ and neglecting the changes in the size of MX. Murata et al. (2009) reported that the volume fractions of the Z-phase in the gauge portions of the above mentioned $9.5 \mathrm{Cr}$ and $10.5 \mathrm{Cr}$ steels are largely increased as compared to those for grips at $650{ }^{\circ} \mathrm{C}$, respectively. The results on T91 indicate that the amount of the Z-phase in a gauge portion is larger than that for a grip even under long-term tests. Therefore, in addition to the lattice diffusion inside grains, other transport systems toward boundaries other than pipe diffusion for the constituent elements of the Z-phase should operate during creep. Further, there are still many excess dislocations in the sub-grains of martensitic steel with high strength, not only in the gauge portion but also in the grip portion after long-term testing (Panait et al., 2010b; Fedoseeva, Dudova, \& Kaibyshev, 2016). 
Therefore, the existence of excess dislocations or the role of pipe diffusion is not essential for explaining the accelerated formation and coarsening of Z-phase particles in the gauge portion of high-strength martensitic steels. Instead, straining itself or the role of moving dislocations during creep must be considered when explaining the observable accelerating formation of the Z-phase in the gauge portion of high-strength martensitic steel.

Figure 9 illustrates feasible mechanisms to accelerate the boundary precipitation including the Z-phase. Lundin, Norell, Andren, and Nyborg (1997) provided the evidence for latent creep resistance proposed by Glen (1958), which is a type of dynamic strain aging. They observed clusters of $\mathrm{Cr}, \mathrm{V}$, and $\mathrm{N}$ along a dislocation using an atom-probe field ion microscope in a creep-interrupted specimen of $11 \mathrm{Cr}-1 \mathrm{Mo}-1 \mathrm{~W}-\mathrm{VNbN}$ steel. The concept of latent creep resistance is supported by Kubon, Foldyna, and Vodarek (1998), Kubon, Foldyna, Hajduk, and Simecek (2000), and Azuma, Miki, Tanaka, and Ishiguro (2002) as one of the strengthening mechanisms for high-strength martensitic steel. The rapid transportation of these segregated solute atoms along a dislocation to the grain boundaries by pipe diffusion is a potential mechanism to increase the total amount of solute atoms to be transported because the dislocations near the boundaries are possibly connected to boundaries and many dislocations stagnate near boundaries of the $\mathrm{Cr}-\mathrm{W}$ steel when compared with those of plain $\mathrm{Cr}$ steel (Abe et al., 1992).

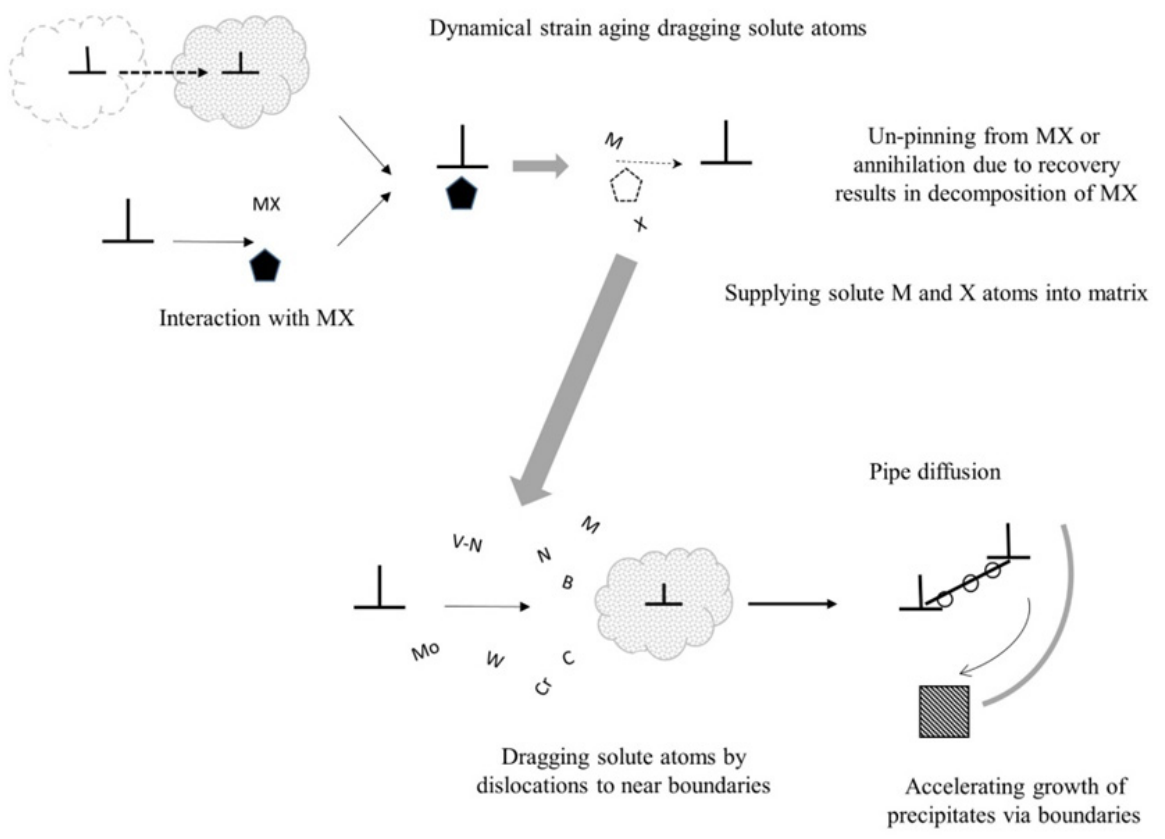

Figure 9. Schematic illustration for accelerating formation and coarsening of boundary precipitates in high $\mathrm{Cr}$ martensitic steel with high strength

Cui et al. (2001) suggested that the observed enhanced precipitation and growth of the Laves phase are caused by the dragging effect of moving dislocations for $\mathrm{W}$ atoms. Hayakawa, Terada, Yoshida, Nakashima, and Goto (2003a; 2003b) and Hayakawa, et al. (2007a; 2007b) showed that applying the rapid stress change tests on several Cr-Mo steels cause dislocations to move while dragging solute atoms Mo during creep; the dragging solute atoms is the rate-controlling process for the creep of Cr-Mo steels. Further, they suggested that the effective stress to the drag of solute atoms is estimated to be, at most, $10 \%$ of the applied stress, whereas the remaining is the back stress for the moving dislocations. The magnitude of the equivalent back stress can be estimated in this study; however, the estimated back stress using the exponential law is significantly greater than the applied stress. There could be a clear gap between the above two lines of approach. However, there is no discrepancy, as discussed in the previous work (Tamura \& Abe, 2021b), and therefore, I do not deny but instead support the drag mechanism proposed by Cui et al. (2001) and Hayakawa et al. (2003a; 2003b; 2007a; 2007b). The solute atoms of Mo dragged by the dislocations arrive near grain boundaries along with the dislocations during creep. When the dislocations are annihilated because of recovery, Mo atoms are segregated on the boundaries, which promotes the formation, growth, or coarsening of the Laves phase. The solute atoms of $\mathrm{W}, \mathrm{Cr}$, 
$\mathrm{V}, \mathrm{Nb}, \mathrm{C}, \mathrm{N}$, and $\mathrm{B}$ can also interact with the dislocations. Hence, these solute atoms including Mo are potentially swept out to the grain boundaries during creep. Consequently, the formation, growth, coarsening, re-precipitation, or all of them of the $\mathrm{Cr}_{23} \mathrm{C}_{6}, \mathrm{MX}$, Laves phase, and Z-phase are promoted on boundaries based on the drag mechanism by moving dislocations when the precipitation is not completed.

There is plenty of Mo, $\mathrm{W}$, and $\mathrm{Cr}$ atoms that can form the Laves phase in the matrix among the above-mentioned solute atoms; therefore, these atoms are scarcely exhausted in the accelerated segregation reactions on the boundaries. However, $\mathrm{Nb}$ and $\mathrm{V}$ are the constituent elements of the Z-phase and the solubility limits for each are thought to be considerably small in high-Cr high-strength martensitic steels. Moreover, the total amount of $\mathrm{Nb}$ and $\mathrm{V}$ is not so large; thus, these elements are easily exhausted in the matrix. Therefore, a special mechanism other than pipe diffusion, lattice diffusion, and simple dragging of solute atoms by moving dislocations is required to continue the accelerating formation of the Z-phase with increasing creep strain.

Tamura et al. (2004) observed that, in low-carbon $7 \mathrm{Cr}-0.4 \mathrm{~V}-0.09 \mathrm{~N}$ martensitic steel, the soluble $\mathrm{V}$ in the matrix discontinuously increases and then decreases over a short time during tempering at $740-800{ }^{\circ} \mathrm{C}$ for up to $100 \mathrm{~h}$, even though the precipitation of $\mathrm{VN}$ is approximately complete after $20 \mathrm{~h}$ at least. A similar phenomena occurs for $\mathrm{NbC}$ in a $9 \mathrm{Cr}-1 \mathrm{Mo}-0.18 \mathrm{~V}-0.085 \mathrm{Nb}$ system. Tamura, Nakamura, Shinozuka, and Esaka (2008) showed that, in a low-carbon $7 \mathrm{Cr}-0.1 \mathrm{~V}-0.06 \mathrm{Nb}-0.077 \mathrm{~N}$ system, the amount of MX decreases gradually at the macroscopic scale during tempering at $750{ }^{\circ} \mathrm{C}$, whereas that of $\mathrm{Cr}_{2} \mathrm{~N}$ increases and the $\mathrm{V}$ and $\mathrm{Nb}$ contents in $\mathrm{MX}$ increase, and the $\mathrm{Cr}$ content does not. During the tempering of this steel up to $1000 \mathrm{~h}$, discontinuous changes in the chemical compositions of MX are clearly observed at least three times by accompanying the discontinuous changes in the amount and size. Here, the chemical composition of MX with the highest $\mathrm{Cr}$ content, i.e., $50 \mathrm{Cr}-35 \mathrm{~V}-15 \mathrm{Nb}$ in at $\%$, corresponds to that of the Z-phase (Suzuki et al., 2003; Sawada et al., 2006 and 2007). However, the MX particles with high $\mathrm{Cr}$ content have a cubic structure rather than a tetragonal structure of the Z-phase. Therefore, (Cr,M)X particles with high $\mathrm{Cr}$ content are not the Z-phase. Cipolla et al. (2010) demonstrated that the transient compound with the hybrid structure composed of the cubic MX and the tetragonal Z-phase are formed in a $12 \%$ $\mathrm{Cr}$ model steel during aging at $650{ }^{\circ} \mathrm{C}$ for up to $1000 \mathrm{~h}$. However, such a compound is not found during the tempering of the low-carbon $7 \mathrm{Cr}-0.1 \mathrm{~V}-0.06 \mathrm{Nb}-0.077 \mathrm{~N}$ steel. If particles with $50 \mathrm{Cr}-35 \mathrm{~V}-15 \mathrm{Nb}$ were the Z-phase with the tetragonal structure, the $\mathrm{Cr}$ content of the particles with 50 at $\% \mathrm{Cr}$ would never decrease because the Z-phase with the tetragonal structure is the thermodynamically stable phase (Kocer et al., 2009).

Discontinuous changes in the precipitation reactions mentioned above are interpreted by combining the information on hardness and the analytical results of XRD. The MX particles formed on the sub-boundaries remain in the original positions for a while when the sub-grains are newly formed or grown during tempering. Isolated MX particles become energetically unstable and dissolve into the matrix, and then, they re-precipitate on nearby stable sites such as dislocations and newly formed sub-boundaries. Similar processes are feasible to operate for MX particles precipitated on dislocations in a stress-free specimen because internal stresses always act on the dislocations, even in tempering. In this case, the change induced for each event may be too small to detect. However, there are numerous dislocations in martensitic steel to be annealed out, and in some cases, the numerous dislocations are annealed out dramatically when several sub-grains were simultaneously and newly born, which enables the changes to appear or to be detected as though they occur discontinuously against time. Similar DFRP of MX particles should occur, even for an extended period of creep time for the martensitic steel containing $\mathrm{V}$ and $\mathrm{Nb}$ because the applied stress, in addition to the internal stress, always act on the moving dislocations during creep. In such cases, where moving dislocations interact with MX particles, the soluble V, $\mathrm{Nb}$, and $\mathrm{N}$ contents in the matrix can maintain a higher level for each, compared to those calculated using a thermodynamic calculation software (Tamura et al., 2004). High levels of 0.15 and $0.02 \%$ for $\mathrm{V}$ and $\mathrm{Nb}$, respectively, are certainly confirmed after tempering a $7 \mathrm{Cr}-0.4 \mathrm{~V}-0.09 \mathrm{~N}$ system at $740{ }^{\circ} \mathrm{C}$ for $90 \mathrm{~h}$ and a $9 \mathrm{Cr}-1 \mathrm{Mo}-0.18 \mathrm{~V}-0.085 \mathrm{Nb}$ system at $740^{\circ} \mathrm{C}$ for $4 \mathrm{~h}$, respectively (Tamura et al., 2004; 2008).

Tamura et al. (2011) also found a new and unbelievable phenomenon that some finely dispersed particles of a stable phase of $\mathrm{Ti}_{2} \mathrm{Y}_{2} \mathrm{O}_{7}$ are temporally decomposed into the matrix. Consequently, $\mathrm{TiO}_{2}$ and $\mathrm{Y}_{2} \mathrm{O}_{3}$ are formed when mechanically alloyed $\mathrm{Cr}-\mathrm{W}$ steel with $\mathrm{Ti}_{2} \mathrm{Y}_{2} \mathrm{O}_{7}$ is austenitized and then air cooled. In these processes, $\mathrm{Ti}_{2} \mathrm{Y}_{2} \mathrm{O}_{7}$ should never thermally be decomposed; however, they can be decomposed with the aid of dislocations introduced through the $\gamma$ to a transformation of the matrix. Again, fine particles of $\mathrm{Ti}_{2} \mathrm{Y}_{2} \mathrm{O}_{7}$ are reproduced after further tempering because the introduced dislocations are annealed out during tempering. These sequential reactions indicate that the existence of dislocations allows solute atoms in a supersaturated state to segregate on the dislocations.

Therefore, it is natural to consider that high levels of soluble $\mathrm{Nb}$ and $\mathrm{V}$ are maintained continuously during creep because many moving dislocations are always supplied in a gauge portion during creep, especially within an 
HRHD zone; therefore, a sufficient amount of $\mathrm{Nb}$ and $\mathrm{V}$ can be always supplied on the boundaries to form Z-phase during creep. Thus, it can be said that, when HRHD occurs during the creep of high $\mathrm{Cr}$ martensitic steel containing $\mathrm{V}$ and $\mathrm{Nb}$, many moving dislocations in an HRHD zone assist in transporting the solute atoms to the boundaries quickly through several processes mentioned above, which leads to enhanced formation and the subsequent occurrence of the coarsening of precipitates for the Z-phase in a gauge portion.

\subsection{Roles of Precipitates}

\subsubsection{Laves Phase}

The formation of the Z-phase is undoubtedly responsible for the degradation in the strength in Gr.IIIa; further, it is distinctly observed that the number density of the Z-phase increases with an increase in the creep strain because of the consumption of MX particles (Sawada et al., 2011). The trend in Table 7 indicates that the larger the $E L$, the larger is the degradation in strength for Gr.IIIa at $600{ }^{\circ} \mathrm{C}$. This trend is considered approximately accurate to some extent. However, as seen in Figure 5, the distinct differences in the degradation in strength can be confirmed, even for a specific creep strain of $1 \%$. It is essential for us to know the degree of strain within an HRHD zone and not a nominal strain to explain the differences in the degree of degradation shown in Figure 5 because at $1 \%$ strain, $V$ for Gr.IIIa already starts to decrease and the HRHD is inferred to start as summarized in Table 8. However, unfortunately, to the best of our knowledge, no investigations have been performed within an HRHD zone. Therefore, until the aforementioned investigation can be realized, another approach is required to explain the degradation in strength. To solve this problem, we consider the hint that even though the nose temperatures of the TTP curve of the Z-phase for Grades T91 and T92 are similar $\left(\sim 650{ }^{\circ} \mathrm{C}\right)$, the average temperatures of Grs.IIIa of MJP and MJT are 634 and $622^{\circ} \mathrm{C}$, respectively, whereas those for T91/MGC and pl-91/MgC are much lower $\left(583{ }^{\circ} \mathrm{C}\right.$ and $581{ }^{\circ} \mathrm{C}$, respectively), as shown in Table 8 . There is a distinct difference between the average temperatures of Grs.IIIa between the Grades 92 and 91 steels, i.e., Fe-Cr-W and Fe-Cr-Mo systems, respectively. The major differences in the chemical compositions of Grades 92 and 91 steels are attributed to the Mo and $\mathrm{W}$ contents, which are not considered to impact the formation of the Z-phase directly. Instead, it is more reasonable that the above-mentioned differences in the average temperature of Gr.IIIa are attributed to the formation temperature of the Laves phase in the Grade 91 and 92 steels. Tamura et al. (1988) reported the TTP curves for $\mathrm{Fe}_{2} \mathrm{Mo}$ and $\mathrm{Fe}_{2} \mathrm{~W}$ in $9 \mathrm{Cr}-1 \mathrm{MoVNbN}$ steel and $8 \mathrm{Cr}-2 \mathrm{WVTa}$ steel plates, respectively. The aforementioned curves indicate that the nose temperatures for $\mathrm{Fe}_{2} \mathrm{Mo}$ and $\mathrm{Fe}_{2} \mathrm{~W}$ are 575 and $654{ }^{\circ} \mathrm{C}$, respectively. The information pertaining to the nose temperatures for Laves phases, average temperatures of Gr.IIIa for Grade 91 and 92 steels, and degradation in strength for Grs.IIIa of P92/MJP, T92/MJT, T91/MGC, and $\mathrm{pl}-91 / \mathrm{MgC}$ are shown in the previous paper (Tamura \& Abe, 2021b) and Figure 1 in this paper. These features suggest that the degradation in the long-term rupture strength of high-Cr high-strength martensitic steel is related to the coarsening of the Laves phases and the consumption of several MX particles caused by the formation of the Z-phase. Figures 4 and 5 show that considerable degradation is observed for T91/MGC (and pl-91/MgC) at a temperature of $600{ }^{\circ} \mathrm{C}$ ( several thousands of hours), which is higher than the nose temperature for $\mathrm{Fe}_{2} \mathrm{Mo}$. At high temperatures, the diffusion rate is high and the nucleation rate of the precipitates is low. However, at low temperatures, the opposite is true. A nose temperature is determined by the diffusion-nucleation balance. These kinematical characteristics of the precipitation phenomena around the nose point of a TTP curve are well understood both experimentally and theoretically (Arai, 1970; Medina, 1997; Milkereit, Giersberg, Kessler, \& Schick, 2014). Therefore, when Laves phase particles in T91/MGC and pl-91/MgC readily grow and are coarsened at $600{ }^{\circ} \mathrm{C}$, grain boundary strengthening by the Laves phase becomes incomplete, even after a small strain under low stress. This causes HRHD and strain concentration to occur in an HRHD zone. Therefore, the vicious cycle of the coarsening of the Laves phase, HRHD, and formation of the Z-phase by consuming MX particles occurs even from a small nominal strain, and this leads to serious degradation in strength for the Gr.IIIa of MGC and $\mathrm{MgC}$ at $600{ }^{\circ} \mathrm{C}$ compared to the P92/MJP and T92/MJT.

Figure 10 shows changes in the average diameter of the Laves phase observed in the gauge portion of ruptured specimens of Grade T91 (Suzuki et al., 2000) and Grade 92 steel (Jiang, Zhu, \& Wang, 2013; Dudko, Belyakov, Molodov, \& Kaibyshev, 2013; Nie et al., 2014). In this figure, creep-interrupted data are distinguished by thrash marks and the data at $650^{\circ} \mathrm{C}$ for P911 (3Co) steel (Kipelova, Belyakov, \& Kaibyshev; 2012) are added. Broken and solid lines in the figure represent regression lines for Grade 91 and 92 steels at $600{ }^{\circ} \mathrm{C}$, respectively. Combining data in the grip portions and aged specimens with data for both creep-interrupted and ruptured specimens, the following trends were deduced (related figures are omitted for simplicity): i) The Laves phase is coarsened by increasing the aging temperature (Haetterstrand \& Andren, 2001); ii) straining promotes the growth of the Laves phase (Nie et al., 2014); and iii) the addition of boron suppresses the growth of the Laves phase (Azuma et al., 2002). As shown in Figure 10, the growth rate of the Laves phase (slope of the line) in Grade 92 
steel appears to be lower than that in Grade 91 steel at $600{ }^{\circ} \mathrm{C}$ despite the lack of long-term data for Grade 92 steel. The growth rate of the Laves phase in Grade 92 steel at $600{ }^{\circ} \mathrm{C}$ is controlled by the diffusion rate of constituent elements at that temperature or $600^{\circ} \mathrm{C}$ because the test temperature is below the nose temperature for $\mathrm{Fe}_{2} \mathrm{~W}\left(\sim 650{ }^{\circ} \mathrm{C}\right)$ and the diffusion rate of $\mathrm{W}$ in $\alpha-\mathrm{Fe}$ is slower than both of Mo and the self-diffusion of $\alpha-\mathrm{Fe}$ (Oikawa, 1982). Therefore, the Laves phase particles of $\mathrm{Fe}_{2} \mathrm{~W}$ are finer than those for Grade 91 steel. Further, the total amount of Mo and W is approximately 1.4 times larger than that for Grade 91 steel in atomic ratio causes clear Laves phase hardening observed in Gr.II of Grade 92 steel. In addition, in the case of Gr.IIIa of Grade 92 steel, the strengthening effect caused by the Laves phase may be observed at a small strain. Thus, HRHD is more difficult to achieve for Grade 92 steel than it is for Grade 91 steel, and this resulted in less degradation in strength for Grade 92 steel, as indicated in Figures 4 and 5.

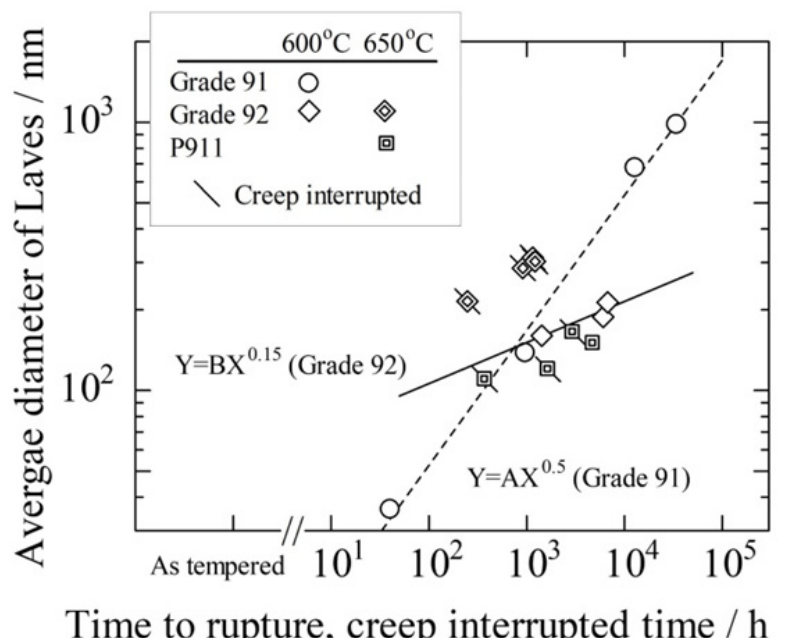

Figure 10. Average diameters of Laves phases in Grade 91 steel, Grade 92 steel, and P911 steel in a gauge portion of ruptured specimens. Creep interrupted specimens are investigated and distinguished by thrash

The above discussion indicates that the stability of the Laves phase under a given condition is considered the underlying cause for breakdown in strength, even though the direct reason is the partial consumption of MX caused by the formation of the Z-phase. In other words, the growth and coarsening of the Laves phase triggers the beginning of HRHD, which promotes the formation of the Z-phase because of a high local strain in the HRHD zone. The Laves phase shows a positive effect on grain boundary strengthening that delays the beginning of HRHD. However, the positive effect is easily lost when the Laves phase particles grow, which promotes the formation of the Z-phase, and ultimately, the rapid degradation in strength. Therefore, it is very important to improve the stability of the Laves phase together with $\mathrm{M}_{23} \mathrm{C}_{6}$ to delay the occurrence of HRHD and the formation of the Z-phase. Hashizume et al. (2009) showed that a small addition of Re to 9Cr-4W-3Co-NbVN steel remarkably suppresses the growth of the Laves phase and increases the rupture strength at $650{ }^{\circ} \mathrm{C}$. Kunieda, Murata, Morinaga, and Koyama (2004) and Kunieda et al (2006) suggest that Re retards the diffusion rate of W in $\alpha-$ Fe. The Laves phase in P911(3Co) is fine, even at $650{ }^{\circ} \mathrm{C}$, as shown in Figure 10. However, they did not completely discuss their results in their paper. Further, Fedoseeva, Nikitin, Dudova, and Kaibyshev (2019) showed that the addition of $0.17 \%$ Re to $10 \mathrm{Cr}-3 \mathrm{Co}-3 \mathrm{~W}$ martensitic steel is effective to suppress the coarsening rate of the Laves phase and the typical size is $200 \mathrm{~nm}$ in a ruptured specimen at $650{ }^{\circ} \mathrm{C}$ for $\sim 10000 \mathrm{~h}$. The temperature of $650{ }^{\circ} \mathrm{C}$ is close to the nose temperature for $\mathrm{Fe}_{2} \mathrm{~W}$; therefore, the growth rate may be predominantly controlled by the nucleation rate rather than the diffusion rate at $\sim 650{ }^{\circ} \mathrm{C}$. Thus, it is considered that reducing the interfacial energy by controlling the amount of microalloying elements may be effective to stabilize the Laves phase for Grade 92 steel at $650{ }^{\circ} \mathrm{C}$. However, no literature on the aforementioned issue has been identified as yet.

6.3.2 $\mathrm{M}_{23} \mathrm{C}_{6}$

$\mathrm{M}_{23} \mathrm{C}_{6}$ particles formed on PAGBs and sub-boundaries play an important role in maintaining the strength of martensitic steel and preventing the growth of sub-grains. $\mathrm{M}_{23} \mathrm{C}_{6}$ particles remain moderately sized throughout 
long-term creep deformation using the DFRP phenomena. Besides the stability of the Laves phase, the DFRP reaction of $\mathrm{M}_{23} \mathrm{C}_{6}$ is very effective in delaying the occurrence of HRHD around the strain for $Q_{\max }$. Figure 11 shows the relationship between the size of $\mathrm{M}_{23} \mathrm{C}_{6}$ and $t_{r}$ for Grade 91 and 92 steels. Data shown in the figure with thrash marks indicate the results from the creep-interrupted specimens (Dudko et al., 2013). The size of $\mathrm{M}_{23} \mathrm{C}_{6}$ for a creep-interrupted specimen is between those for a gauge and a grip of the ruptured specimen because the size in a ruptured specimen is larger than that of a grip (Haetterstrand \& Andren, 2001; Ennis \& Czyrska-Filemonowicz, 2003; Dimmer et al., 2003, Dudko et al., 2013). Nie et al. (2014) reported the size of the $\mathrm{M}_{23} \mathrm{C}_{6}$ of Grade P92 steel ruptured at $700{ }^{\circ} \mathrm{C}$; however, because the exact $t_{r}$ could not be ascertained in their paper, the data were omitted. The lines for Grade 91 and 92 steels are guidelines for a lower limit; these are not the regression lines. Under the assumption that all data are valid, the following trends were deduced: i) the size at $650{ }^{\circ} \mathrm{C}$ is coarser than that at $600{ }^{\circ} \mathrm{C}$, except for the data reported by Jiang et al. (2013); ii) the time exponent for Grade 92 steel $(n=0.16)$ seems to be smaller than that for Grade 91 steel $(n=0.2)$; and iii) the growth or coarsening rate, or both, for Grade 92 steel appears slower than that for Grade 91 steel, which may be attributed to the W and B contents in Grade 92 steel, although there was no data directly comparing Grade 91 and 92 steels presented in a single paper. However, the difference between the time exponents $n=0.16-0.2$ may not be so significant because of the large scattering for both steels. We can observe the large difference between the time exponents of Grade 91 and 92 steels for the Laves phase as shown in Figure 10 because the rate-determining processes for the growth or coarsening of the Laves phase for these steels differ from each other. However, the rate-determining process for $\mathrm{M}_{23} \mathrm{C}_{6}$ is the same at $\sim 600{ }^{\circ} \mathrm{C}$ for both grades and the diffusion of constituent elements is a rate-controlling process because the nose temperature of the corresponding TTP curve is higher than the tempering temperature. Thus, from the above-mentioned metallurgical considerations, the time exponent for Grade 92 steel should be slightly smaller than that for Grade 91 steel. The size of the $\mathrm{M}_{23} \mathrm{C}_{6}$ formed on the PAGBs is considerably larger than that on the sub-boundaries (Abe, 2008; 2009); however, the variations in the size of the $\mathrm{M}_{23} \mathrm{C}_{6}$ systematically investigated for Grade 91 and 92 steels during creep are not yet ascertained.

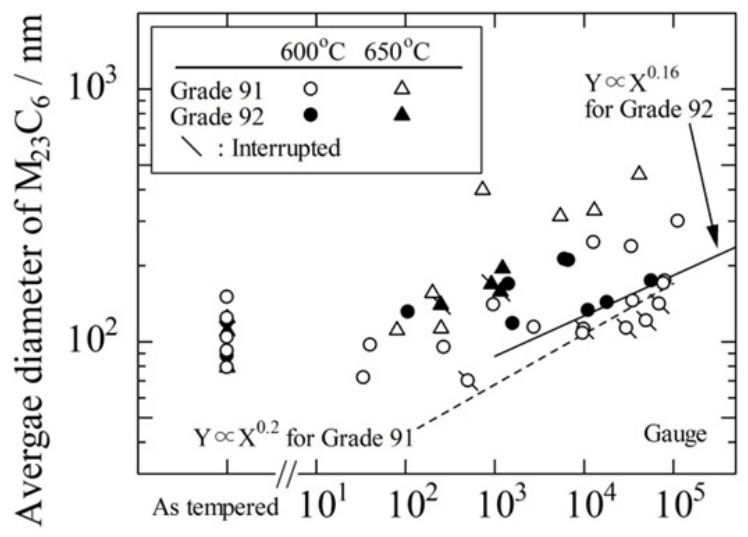

Time to rupture and creep interrupted time/ $\mathrm{h}$

Figure 11. Relationship between time to rupture and average diameter of $\mathrm{M}_{23} \mathrm{C}_{6}$ formed at 600 and $650{ }^{\circ} \mathrm{C}$ in Grade 91 and 92 steels. Slashed marks correspond to creep interrupted specimens and the data by Jiang et al. (2013) are marked by gray, the details of which are explained in the text. A dotted and real lines are drawn for the lower limits to Grade 91 and 92 steels, respectively, using naked eyes

$\mathrm{Cr}_{23} \mathrm{C}_{6}$ is stabilized by dissolving Fe, Mo, and W (Yi, Xu, Xia, Gang, \& Chen, 2017; Sanhueza et al., 2019). The diffusion of constituent elements of the $\mathrm{M}_{23} \mathrm{C}_{6}$ particles is required for the nucleation and growth of the particles. The diffusion rate in $\alpha$-Fe at $\sim 600{ }^{\circ} \mathrm{C}$ increases in the order of $D_{M o}>D_{C r}>D_{F e}>D_{W}$, where the suffixes denote each constituent element (Oikawa, 1982). Therefore, Mo may not suppress the growth of $\mathrm{M}_{23} \mathrm{C}_{6}$ through a diffusion process. However, Mo has been utilized in many heat-resistant steel for an extended duration, and therefore, Mo appears to stabilize $\mathrm{M}_{23} \mathrm{C}_{6}$ through a nucleation process. Further, W definitely suppresses the growth rate of $\mathrm{M}_{23} \mathrm{C}_{6}$ because the diffusion of $\mathrm{W}$ is slower than other constituent elements of $\mathrm{M}_{23} \mathrm{C}_{6}$. Thus, the growth and coarsening rates of $\mathrm{M}_{23} \mathrm{C}_{6}$ in Grade 92 steel are expected to be slower than those in Grade 91 steel. Yoshizawa, Igarashi, and Nishizawa (2005) showed that the coarsening rate of $\mathrm{M}_{23} \mathrm{C}_{6}$ in the W-containing 
martensitic steel is lower than that of $\mathrm{W}$-free steel; they explain this phenomenon semi-quantitatively by assuming Ostwald ripening (Lifschitz \& Siyozov, 1961; Wagner, 1961).

The average chemical composition of the $\mathrm{M}_{23} \mathrm{C}_{6}$ of ruptured specimens for Grade 91 steel at $600{ }^{\circ} \mathrm{C}$ is 64.4Cr-21.8Fe-9.9Mo-NbVSi. $\mathrm{Cr}$ is slightly enriched during long-term tests; however, the compositional range varies steadily during creep (Suzuki et al., 2000; Kimura et al., 2002). The chemical composition of $\mathrm{M}_{23} \mathrm{C}_{6}$ in Grade 92 steel is rarely reported: $46.1 \mathrm{Cr}-23.6 \mathrm{Fe}-27.3 \mathrm{~W}-2.2 \mathrm{Mo}-0.9 \mathrm{~V}$ at $600{ }^{\circ} \mathrm{C}$ for $t_{r}=9755 \mathrm{~h}$ (Ennis, Zielinska-Lipiec, Wachter, \& Czyrska-Filemonowicz, 1997), $6.3 \mathrm{Cr}-8.7 \mathrm{Fe}-46.3 \mathrm{~W}-7.7 \mathrm{Mo}$ at $600{ }^{\circ} \mathrm{C}$ for $t_{r}=8472 \mathrm{~h}$ (Nie et al., 2014), and $63 \mathrm{Cr}-19 \mathrm{Fe}-12 \mathrm{~W}-4.4 \mathrm{Mo}$ aged at $700{ }^{\circ} \mathrm{C}$ for $2000 \mathrm{~h}$ (Gao et al., 2017). This seems to imply that the compositional range of $\mathrm{M}_{23} \mathrm{C}_{6}$ in Grade 92 steel could be wider than that for Grade 91 steel because of the microsegregation of W. Maruyama, Sawada, and Koike (2001) reported that the addition of $\mathrm{Ni}$ to $12 \mathrm{Cr}-0.5 \mathrm{Mo}-\mathrm{VNb}$ steel increases the size of the $\mathrm{M}_{23} \mathrm{C}_{6}$ particles during creep at $600{ }^{\circ} \mathrm{C}$. Further, Ni is not a constitutional element of $\mathrm{M}_{23} \mathrm{C}_{6}$, and therefore, this phenomenon can be explained as follows: The addition of $\mathrm{Ni}$ decreases an $\alpha-\gamma$ transformation temperature (Fujita, Yamashita, \& Miyake, 1980), which promotes the recovery and diffusion of the matrix. Thus, the size of $\mathrm{M}_{23} \mathrm{C}_{6}$ increases with the addition of Ni. However, there is no report on the effect of a small amount of $\mathrm{Ni}$ on the size of $\mathrm{M}_{23} \mathrm{C}_{6}$ in Grade 91 and 92 steels. The addition of small amounts of boron to high-Cr martensitic steel is confirmed to suppress the coarsening of $\mathrm{M}_{23} \mathrm{C}_{6}$ and improve the rupture strength (Azuma et al., 2002; Danielsen, 2007; Abe, 2008, 2009, 2011). This technique is explained as follows: After boron is segregated on grain boundaries during normalizing, the segregated boron atoms on the PAGBs move towards the newly formed $\mathrm{M}_{23} \mathrm{C}_{6}$ during tempering and stabilize with the $\mathrm{M}_{23} \mathrm{C}_{6}$ particles for an extended duration (Abe, 2008, 2009, 2011; Liu, Fors, Golpayegani, Andren, \& Wahnstrom, 2012). However, a majority of boron in the typical Grade 92 steel is used to form massive BN particles, which reduce the reduction of area (Tamura \& Abe, 2021b). Therefore, boron is not used effectively in Grade 92 steel. Liu et al. (2012) and Sanhueza et al. (2019) attempted to explain the time rule for the precipitated $\mathrm{M}_{23} \mathrm{C}_{6}$ during the creep of martensitic steel containing boron based on Ostwald ripening; unfortunately, they were unsuccessful in their attempts. The time exponents shown in Figure 11 are approximately close to $1 / 3$; however, this does not necessarily indicate that the coarsening process is Ostwald ripening. The diffusion of constitutional elements of $\mathrm{M}_{23} \mathrm{C}_{6}$ is very important for the growing process of $\mathrm{M}_{23} \mathrm{C}_{6}$ because the creep temperature of martensitic steel is far below the nose temperature of the respective TTP curve of martensitic steel. However, the $\mathrm{M}_{23} \mathrm{C}_{6}$ during the creep of martensitic steel is in a nucleation and the growth process, as opposed to in a simple coarsening process. This lends credibility to the DFRP process of $\mathrm{M}_{23} \mathrm{C}_{6}$ on the sub-boundaries during creep, and the rearrangement of the $\mathrm{M}_{23} \mathrm{C}_{6}$ arising from HRHD, which occurs from the early stage of creep as explained in the previous work (Tamura \& Abe, 2021a) or as briefly explained in Section 1. Therefore, the average composition of $\mathrm{M}_{23} \mathrm{C}_{6}$ should continuously change during creep, although the experimental results for Grade 92 steel have not been obtained sufficiently. The segregation of boron onto $\mathrm{M}_{23} \mathrm{C}_{6}$ is presumed to occur after the nucleation of $\mathrm{M}_{23} \mathrm{C}_{6}$ from the boron profile across an $\mathrm{M}_{23} \mathrm{C}_{6}$ particle (Abe, 2011). Moreover, there are several types of precipitation sites in martensitic steel. These facts indicate that the interfacial energy between $\mathrm{M}_{23} \mathrm{C}_{6}$ and the matrix during creep of martensitic steel cannot be regarded as constant as the Ostwald ripening in liquids.

\subsection{Comparison between Grade 91 and Grade 92 steels}

The rupture strengths of Grade 92 steel $\left(\sim 600{ }^{\circ} \mathrm{C}, 100000 \mathrm{~h}\right)$ are larger than those of Grade 91 steel; however, there is a heat-to-heat variation in the strength in each grade. This difference is attributed to the consumption of finely dispersed MX particles caused by the formation of the Z-phase, as indicated by Sawada et al. (2011). However, this difference in strength - the amount of Z-phase formed at $600{ }^{\circ} \mathrm{C}$ for longer than several tens of thousands hours - is not directly related to $E L$ but with the alloy system itself, i.e., Fe-Cr-W or Fe-Cr-Mo system. At $\sim 600{ }^{\circ} \mathrm{C}$, the $\mathrm{Fe}_{2} \mathrm{Mo}$ particles are coarsened easily compared to $\mathrm{Fe}_{2} \mathrm{~W}$ particles (Figure 10), which causes the HRHD to initiate at a smaller strain, consequently forming a larger amount of the Z-phase. Figure 12 shows the relationship between the average NSR and the strain for Gr.IIIa of the four steels of Grade 91 and 92 steels. Clear differences in the transient creep are confirmed between Grade 91 and 92 steels. The average NSRs for Grade 91 steel are smaller than those for Grade 92 steel in the transient creep, which indicates that Grade 91 steel is more easily hardened than Grade 92 steel. This difference is attributed to the formation of the Laves phase particles being faster in Grade 91 steel $\left(\mathrm{Fe}_{2} \mathrm{Mo}\right)$ than that in Grade 92 steel $\left(\mathrm{Fe}_{2} \mathrm{~W}\right)$ in the transient creep. In the accelerating creep, the average NSRs through 1-5\% for Grade 91 steel appear slightly larger on average than those for Grade 92 steel. This can be explained as follows: Table 8 shows that finer Laves phase particles are readily formed in an Fe-Cr-Mo system (Grade 91 steel), and consequently, $Q V C_{\max }$ is obtained at a smaller strain followed by the decrease in $Q$ and the occurrence of HRHD accompanying a faster growth of the Laves phase (Figure 10). This causes a faster formation of the Z-phase and a faster recovery even in the transient creep 
of Gr.IIIa, when compared with those for an Fe-Cr-W system (Grade 92 steel). These sequential phenomena are passed more severely from the transient creep to the accelerating creep, and ultimately, the $t_{r}$ for Grade 91 steel becomes shorter than that of Grade 92 steel.

Hasegawa, Ohgami, and Muraki (2003) and Hasegawa et al. (2004) reported that the Laves phase together with $\mathrm{M}_{23} \mathrm{C}_{6}$ can strengthen the block boundaries during the creep of Grade P92. Kipelova, Belyakov, and Kaibyshev (2012) confirmed that fine Laves phase particles are formed on the lath boundaries of the crept specimen by $1 \%$ strain at $650{ }^{\circ} \mathrm{C}\left(t_{1}=374 \mathrm{~h}\right)$ of P911(3Co) steel. Moreover, Zeng, Jia, Cai, Dong, and Wang (2018) recently reported that the Laves phase not only forms on the PAGBs and lath boundaries but also finely precipitates inside the lath martensite at a scale of $100 \mathrm{~nm}$ order for a reheater tube of P92 served for $9854 \mathrm{~h}$ in an actual power plant operated at $603{ }^{\circ} \mathrm{C}$ and under $5.87 \mathrm{MPa}$. These facts indicate that creep strength of Grade 92 steel at around $6500^{\circ} \mathrm{C}$ is superior to that of Grade 91 .

However, the growth rate of the Laves phase is high and the sizes become approximately 200 and $300 \mathrm{~nm}$ in the necked portions of the ruptured specimens of $\mathrm{P} 92$ tested at 600 and $649^{\circ} \mathrm{C}$ for about $5000 \mathrm{~h}$, respectively (Nie et al., 2014). Much larger sizes of 300 and $700 \mathrm{~nm}$ are reported for the aged specimens of $\mathrm{P} 92$ at 600 and $650{ }^{\circ} \mathrm{C}$ for $5000 \mathrm{~h}$, respectively (Haetterstrand \& Andren, 2001). The precipitation site of the Laves phase after long-term creep is on the PAGBs (Yan et al., 2013). These massive Laves phase particles are frequently observed in P92 near the coarse $\mathrm{M}_{23} \mathrm{C}_{6}$ particles (Dimmler, Weinert, Kozeschnik, \& Cerjak, 2003; Dudko, Belyakov, Molodov, \& Kaibyshev, 2013; Nie et al., 2014; Xu et al., 2015; Maddi et al., 2016; Zielinski, Golanski, \& Sroka, 2016). However, these information do not yet been reflected in Figures 10 and 11 . Therefore, special attention needs to be paid to the degradation in long-term rupture strength of Grade 92 at around $600{ }^{\circ} \mathrm{C}$ caused by the interaction between Laves phase and $\mathrm{M}_{23} \mathrm{C}_{6}$.

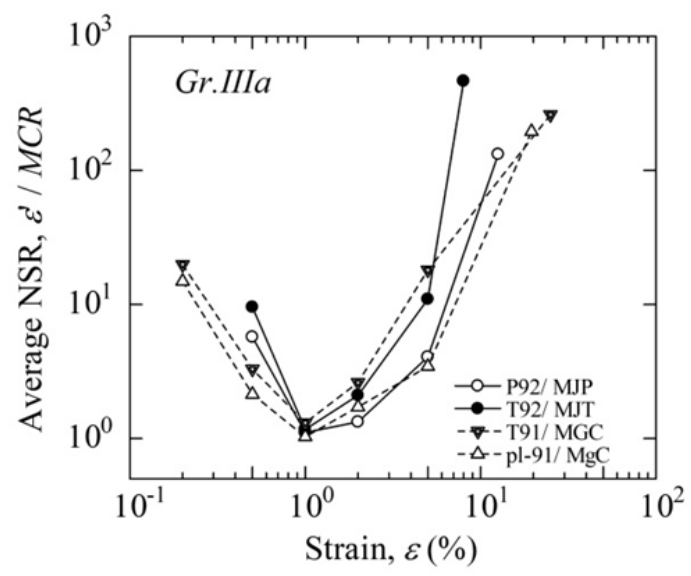

Figure 12. Comparison among the average NSRs for each Gr.IIIa of P92/MJP, T92/MJT, T91/MGC, and $\mathrm{pl}-91 / \mathrm{MgC}$ as functions of creep strain

\section{Conclusions}

The long-term creep curves of four types of Grade 91 and 92 steels were analyzed by applying an exponential law to $T, \sigma$, and $t_{r}$ or $t_{\varepsilon}$ for clarifying the root cause of degradation in long-term rupture strength of martensitic steel with high strength. Observed creep variables of $T, \sigma$, and $t_{r}$, or $t_{\varepsilon}$ are converted to the $Q, V$, and $C$ without using any adjustable parameters. The variations in $Q, V$, and $C$ as functions of creep strain are discussed metallurgically and the following conclusions are obtained:

1) Remarkable degradation in the rupture strength of Grade 91 and 92 steels is observed at approximately $600{ }^{\circ} \mathrm{C}$ for hundreds of thousands of hours and the degree of degradation tends to be mitigated for further longer-term tests because of the growth of sub-grains and the rearrangement of $\mathrm{M}_{23} \mathrm{C}_{6}$.

2) At the initial stage of creep, the sub-boundaries of high $\mathrm{Cr}$ and high strength martensitic steel are strengthened by dislocations swept out of sub-grains, DFRP of fine $\mathrm{M}_{23} \mathrm{C}_{6}$ particles, and precipitation of the Laves phase, which increases $Q, V$, and $C$.

3) Under the test conditions for the remarkable degradation in the rupture strength, some boundaries start to be weakened because of the coarsening of boundary precipitates (Laves phase) from a small strain (ex. $0.5 \%$ ). 
Consequently, HRHD starts near several of the weakest boundaries. As a result, $Q, V$, and $C$ start to decrease simultaneously while increasing strain even in transient creep.

4) Large straining inside an HRHD zone promotes the decomposition of microstructure, i.e., further coarsening of the Laves phase and formation of the Z-phase consuming finely dispersed MX particles, which results in further decreases in $Q, V$, and $C$ with increasing nominal strain even in transient creep.

5) Further decrease in $Q$ causes the start of the accelerating creep and the degradation in rupture strength. The heterogeneous coarsening of the Laves phase particles induces the occurrence of the HRHD, which triggers an unexpected degradation in rupture strength because of the accelerated formation of the Z-phase consuming the MX particles nearby an HRHD zone.

6) Transportation of solute atoms by moving dislocations inside the HRHD zone based on a drag mechanism promotes the accelerating formation of coarse particles of the Laves phase and Z-phase consuming a strengthening factor of MX particles nearby an HRHD zone.

7) Long-term rupture strength of Grade 91 steel is lower than that of Grade 92 steel at approximately $600{ }^{\circ} \mathrm{C}$. This is attributed to the Laves phase that is easily coarsened in an Fe-Cr-Mo system compared with that of an Fe-Cr-W system, i.e., Grade 92 steel, because a temperature of $600{ }^{\circ} \mathrm{C}$ is higher than the nose temperature of the TTP curve of $\mathrm{Fe}_{2} \mathrm{Mo}, 575{ }^{\circ} \mathrm{C}$ on the other hand the nose temperature for $\mathrm{Fe}_{2} \mathrm{~W}, 654{ }^{\circ} \mathrm{C}$, is higher than $600{ }^{\circ} \mathrm{C}$. Stabilizing not only the Laves phase but also $\mathrm{M}_{23} \mathrm{C}_{6}$ is very important to mitigate the degradation in strength.

\section{List of Symbols and Abbreviations}

\begin{tabular}{ll}
$\varepsilon$ & Strain \\
$\dot{\varepsilon}$ & Creep rate \\
$\lambda$ & Maximum distance that a dislocation can move from a start point to the next stable position \\
$v_{e f f}$ & Effective attempt frequency per unit time to overcome the obstacles \\
$\rho$ & Dislocation density \\
$\rho_{z}$ & The number density of Z-phase \\
$\sigma$ & Applied stress \\
$\Delta S$ & Entropy change in the activation process \\
ASME & The American Society of Mechanical Engineers \\
$b$ & Length of the Burgers vector \\
$C$ & Larson-Miller constant \\
$C_{S}$ & Larson-Miller constant calculated based on strain rate \\
$C_{M G}$ & Monkman-Grant constant \\
DFRP & Dissolving and finely re-precipitation \\
$E L$ & Rupture elongation \\
HRC & Rockwell hardness number \\
HRHD & Heterogeneous recovery and heterogeneous deformation \\
$M C R$ & Minimum creep rate \\
$M T D$ & Minimum creep time for detectable degradation as compared with the shorter time data group. \\
$M X$ & Carbonitride of (Cr,Nb,V)(C,N) type \\
NIMS & National Institute for Materials Science in Tsukuba, Japan \\
$N S R$ & Normalized strain rate, Strain rate at a specific strain is divided by each $M C R$ \\
PAGB & Prior austenitic grain boundary \\
$Q$ & Activation energy \\
$Q_{S}$ & Activation energy calculated based on strain rate \\
{$[Q]$} & $Q / 2.3 R T$ \\
{$[Q]_{S}$} & $Q_{s} / 2.3 R T$ \\
\hline
\end{tabular}




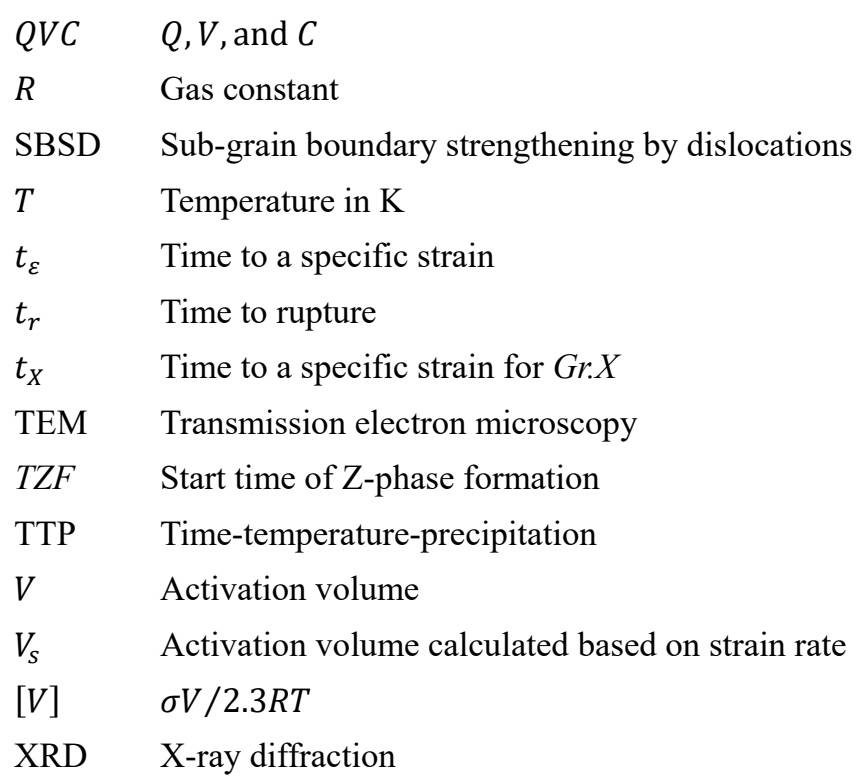

\section{References}

Abe, F. (2006a). Metallurgy for long-term stabilization of ferritic steels for thick section boiler components in USC power plant at $650{ }^{\circ} \mathrm{C}$. In Proceedings of the 8th Liege Conference on Materials for Advanced Power Engineering, 2006, September 18-20, 2006, Liege, Belgium (pp. 965-980). Forschungszentrum Juelich, Germany. Retrieved from https://www.fz-juelich.de/zb/DE/Home/home_node.html

Abe, F. (2006b). Present status of advanced high-Cr ferritic heat resistant steels for ultra-supercritical power plants. Bulletin of the Iron and Steel Institute of Japan, 11, 197-207. Retrieved from https://www.isij.or.jp/

Abe, F. (2008). Precipitate design for creep strengthening of $9 \% \mathrm{Cr}$ tempered martensitic steel for ultra-supercritical power plants. Science and Technology of Advanced Materials, 9, 013002 (pp.1-15). https://doi.org/10.1088/1468-6996/9/1/013002

Abe, F. (2009). Analysis of creep rates of tempered martensitic $9 \% \mathrm{Cr}$ steel based on microstructure evolution. Materials Science and Engineering A, 510-511, 64-69. https://doi.org/10.1016/j.msea.2008.04.118

Abe, F. (2011). Effect of boron on microstructure and creep strength of advanced ferritic power plants steels. Procedia Engineering, 10, 94-99. https://doi.org/10.1016/j.proeng.2011.04.018

Abson, D. J., \& Rothwell, J. S. (2013). Review of type IV cracking of weldments in 9-12\%Cr creep strength enhanced ferritic steels. International Materials Reviews, 58, 437-473. https://doi.org/10.1179/1743280412Y.0000000016

Arai, H. (1970). A theoretical study on the formation of carbide and chromium-depleted-layer in austenitic stainless steel. Tetsu-to-Hagane, 56, 44-54. https://doi.org/10.2355/tetsutohagane1955.56.1_44

Azuma, T., Miki, K., Tanaka, Y., \& Ishiguro, T. (2002). Effect of B on microstructural change during creep deformation in high $\mathrm{Cr}$ ferritic heat resistant steel. Tetsu-to-Hagane, 88, 678-685. https://doi.org/10.2355/tetsutohagane1955.88.10_678

Brailsford, A. D., \& Aaron, H. B. (1969). Growth of grain-boundary precipitates. Journal of Applied Physics, 40, 1702-1710. https://doi.org/10.1063/1.1657835

Cipolla, L., Danielsen, H. K., Venditti, D., Nunzio, P. E. D., Hald, J., \& Somers, M. A. J. (2010). Conversion of MX nitrides to Z-phase in a martensitic $12 \% \mathrm{Cr}$ steeel. Acta Materialia, 58, 669-679. https://doi.org/10.1016/j.actamat.2009.09.045

Cui, J., Kim, I-S., Kang, C-Y., \& Miyahara, K. (2001). Creep stress effect on the precipitation behavior of Laves phase in $\mathrm{Fe}-10 \% \mathrm{Cr}-6 \% \mathrm{~W}$ alloys. ISIJ International, $41, \quad 368-371$. https://doi.org/10.2355/isijinternational.41.368

Danielsen, H. K. (2007). Z-Phase in 9-12\%Cr steels (Dissertation of Ph. D.). Technical University of Denmark, Lyngby, Denmark. https://backend.orbit.dtu.dk/ws/files/4899462/HilmarThesis.pdf

Danielsen, H. K., \& Hald, J. (2009). Influence of Z-phase on long-term creep stability of martensitic 9 to $12 \% \mathrm{Cr}$ steels. $\quad V G B \quad$ Power Technology, 5, 68-73. Retrieved from https://www.vgb.org/vgbmultimedia/danielsen_pt09_05-p-3571.pdf 
Di-Gianfrancesco, A., Vipraio, S. T., \& Venditti, D. (2013). Long-term microstructural evolution of 9-12\%Cr steel Grades for steam power generation plants. Procedia Engineering, 55, 27-35. https://doi.org/10.1016/j.proeng.2013.03.214

Dimmler, G., Weinert, P., Kozeschnik, E., \& Cerjak, H. (2003). Quantification of the laves phase in advanced 9-12\% $\mathrm{Cr}$ steels using a standard SEM. Materials Characterization, 51, 341-352. https://doi.org/10.1016/j.matchar.2004.02.003

Dudko, V., Belyakov, A., Molodov, D., \& Kaibyshev, R. (2013). Microstructure evolution and pinning of boundaries precipitates in a 9 pct $\mathrm{Cr}$ heat resistant steel during creep. Metallurgical and Materials Transactions A, 44A, S162-S172. https://doi.org/10.1007/s11661-011-0899-1

Dudova, N., Plotnikova, A., Molodov, A., Belyyakov, A., \& Kaibyshev, R. (2012). Structural changes of tempered martensitic $9 \% \mathrm{Cr}-2 \% \mathrm{~W}-3 \% \mathrm{Co}$ steel during creep at $650{ }^{\circ} \mathrm{C}$. Materials Science and Engineering: A, 534, 632-639. https://doi.org/10.1016/j.msea.2011.12.020

Ennis, P. J., Zielinska-Lipiec, A., Wachter, O., \& Czyrska-Filemonowicz, A. (1997). Microstructural stability and creep rupture strength of the martensitic steel P92 for advanced power plant. Acta Materialia, 45, 4901-4907. https://doi.org/10.1016/S1359-6454(97)00176-6

Ennis, P. J., Zielinska-Lipiec, A., \& Czyrska-Filemonowicz, A. (2000). Quantitative microscopy and creep strength of $9 \%$ chromium steels for advanced power stations. In A. Strang, W. M. Bank, R. D. Conroy, G. M. McColvin, J. C. Neal, and S. Simpson (Eds.), Proceedings of 5th International Charles Parsons Turbine Conference, 3-7 July, 2000, Cambridge, (pp. 498-507). London, JOM Communication Ltd. Retrieved from https://catalyst.library.jhu.edu/catalog/bib_2158972

Ennis, P. J., \& Czyrska-Filemonowicz, A. (2003). Recent advances in creep-resistant steels for power plant applications. Sadhana, 28, 709-730. https://doi.org/10.1007/BF02706455

Esherby, J. D. (1956). The continuum theory of lattice defects. In F. Seitz and D. Turnbull (Eds.), Solid State Physics: Advances in Research and Applications, 3, 79-145. NY: Academic Press Inc. https://doi.org/10.1016/S0081-1947(08)60132-0

Fedorova, I., Kipelova, A., Belyakov, A., \& Kaibyshev, R. (2013). Microstructure evolution in an advanced 9 pct $\mathrm{Cr}$ martensitic steel during creep at $923 \mathrm{~K}\left(650{ }^{\circ} \mathrm{C}\right)$. Metallurgical and Materials Transactions A, 44A, S128-S135. https://doi.org/10.1007/s11661-012-1182-9

Fedoseeva, A., Dudova, N., \& Kaibyshev, R. (2016). Creep strength breakdown and microstructure evolution in a $3 \% \mathrm{Co}$ modified P92 steel. Materials Science \& Engineering A, 654, 1-12. https://doi.org/10.1016/j.msea.2015.12.027

Fedoseeva, A., Nikitin, I., Dudova, N., \& Kaibyshev, R. (2019). Creep behavior and microstructure of a prospective Re-containing 10\%Cr-3\%Co-3\%W martensitic steel. In Jiont EPRE-123HiMAT International Conference on Advances in High-Temperature Materials: Proceedings from EPRI's 9th International Conference on Advances in Materials Technology for Fossil Power Plants and the 2nd International 123HiMAT Conference on High-Temperature Materials, Octorber 21-24, 2019, Nagasaki, Japan, ASM $\begin{array}{lllll}\text { International (pp. 217-226). } & \text { Retrieved }\end{array}$ http://www.123himat-2019.mtl.titech.ac.jp/Leaflet_FinalProgram_191015_FinalVersion.pdf

Fujita, T., Yamashita, K., \& Miyake, H. (1980). The effect of nickel and cobalt on elevated temperature properties and microstructures of $10 \mathrm{Cr}-2 \mathrm{Mo}$ heat resisting steels. Transactions ISIJ, 20, 384-391. https://doi.org/10.2355/isijinternational1966.20.384

Glen, J. (1958). A new approach to the problem of creep. Journal of the Iron and Steel Institute, 189, 333-343. Retrieved from https://iss.ndl.go.jp/books/R100000002-I000000124643-00

Gao, Q., Zhang, Y. Zhang, H., Li, H., Qu, F., Zhan, J., Lu, C., Wu, B., Lu, Y., \& Ma, Y. (2017). Coarsening behavior of M23C6 carbides in creep-resistant steel exposed to high temperatures. Scientific Reports, 7 , Articl No. 5859. https://www.nature.com/articles/s41598-017-06191-2

Haetterstrand, M., \& Andren, H -O. (2001). Evaluation of particle size distribution of precipitates in a 9\% chromium steel using energy filtered transmission electron microscopy. Micron, 32, 789-797. https://doi.org/10.1016/S0968-4328(00)00086-X

Hald, J. (2008). Microstructure and long-term creep properties of 9-12\% Cr steels. International Journal of Pressure Vessels and Piping, 85(1-2), 30-37. 
Hasegawa, Y., Ohgami, M., \& Muraki, T. (2003). Grain boundary strengthening mechanism of tungsten containing 9 to $12 \%$ chromium ferritic heat resistant steels at $650 \mathrm{oC}$. Journal of the Society of Materials Science, Japan, 52, 843-850. https://doi.org/10.2472/jsms.52.843

Hasegawa, Y., Muraki, T., Yoshida, S., Ohgami, M., Okayama, Y., Kawazoe, F., \& Umeki, S. (2004). Alloy design of nano-scale precipitates bearing high strength ferritic heat resistant steels. Shinnittetsu Giho, No.381, 61-65. Retrieved from https://www.nipponsteel.com/tech/report/nsc/

Hasegawa, Y. (2014). Grade 92 creep-strength-enhanced ferritic steel. In A. Shibli ed., Coal Power Plant Materials and Life Assessment - Development and Applications (pp. 52-86). Cambridge, UK, Woodhead Publishing. https://doi.org/10.1533/9780857097323.1.52

Hashizume, R., Tamura, O., Miki, K., Azuma, T., Ishiguro, T., Murata, Y., \& Morinaga, M. (2009). Benefitical effect of Re on the long-term creep strength of high $\mathrm{Cr}$ ferritic heat resistant steels. Tetsu-to-Hagane, 95, 176-185. https://doi.org/10.2355/tetsutohagane.95.176

Hassan, B., \& Corney, J. (2017). Grain boundary precipitation in Inconel 718 and ATI 718Plus. Materials Science and Technology, 33, 1879-1889. https://doi.org/10.1080/02670836.2017.1333222

Hayakawa, H., Terada, D., Yoshida, F., Nakashima, H., \& Goto, Y. (2003a). Evaluation of mobile dislocation density of modified 9Cr-1Mo steel by stress change test. Tetsu-to-Hagane, 89, 1076-1081. https://doi.org/10.2355/tetsutohagane1955.89.10_1076

Hayakawa, H., Terada, D., Yoshida, F., Nakashima, H., \& Goto, Y. (2003b). Characterization of creep deformation mechanism and evaluation of dislocation mobility of modified $9 \mathrm{Cr}-1 \mathrm{Mo}$ steel by stress change test. Journal of Japan Institute of metals, 67, 22-26. https://doi.org/10.2320/jinstmet1952.67.1_22

Hayakawa, H., Nakashima, S., Kusumoto, J., Kanaya, A., Terada, D., Yoshida, F., Nakashima, H. (2007a). Evaluation of creep deformation mechanism of heat resistant steel by stress change test. In Proceedings of CREEP8, 8th International conference on Creep and Fatigue at Elevated Temperatures, July 22-26, 2007, San Antonio, Texas (CREEP2007-26501, pp. 1-10). ASME. Retrieved from https://asmedigitalcollection.asme.org/proceedings

Hayakawa, H., Terada, D., Yoshida, F., Nakashima, H., Kanaya, A., \& Nakashima, S. (2007b). Characterization of creep deformation of $2.25 \mathrm{Cr}-1 \mathrm{Mo}$ steel by stress change test. Tetsu-to-Hagane, 93, 466-471. https://doi.org/10.2355/tetsutohagane.93.466

Hori, S., \& Saji, S. (1981). Grain boundary reaction. Bulletine of Japan Institute of Metals, 20, 863-869. Retrieved from https://doi.org/10.2320/materia1962.20.863

Hosoi, Y., Wade, N., Kunimitsu, S., \& Urita, T. (1986). Precipitation behavior of Laves phase and its effect on toughness of 9Cr-2Mo ferritic-martensitic steel. Journal of Nuclear materials, 141-143, 461-467. https://doi.org/10.1016/S0022-3115(86)80083-6

Hu, P., Yan, W., Sha, W., Wang, W., Guo, Z., Shan, Y., \& Yang, K. (2009). Study on Laves phase in an advanced heat-resistant steel. Frontier Materials Science, China, 3, 434-441. https://doi.org/10.1007/s11706-009-0063-7

Jiang, J., Zhu, L., \& Wang, Y. (2013). Hardness variation in P92 heat-resistant steel based on microstructural evolution during creep. Steel Research International, 84, 732-739. https://doi.org/10.1002/srin.201200265

Kabadwal, A., Tamura, M., Shinozuka, K., \& Esaka, H. (2010). Recovery and precipitate analysis of 9 pct Cr-1 pct $\mathrm{MoVNb}$ steel during creep. Metallurgical Transactions A, 41A, 364-379. https://doi.org/10.1007/s11661-009-0094-9

Karashima, S., Iikubo, T., Watanabe, T., \& Oikawa, H. (1971). Transmission electron microscopy of substructures developed during high-temperature creep in alpha-iron. Transactions of JIM, 12, 369-374. https://doi.org/10.2320/matertrans1960.12.369

Karashima, S., Iikubo, T., \& Oikawa, H. (1972). On the high-temperature creep behavior and substructures in alpha-iron single crystal. Transactions of JIM, 13, 176-181. https://doi.org/10.2320/matertrans1960.13.176

Kimura, H., Sato, T., Bergins, C., Imano, S., \& Saito, E. (2011). Development of technologies for improving efficiency of large coal-fired thermal power plants. Hitachi Review, 60(7), 365-371. Retrieved from http://www.hitachi.com/rev/pdf/2011/r2011_07_102.pdf

Kimura, K., Suzuki, K., Toda, Y., Kushima, H., \& Abe, F. (2002). Precipitation of Z-phase and degradation behavior of mod.9Cr-1Mo steel. In Proceedings of the 7th Liege Conference on Materials for Advanced Power Engineering 2002, (pp. 1171-1180). Forschungszentrum Juelich, Germany. Retrieved from https://www.fz-juelich.de/zb/DE/Home/home_node.html 
Kimura, K. (2009). Creep rupture life prediction of creep resistant steels. Journal of Japan Institute of Metals, 73, 323-333. https://doi.org/10.2320/jinstmet.73.323

Kimura, K., Sawada, K., Kushima, H., \& Toda, Y. (2013). Influence of chemical composition and heat treatment on long-term creep strength of Grade 91 steel. Procedia Engineering, 55, 2-9. https://doi.org/10.1016/j.proeng.2013.03.211

Kipelova, A., Belyakov, A., \& Kaibyshev, R. (2012). Laves phase evolution in a modified P911 heat resistant steel during creep at $923 \mathrm{~K}$. Materials Science and Engineering A, 532, 71-77. https://doi.org/10.1016/j.msea.2011.10.064

Kocer, C., Abe, T., \& Soon, A. (2009). The Z-phase in 9-12\% Cr ferritic steels: A phase stability analysis. Materials Science and Engineering A, 505, 1-5. https://doi.org/10.1016/j.msea.2008.10.028

Kubon, Z., Foldyna, V., \& Vodarek, V. (1998). Analysis of strengthening mechanisms in 9 to 12 chromium steels. In A. Strang, T. Canley, and G. W. Greenwood (Eds.), Microstructural Stability of Creep Resistant Alloys for High Temperature Plant Applications (pp. 257-270). London, Institute of Materials. http://metal2012.tanger.cz/files/proceedings/metal_00/papers/318.pdf

Kubon, Z., Foldyna, V., Hajduk, D., \& Simecek, P. (2000). Creep and relaxation properties of 9-12\% Cr steels. In A. Strang, W. M. Bank, R. D. Conroy, G. M. McColvin, J. C. Neal, and S. Simpson (Eds.), Proceedings of 5th International Charles Parsons Turbine Conference, 3-7 July, 2000, Cambridge, (pp. 485-497). London, JOM Communication Ltd. Retrieved from https://catalyst.library.jhu.edu/catalog/bib_2158972

Kunieda, T., Murata, Y., Morinaga, M., \& Koyama, T. (2004). Effect of refractory elements (X: Mo, W, Re) on the microstructure evaluation of Fe-8Cr-0.1C-X martensitic steels during tempering. Materials Transactions, 45, 392-395. https://doi.org/10.2320/matertrans.45.392

Kunieda, T., Yamashita, K., Murata, Yoshinori, Koyama, T., \& Morinaga, M. (2006). Effect of rhenium addition on tungsten diffusivity in iron-chromium alloys. Materials Transactions, 47, 2106-2108. https://doi.org/10.2320/matertrans.47.2106

Kushima, H, Kimura, K., \& Abe, F. (1999). Degradation of mod. 9Cr-1Mo steel during long-term creep deformation. Tetsu-to-Hagane, 85, 841-847. https://doi.org/10.2355/tetsutohagane1955.85.11_841

Larson, F. R., \& Miller, J. (1952). A time-temperature relationship for rupture and creep stresses. Transactions of the American Institute of Mining and Metallurgical Engineers, 74, 765-775. Retrieved from https://search.lib.virginia.edu/catalog/u744571

Lifshitz, I. M., \& Slyozov, V. V. (1961). The kinetics of precipitation from supersaturated solid solution. Journal of Physics and Chemistry of Solids, 19, 35-50. https://doi.org/10.1016/0022-3697(61)90054-3

Lim, R., Sauzay, M., Dalle, F., Tournie, I., Bonnaillie, P, \& Gourgues-Lorenzon, A. -F. (2011). Modelling and experimental study of the tertiary creep stage of Grade 91 steel. International Journal of Fracture, 169, 213-228. https://doi.org/10.1007/s10704-011-9585-y

Liu, F., Fors, D. H. R., Golpayegani, A., Andren, H. -O., \& Wahnstrom, G. (2012). Effect of boron on carbide coarsening at $873\left(600^{\circ} \mathrm{C}\right)$ in 9 to $12 \mathrm{pct}$ chromium steels. Metallurgical and Materials Transactions A, 43A, 4053-4062. https://doi.org/10.1007/s11661-012-1205-6

Lundin, L., Norell, M., Andren, H. -O., \& Nyborg, L. (1997). Remanent life assessment of creep-resistant modified $12 \%$ chromium steels: microstructural analysis and microstructural development models. Scandinavian Journal of Metallurgy, 26, 27-40. Retrieved from https://www.scimagojr.com/journalsearch.php?q=28362\&tip=sid\&clean=0

Maddi, L., Deshmukh, G. S., Ballal, A. R., Peshwe, D. R., Paretkar, R. K., Laha, K., \& Mathew, M. D. (2016). Effect of Laves phase on the creep rupture properties of P92 steel. Materials Science \& Engineering A, 668, 215-223. https://doi.org/10.1016/j.msea.2016.05.074

Maruyama, K., Sawada, K., \& Koike, J. (2001). Strengthening mechanisms of creep resistant tempered martensitic steel. ISIJ International, 41, 641-625. https://doi.org/10.2355/isijinternational.41.641

Maruyama, K. (2019). Reliable evaluation of long-term creep properties at elevated temperature. Tetsu-to-Hagane, 105, 767-777. https://doi.org/10.2355/tetsutohagane.TETSU-2019-006

Masuyama, F. (2001). History of power plants and progress in heat resistant steels. ISIJ International, 41, 612-625. https://doi.org/10.2355/isijinternational.41.612

Medina, S. F. (1997). Determination of precipitation-time-temperature (TTP) diagrams for Nb, Ti or V

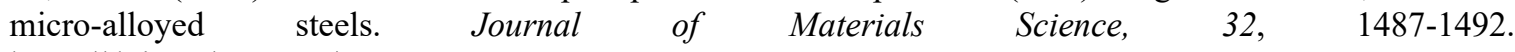
https://doi.org/10.1023/A:1018562202876 
Milkereit, B., Giersberg, L., Kessler, O., \& Sciek, C. (2014). Isothermal time-temperature-precipitation diagram for an aluminium alloy 6005A by in situ DSC experiments. Materials, 7, 2631-2649. https://doi.org/10.3390/ma7042631

Monkman, F. C., \& Grant, N. J. (1956). An empirical relationship between rupture life and minimum creep rate in creep-rupture tests. Proceedings of American Society for Testing and Materials, 56, 593-620. Retrieved from http://www.astm.org/DIGITAL_LIBRARY/STP/MMR/PAGES/PRO1956-56.htm

Morooka, S., Tomoda, Y., Adachi, Y., Morito, S., \& Kamiyama, T. (2008). Hierarchical characterization by EBSD and neutron diffraction on heterogeneous deformation behavior of a martensitic steel. Tetsu-to-Hagane, 94, 313-320. https://doi.org/10.2355/tetsutohagane.94.313

Mura, T., \& Mori, T. (1976). Micromechanics-Dislocation and Inclusions (in Japanese), Tokyo: Baihukan. ASIN: B000JA16HW. Retrieved from https://iss.ndl.go.jp/books/R100000002-I000001129159-00

Murata, Y., Yamashita, K., Morinaga, M., Hara, T., Miki, K., Azuma, T., Ishiguro, T., \& Hashizume, R. (2009). Dependence of precipitation behavior and creep strength on $\mathrm{Cr}$ content in high $\mathrm{Cr}$ ferritic heat resistant steels. Journal of Solid Mechanics and Materials Engineering, 3, 457-463. https://doi.org/10.1299/jmmp.3.457

Muroki, M. (2017). The way to high efficiency boilers for power plant led by Ni-based alloy: from $600^{\circ} \mathrm{C}$-class ultra-super critical (USC) boilers to $700^{\circ} \mathrm{C}$-class advanced ultra-super-critical (A-USC) boilers. IHI Engineering Review, 50(1), 26-29. Retrieved from http://www.ihi.co.jp/en/

Nie, M., Zhang, J., Huang, F., Liu, J. W., Zhu, X. K., Chen, Z. L., \& Ouyang, L. Z. (2014). Microstructure evolution and life assessment of P92 steel during long-term creep. Journal of Alloys and Compounds, 588, 348-356. https://doi.org/10.1016/j.jallcom.2013.11.080

NIMS: Creep Data Sheet on Creep Deformation Properties of 9Cr-1Mo-V-Nb Steel Tubes for Boilers and Heat Exchangers and 9Crt-1Mo-V-Nb Steel Plate for Boilers and Pressure Vessels, No. D-1. (2007). Tsukuba, Japan. Retrieved from http://www.nims.go.jp/mits/english/creep_lst._e.htm

NIMS: Data Sheets on the Elevated-Temperature Properties of $11 \mathrm{Cr}-2 \mathrm{~W}-0.4 \mathrm{Mo}-1 \mathrm{Cu}-\mathrm{Nb}-\mathrm{V}$ stainless steel pipe for high temperature service (KA-SUS $410 \mathrm{~J} 3 \mathrm{TP}$ ), $11 \mathrm{Cr}-2 \mathrm{~W}-0.4 \mathrm{Mo}-1 \mathrm{Cu}-\mathrm{Nb}-\mathrm{V}$ stainless steel plate for power plants (KA-SUS $410 \mathrm{~J} 3$ ), and $11 \mathrm{Cr}-2 \mathrm{~W}-0.4 \mathrm{Mo}-1 \mathrm{Cu}-\mathrm{Nb}-\mathrm{V}$ stainless steel tube for power boilers (KA-SUS 410J3 TB), No. 51A. (2013). Tsukuba, Japan. Retrieved from http://www.nims.go.jp/mits/english/creep_lst._e.htm

NIMS: Data Sheets on the Elevated-Temperature Properties of 9Cr-1Mo-V-Nb Steel Tubes for Boilers and Heat Exchangers, 9Crt-1Mo-V-Nb Steel Plates for Boilers and Pressure Vessels, and 9Crt-1Mo-V-Nb Steel Seamless Pipe for High Temperature Service, No. 43A. (2014). Tsukuba, Japan. Retrieved from http://www.nims.go.jp/mits/english/creep_lst._e.htm

NIMS: Data Sheets on the Elevated-Temperature Properties of 9Cr-0.5Mo-1.8W-V-Nb Steel Tubes for Power Boilers and 9Cr-0.5Mo-1.8W-V-Nb Steel Pipe for High Temperature Service, No. 48B. (2018). Tsukuba, Japan. Retrieved from http://www.nims.go.jp/mits/english/creep_lst._e.htm

Norton, F. H. (1929). The Creep of Steel at High Temperatures. NY: McGraw-Hill Book Co. Retrieved from https://archive.org/details/creepofsteelathi00nort

Oikawa, H. (1982). Lattice self-diffusion in solid iron: A critical review. Technology Reports of the Tohoku University, 47, 67-77. Retrieved from http://www.worldcat.org/title/technology-reports-of-the-tohoku-university/oclc/2451160

Orowan, E. (1940). Problems of plastic gliding. Proceedings of the Physical Society, 52, 8-22. https://doi.org/10.1088/0959-5309/52/1/303

Panait, C. G., Bendick, W., Fuchsmann, A., Gourgues-Lorezon, A.-F., \& Besson, J. (2010a). Study of the microstructure of the Grade 91 steel after more than $100000 \mathrm{~h}$ of creep exposure at $600{ }^{\circ} \mathrm{C}$. International Journal of Pressure Vessels and Piping, 87, 326-335. https://doi.org/10.1016/j.ijpvp.2010.03.017

Panait, C. G., Zielinska-Lipiec, A., Koziel, T., Czyrska-Filemonowicz, A., Gourgues-Lorenzon, A. -F., \& Bendick, W. (2010b). Evolution of dislocation density, size of subgrains and MX-type precipitates in a P91 steel during creep and during thermal ageing at $600{ }^{\circ} \mathrm{C}$ for more than $100000 \mathrm{~h}$. Materials Science and Engineering A, 527, 4062-4069. https://doi.org/10.1016/j.msea.2010.03.010

Sanhueza, J. P., Rojas, D., Garcia, J., Melendrez. M. F., Toledo, E., Montalba, C., Alvarado, M. I., \& Jaramillo, A. F. (2019). Computational modeling of the effect of $\mathrm{B}$ and $\mathrm{W}$ in the phase transformation of M23C6 carbides in 9 to 12 pct $\mathrm{Cr}$ martensitic/ferritic steels. Materials Research Express, 6, 1-15. https://doi.org/10.1088/2053-1591/ab500c 
Sawada, K., Takeda, M., Maruyama, K., Ishii, R., Yamada, M., Nagae, Y., \& Komine, R. (1999). Effect of W on recovery of lath structure during creep of high chromium martensitic steels. Materials Science and Engineering A, 267, 19-25. https://doi.org/10.1016/S0921-5093(99)00066-0

Sawada, K., Kubo, K., \& Abe, F. (2003). Contribution of coarsening of MX carbonitrides to creep strength degradation in high chromium ferritic steel. Materials Science and Technology, 19, 732-738. https://doi.org/10.1179/026708303225010687

Sawada, K., Kushima, H., \& Kimura, K. (2006). Z-phase formation during creep and aging in 9-12\% Cr heat resistant steels. ISIJ International, 46, 769-775. https://doi.org/10.2355/isijinternational.46.769

Sawada, K., Kushima, H., Kimura, K., \& Tabuchi, M. (2007). TTP diagram of Z phase in 9-12\% Cr heat-resistant steels. ISIJ International, 47, 733-739. https://doi.org/10.2355/isijinternational.47.733

Sawada, K., Suzuki, K., Kushima, H., Tabuchi, M., \& Kimura, K. (2008). Effect of tempering temperature on Z-phase formation and creep strength in $9 \mathrm{Cr}-1 \mathrm{Mo}-\mathrm{V}-\mathrm{Nb}-\mathrm{N}$ steel. Material Science and Engineering A, 480, 558-563. https://doi.org/10.1016/j.msea.2007.09.031

Sawada, K., Bauer, M., Kauffmann, F., Mayr, P., \& Klenk, A. (2010). Microstructural change of $9 \%$ Cr-welded joints after long-term creep. Material Science and Engineering A, 527, 1417-1426. https://doi.org/10.1016/j.msea.2009.10.044

Sawada, K., Kushima, H., Tabuchi, M., \& Kimura, K. (2011). Microstructural degradation of Gr.91 steel during creep under low stress. Materials Science and Engineering A, 528, 5511-5518. https://doi.org/10.1016/j.msea.2011.03.073

Sawada, K., Kushima, H., Hara, T., Tabuchi, M., \& Kimura, K. (2014a). Heat-to-heat variation of creep strength and long-term stability of microstructure in Grade 91 steels. Materials Science and Engineering A, 597, 164-170. https://doi.org/10.1016/j.msea.2013.12.088

Sawada, K., Kushima, M., Tabuchi, M., \& Kimura, K. (2014b). Effect of creep deformation on Z phase formation in Gr.91 steel. Materials Science and Technology, 30, 12-16. https://doi.org/10.1179/1743284713Y.0000000309

Sawada, K., Sekido, K., Kimura, K., Arisue, K., Honda, M., Komai, N., .. \& Kubushiro, K. (2019a). Effect of initial microstructure on creep strength of ASME Grade T91 steel. Tetsu-to-Hagane, 105, 433-442. https://doi.org/10.2355/tetsutohagane.TETSU-2018-066

Sawada, K., \& Kimura, K. (2019b). Stability of long-term creep strength and microstructure in high Cr steels. Bulletin of The Iron and Steel Institute of Japan, 24, 68-72. Retrieved from https://dl.ndl.go.jp/info:ndljp/pid/3381227

Schoeck, G. (1980). Thermodynamics and thermal activation of dislocations. In F.R.N. Nabarro (Ed.), Dislocations in Solids volume 3 Moving Dislocations (pp. 63-159). Amsterdam: North-Holland Pub. Co. https://doi.org/10.1002/crat.19800151012

Sherby, O. D., Orr, R. L., \& Dorn, J. E. (1953). Creep Correlations of Metals at Elevated Temperatures in 25th Techn. Rpt. Sr. 22 Issue 25 N7-on-295 (pp. 1-44). Berkeley, CA: University of California. Retrieved from http://www.dtic.mil/dtic/tr/fulltext/u2/005978.pdf

Shewmon, P. G. (1963). Diffusion in Solid (pp. 164-187). McGraw-Hill Book Co., New York. https://doi.org/10.1016/0038-1101(64)90025-5

Sikka, V. K., Cowgill, M. G., \& Roberts, B. W. (1983). Creep properties of modified 9 Cr-1Mo steel. In J. W. Davis and D. J. Michel (Eds.), Proceedings of Topical Conference on Ferritic Alloys for Use in Nuclear Energy Technologies, Snowbird, Utah, June (pp. 413-423). American Nuclear Society, La Grange Park, IL. https://doi.org/10.2172/5687534

Suzuki, K., Kumai, S., Kushima, H., Kimura, K., \& Abe, F. (2000). Heterogeneous recovery and precipitation of Z-phase during long-term creep deformation of modified 9Cr-1Mo steel. Tetsu-to-Hagane, 86, 550-557. https://doi.org/10.2355/tetsutohagane1955.86.8_550

Suzuki, K., Kumai, S., Kushima, H., Kimura, K., \& Abe, F. (2003). Precipitation of Z-phase and precipitation sequence during creep deformation of mod.9Cr-1Mo steel. Tetsu-to-Hagane, 89, 691-698. https://doi.org/10.2355/tetsutohagane1955.89.6_691

Tamura, M., Hayakawa, H., Yoshitake, A., Hishinuma, A., \& Kondo, T. (1988). Phase stability of reduced activation ferritic steel $8 \% \mathrm{Cr}-2 \% \mathrm{~W}-0.2 \% \mathrm{~V}-0.04 \%$ Ta-Fe. Journal of Nuclear Materials, 155-157, 620-625. https://doi.org/10.1016/0022-3115(88)90384-4 
Tamura, M., Esaka, H., \& Shinozuka, K. (1999). Stress and temperature dependence of time to rupture of heat resisting steels. ISIJ International, 39, 380-387. https://doi.org/10.2355/isijinternational.39.380

Tamura, M., Esaka, H., \& Shinozuka, K. (2000). Physical meaning of the new creep rupture equation for heat resisting steels. Materials Transaction, JIM, 41, 272-278. https://doi.org/10.2320/matertrans1989.41.272

Tamura, M., Esaka, H., \& Shinozuka K. (2003). Applicability of an exponential law in creep of metals. Materials Transactions, 44, 118-126. https://doi.org/10.2320/matertrans.44.118

Tamura, M., Iida, T, Kusuyama, H., Shinozuka, K., \& Esaka, H. (2004). Re-dissolution of VN during tempering in high chromium heat resistant martensitic steel. ISIJ International, 44, 153-161. https://doi.org/10.2355/isijinternational.44.153

Tamura, M., Nakamura, M., Shinozuka, K., \& Esaka, H. (2008). Tempering and precipitation behavior of 7 pct Cr-0.1 pet V-0.06 pet Nb-0.08 pet N steel. Metallurgical and Materials Transactions A, 39A, 1060-1076. https://doi.org/10.1007/s11661-008-9486-5

Tamura, M., Sakasegawa, H., Shiba, K., Tanigawa, H., Shinozuka, K., \& Esaka, H. (2011). Decomposition of Y2Ti2O7 particles in 8 pct $\mathrm{Cr}$ oxide-dispersion-strengthened martensitic steel during tempering, Metallurgical and Materials Transactions A, 42, 2176-2188. https://doi.org/10.1007/s11661-011-0640-0

Tamura, M., Abe, F., Shiba, K., Sakasegawa, H., \& Tanigawa, H. (2013). Larson-Miller constant of heat-resistant steel. Metallurgical and Materials Transactions A, 44, 264-52661. https://doi.org/10.1007/s11661-013-1631-0

Tamura, M. (2015a). Method of estimating the long-term rupture strength of $11 \mathrm{Cr}-2 \mathrm{~W}-0.4 \mathrm{Mo}-1 \mathrm{Cu}-\mathrm{Nb}-\mathrm{V}$ steel. Metallurgical and Materials Transactions A, 46, 1958-1972. https://doi.org/10.1007/s11661-015-2784-9

Tamura, M., \& Abe, F. (2015b). Changes in estimated dislocation density during creep in martensitic heat-resistant steel. Journal of Materials Science Research, 4(4), 48-69. https://doi.org/10.5539/jmsr.v4n4p48

Tamura, M. (2017). Verification of equation for evaluating dislocation density during steady-state creep of metals. Journal of Materials Science Research, 6(2), 20-62. https://doi.org/10.5539/jmsr.v6n2p20

Tamura, M. (2018). Relationship between sub-grain size and dislocation density during steady-state dislocation creep of polycrystalline cubic metals. Journal of Materials Science Research, 7(4), 26-45. https://doi.org/10.5539/jmsr.v7n4p26

Tamura, M., \& Abe, F. (2021a). Analysis on degradation in creep strength of 9Cr-W martensitic steel. Journal of Materials Science Research, 10(1), 1-27. https://doi.org/10.5539/jmsr.v10n1p1

Tamura, M., \& Abe, F. (2021b). Analysis of the degradation in the creep strength of High-Cr Martensitic Steels. Journal of Materials Science Research, 10(2), online. https://doi.org/10.5539/jmsr.v10n2p1

Turnbull, D., \& Fisher, J. C. (1949). Rate of nucleation in condensed system. The Journal of Chemical Physics, 17, 71-73. https://doi.org/10.1063/1.1747055

Wagner, C. (1961). Theorie der altering von niderschlagen durch umloesen (Ostwald Reifung). Zeitschrift fur Electrochemie, 65, 581-591. Retrieved from https://www.researchgate.net/publication/230384240_Theorie_Der_Alterung_Von_Niederschlagen_Durch_ Umlosen_Ostwald-Reifung

Xu, Y., Wang, M., Wang, Y., Gu, T., Chen, L., Zhou, X., Ma, Q., Liu, Y., \& Huang, J. (2015). Study on the nucleation and growth of Laves phase in a $10 \% \mathrm{Cr}$ martensite ferritic steel after long-term aging. Journal of Alloys and Compounds, 621, 93-98. https://doi.org/10.1016/j.jallcom.2014.09.204

Yan, W., Wang, W., Shan, Y. -Y., \& Yang, K. (2013). Microstrucural stability of 9-12\%Cr ferrite/martensite heat-resistant steels. Frontier Materials Science, 7(1), 1-27. https://doi.org/10.1007/s11706-013-0189-5

Yi, Y., Xu, W., Xia, F., Gang, T., \& Chen, L. (2017). Effects of alloying elements M (M=Fe, Mo) on phase stability of Cr23C6 carbides from first-principles. In Proceedings of the 2017 2nd International Conference on Advances in Materials, Mechatronics and Civil Engineering (ICAMMCE 2017), Advances in Engineering Research, 121, 74-80. https://doi.org/10.2991/icammce-17.2017.17

Yoshizawa, M., Igarashi, M., \& Nishizawa, T. (2005). Effect of tungsten on the Ostwald ripening of M23C6 carbides in martensitic heat resistant steel. Tetsu-to-Hagane, 91, 272-277. http://doi.org/10.2355/tetsutohagane1955.91.2_272

Zeng, Y. -P., Jia, J. -D., Cai, W. -H., Dong, S. -Q., \& Wang, Z. -C. (2018). Effect of long-term service on the precipitates in P92 steel. International Journal of Minerals, Metallurgy and Materials, 25, 913-921. https://doi.org/10.1007/s12613-018-1640-5 
Zielinski, A., Golanski, G., \& Sroka, M. (2016). Assessment of microstructure stability and mechanical properties of X10CrWMoVNb9-2 (P92) steel after long-term thermal aging for high-temperature applications. Kovove Materials, 54, 61-70. https://doi.org/10.4149/km_2016_1_61

\section{Appendix}

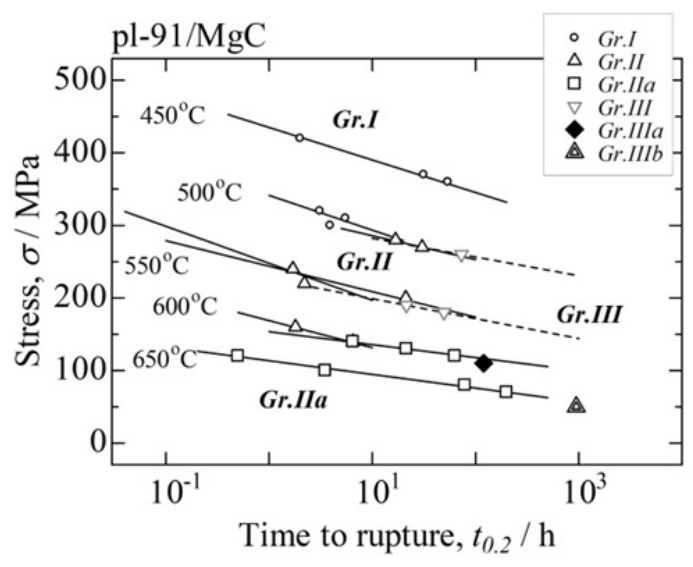

Figure A1. Stress vs. time to $0.2 \%$ strain relationship for $\mathrm{pl}-91 / \mathrm{MgC}$ steel. Definitions of each group are the same as in Figure 1

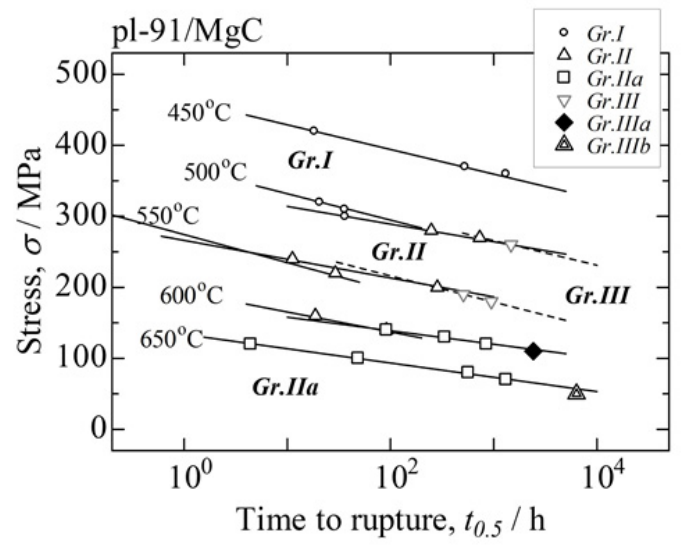

Figure A2. Stress vs. time to $0.5 \%$ strain relationship for $\mathrm{pl}-91 / \mathrm{MgC}$ steel. Definitions of each group are the same as in Figure 1

\section{Copyrights}

Copyright for this article is retained by the author(s), with first publication rights granted to the journal.

This is an open-access article distributed under the terms and conditions of the Creative Commons Attribution license (http://creativecommons.org/licenses/by/4.0/). 